

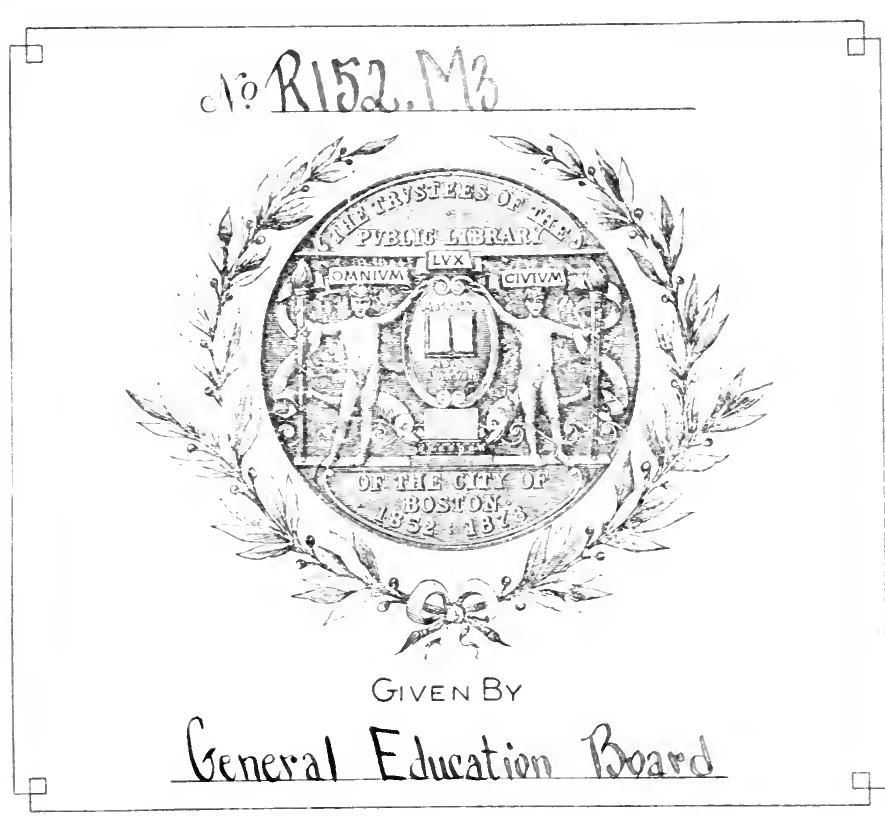




\section{Boston Public Library}

Do not write in this book or mark it with pen or pencil. Penalties for so doing are imposed by the Revised Laws of the Commonwealth of Massachusetts.

This book was issued to the borrower on the date last stamped below.

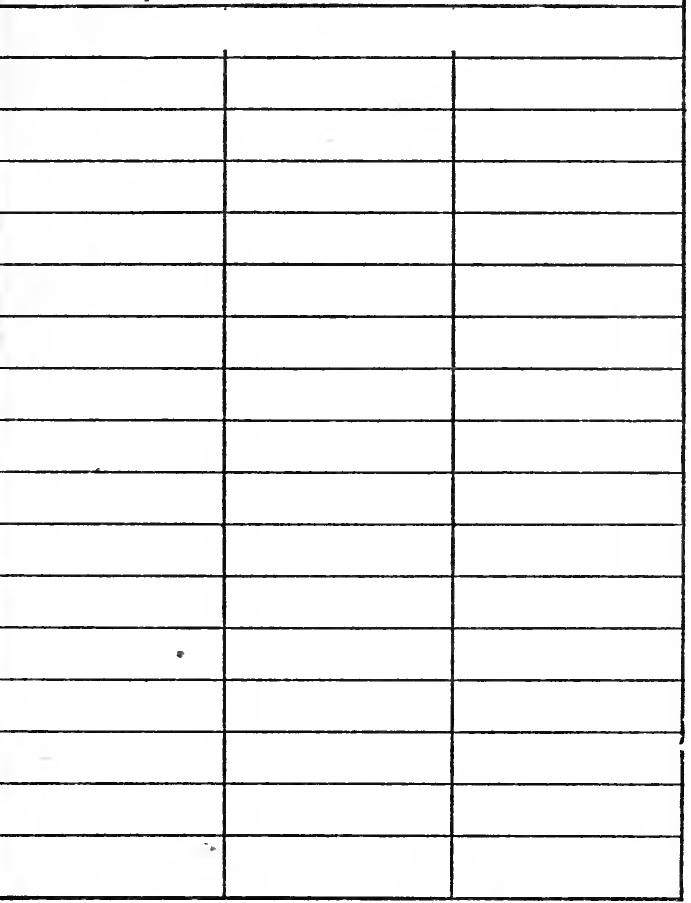

FORM NO. 609: 9,20,38: 100M. 



\section{THE DISTRIBUTION OF PHYSICIANS IN THE UNITED STATES}

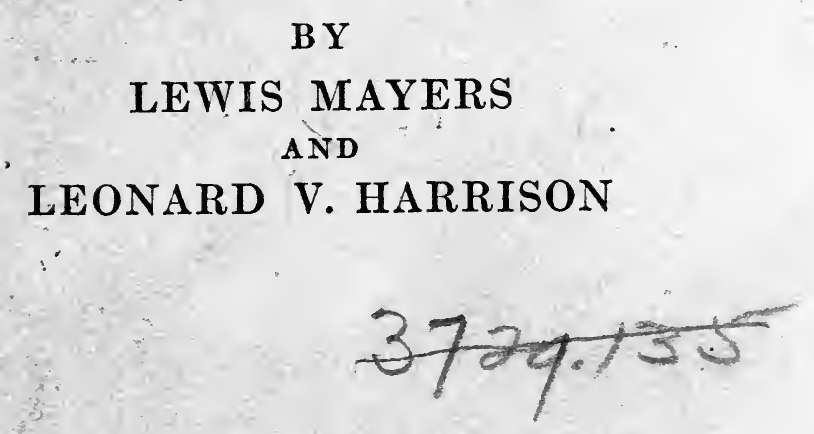

GENERAL EDUCATION BOARD 61 BroadWay

NEW YORK 1924 



\section{THE DISTRIBUTION OF PHYSICIANS IN THE UNITED STATES}






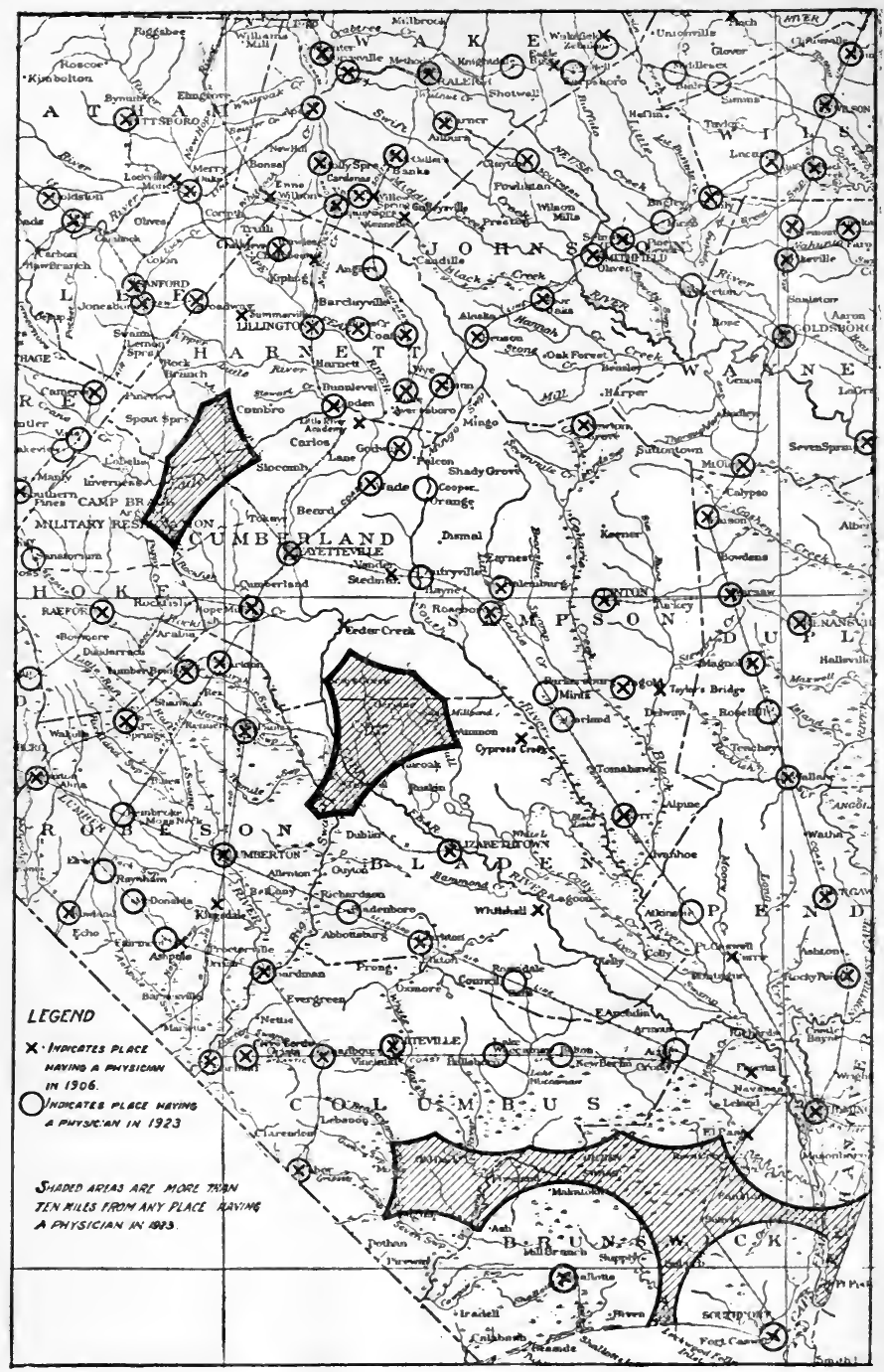

Fig. 3. Specimen map showing places more than ten miles from a physician: An area in the southeastern portion of North Carolina 


\title{
THE DISTRIBUTION OF PHYSICIANS IN THE UNITED STATES
}

\author{
B Y \\ LEWIS MAYERS \\ AND \\ LEONARD V. HARRISON

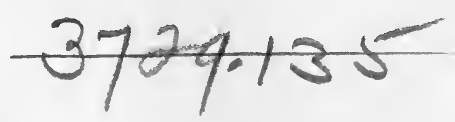

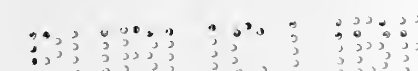

6224

GENERAL EDUCATION BOARD 61 BROADWAY NEW YORK 1924 


$$
\begin{aligned}
& R / 52 \\
& M_{3}
\end{aligned}
$$

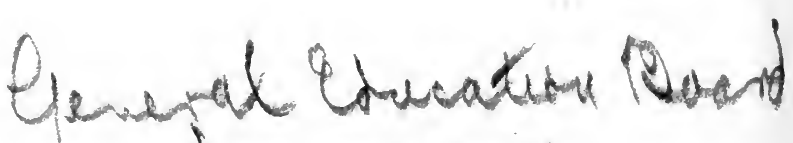
Net: 73 1924 


\section{CONTENTS}

INTRODUCTION

PAGE

vii

I. Basic Factors Affecting the Distribution of Physicians Between Town

and Country . . . . . . . . 3

Urban vs. rural population growth . . . . . . 6

Increased competition in rural practice . . . . . . 8

Increased importance of the town in rural medical service 12

Decreased financial attractiveness of rural practice . . 19

Increased financial and social attractiveness of urban practice . . . . . . . . . . . 26

Increased professional attractiveness of urban practice $\quad 32$

II. The Distribution of Physicians Between

TOWn AND Country . . . . . . . 40

The distribution of population . . . . . . . . 40

Relative number of town and country physicians . . . 47

The decrease of rural physicians . . . . . . . 53

Prospective number of rural physicians . . . . . 60

III. The Accessibility and Cost of Medical

Service in RuRal AReas . . . . . 64

Number of places having physicians $. .9 . \quad . \quad 65$

Distance between physicians. .0 .0 .67$

Importance of seasonal variation in road conditions . . 76

Roads, automobiles and telephones . . . . . 80

Cost . . . . . . . . . . . . . . . . 85

IV. The Vacant Rural Location . . . . . 9I

Types of vacant locations. . . . . . . . . . . . 93

Securing physicians by community action . . . . . 106

The cottage hospital . . . . . . . . . . II8

The town hospital . . . . . . . . . . . . I25

V. Medical Education and the Supply of

Rural Physictans . . . . . . 129

Relation of medical school requirements to number of students . . . . . . . . . . . . . . ${ }^{\mathrm{I}} 3^{\mathrm{I}}$

Current requirements and the poor boy . . . . . . 137

The current medical course as a preparation for rural practice . . . . . . . . . . . . 145

Statistical APPENDIX • . • . • • • • I53 



\section{INTRODUCTION}

Large and populous rural areas, ready, willing and able to support a physician, but unable to induce a physician to locate in them and compelled to rely for medical attention on the uncertain services of practitioners perhaps twenty miles distant: this is the picture which has been drawn with increasing frequency in the past few years wherever physicians or public health workers gather; and almost always the condition described, it is said, has come about only within recent years, and threatens to become more acute in the near future.

The causes assigned for this condition have been various; but certain factors related to the changes in medical education which have come about in the last ten or fifteen years have been charged with a large measure of responsibility - in some discussions, indeed, with sole responsibility. It has been alleged, first, that one reason why there are too few doctors in the rural areas is that there are too few in the country as a whole, in consequence of the fact that too few are being produced by the medical schools under the current régime of high entrance requirements and prolonged course of study; and second, that, even were their numbers adequate, the present-day medical graduates would refuse to locate in or near the rural areas. This reluctance is also ascribed to one or another of the characteristics of present-day medical education-its costliness in time and money, the location of schools in the larger cities, and the alleged 
emphasis on the importance of elaborate equipment and facilities in the diagnosis and treatment of disease. The conclusion is drawn that physicians can be obtained for the rural areas only by reducing the requirements for entrance upon and completion of the medical course; and so persuasive has been the line of argument by which this conclusion has been reached that in several states legislative action looking to a reduction of medical licensure requirements below the standards set by the better medical schools has already been proposed, and in one case taken.

It need hardly be said that the argument outlined, even where it has resulted in action, has been based upon no thorough-going examination of the facts. The causes behind the rural shortage have not been systematically studied; neither has a comprehensive attempt been made to ascertain its extent and character.

Because of the vital bearing of this problem on the development of American medical education, a systematic examination of the question has now been made, in order to develop as accurately as might be a picture of the distribution of the country's physicians to-day, and to compare the present condition with that formerly prevailing; to ascertain the causes which have determined the shifting of practitioners from one location to another, and the selection of initial locations by new graduates; to discover as far as possible any differences which there may be between the older and younger graduates, with respect to the size of towns selected for location and the type of practice favored, and finally, to obtain a comprehensive view of all factors, social, economic and psychological, which enter into the problem of obtaining adequate medical service for rural areas. 
The problem being essentially one of detail, it was concluded that a more accurate picture could be obtained by studying carefully a number of representative areas than by attempting to examine all portions of the country with a less degree of care. The selection of the areas to be studied in detail was influenced by the changes in medical education in recent years. For this reason, especial attention was given to the South, east of the Mississippi, because in no other section have the developments of the last two decades produced so marked a decline in the number of medical schools, students and graduates, and correspondingly, in the number of new graduates locating in the section. In addition, two states of the South furnished particular reasons for study-North Carolina, because it has (with South Carolina) a lower ratio of physicians to population than any other state, showing a marked contrast indeed with its neighbors on the north and south; and Kentucky, because in no other state has complaint of extreme dearth of physicians in the rural areas been so insistent. Similarly, Maine, New York and western Massachusetts were selected because in them, too, the rural medical situation has received much public discussion. Other states were chosen because they represented what seemed to be typical conditions in the sections in which they are respectively located. ${ }^{1}$

To be sure the areas selected do not fully represent all sections of the country, but it is not the section of the country which determines the distribution of physicians

\footnotetext{
1The areas selected are:

New England: Maine and western Massachusetts

Northeast: New York and Michigan

Middle West: Iowa, Missouri

South: $\quad$ North Carolina, Alabams and Kentucky

Pacific Coast: California and Washington
} 
and the availability of medical service in the rural areas; rather are these determined for each rural area by density of settlement, the condition of its roads, wealth, distance from towns and cities, and the general ratio of physicians to population in the surrounding country. In all these fundamental respects, there are found, within the areas selected, such wide if not extreme contrasts, that upon the basis of the conditions found in the selected areas may confidently be founded an appraisal of conditions in the country as a whole.

For each of the selected areas, the attempt has been made not merely to ascertain where physicians are now and formerly were located in relation to the population served by them, but to discern the tendencies in the selection of locations exhibited by the more recent medical graduates as compared with those of earlier years. The source of the data used in the tabulations developed on these subjects has been the successive editions of the American Medical Directory, issued, at two- or threeyear intervals since 1906, by the American Medical Association. ${ }^{1}$

Complementing these statistical investigations in the selected states or areas, questionnaires were used on an extensive scale. Inquiries were addressed to physicians, public health officers and officers of medical societies ${ }^{2}$ calling for information regarding conditions of practice, road conditions, places reported in need of physicians, places which formerly had had physicians, reasons for

\footnotetext{
IAs a basis for discussion of current conditions, the 1923 issue was used, in conjunction with independent data obtained from state sources; and discrepancies were checked by direct correspondence with county secretaries, etc.

2In the State of Alabama a questionnaire was addressed also to the judges of the several counties requesting information regarding locations which might be in need of a physician.
} 
the selection of locations by physicians and their reasons for removal from one location to another. In some cases these questionnaires were sent out directly by the authors; in others they were sent out in coöperation with state boards of health, state boards of medical examiners, and state medical societies, and in a few cases by deans of medical schools. In all, some five thousand replies to these questionnaires have been received.

In addition, in each of the selected areas a limited amount of investigation was carried on in the field, and advantage was taken of meetings of state medical associations to interview considerable numbers of physicians doing rural practice. The detailed investigation of the selected areas has been supplemented by a less thorough examination along similar lines of small rural areas in various other parts of the country.

We desire to express here our sincere thanks to the numerous health officers, medical society officers, teachers in medical schools and individual physicians who so generously assisted us in our investigations.

The reduction to usable form of the material thus assembled has been a process of some difficulty. But the usability of this raw material has in truth been only a secondary obstacle. Far more serious has been the inherent complexity of the subject-the variety of divergent factors and motives which enter into the choice of locations by physicians, and the impossibility of confidently isolating any one of them from the others and measuring its relative force and extent. So basic is this difficulty that even the present study, painstaking as it has been, can be regarded only as an attempt to furnish a basis for sound thinking on the question; it 
cannot pretend to unassailable authority. How much importance then can be attached to the numerous sweeping statements regarding the existing situation and its causes, usually based upon no investigation whatever, which have been given currency in the past few years?

While commonly thought of as exclusively a rural problem, the proper distribution of physicians is quite as fully an urban problem. Whatever the situation in the rural areas, the city has always been and is still overcrowded with physicians. Measures which look to a substantial enlargement of the whole number of physicians, with a view solely to increasing the number in the rural areas, will necessarily increase also the number in the towns and cities, aggravating in them the existing overcrowding, and intensifying the existing competition-a competition which inevitably produces fee-splitting, the prescribing of unnecessary treatments, remedies and drugs, and the general lowering of professional standards. Hence any one who seeks to apply to the rural medical problem a solution which increases the supply of physicians uses a two-edged sword, one, moreover, quite unwieldy and unmanageable. On the other hand, any solution of the rural medical problem which makes rural practice more attractive and so draws or diverts practitioners to it from the towns, is twice-blessed; it blesses the town that gives no less than the countryside that takes. No consideration of the problem can be deemed truly comprehensive which, in asserting the right of the country people to adequate medical service, disregards the right of the city people to be protected against the inevitable evils of an overcrowded medical profession. 


\section{THE DISTRIBUTION OF PHYSICIANS IN THE UNITED STATES}





\section{THE DISTRIBUTION OF PHYSICIANS IN THE UNITED STATES}

\section{CHAPTER I}

THE BASIC FACTORS AFFECTING THE DISTRIBUTION OF PHYSICIANS BETWEEN TOWN AND COUNTRY

In the complex of economic, scientific and psychological factors which bear upon the distribution of physicians between town and country, one fact of overshadowing importance stands clearly disclosed. Always, and everywhere, the people of the towns have among them a substantially greater number of physicians than has an equal rural population. Such has been the situation in this country for fifty years back, beyond which our figures do not go; such is the situation to-day in all foreign countries for which figures are readily available, and, presumably, to an equal extent in countries for which they are not available.

Manifestly this cardinal feature of the distribution of physicians bears no relation to the need for medical service; for, on the basis of need, a given rural population, thinly scattered over an area served only by difficult roads, would require a substantially greater number of physicians than an equal population in a compact urban settle- 
ment. Similarly among the rural areas themselves, the sparser the area and the worse the conditions of travel, the more doctors are needed; whereas in fact, as is well known, the fewer doctors there are found. What determines the distribution of physicians between town and country under the régime of individualism in medical practice is not the relative need for medical service but the relative attractions of the several towns, villages, and rural locations as possible fields for the practice of medicine. ${ }^{1}$

It is not open to doubt that, from the standpoint of professional satisfaction, personal comfort and social environment, the city and the town have always offered to the average trained physician greater attractions than the isolated village; given equal income and prestige there are and ever have been but few physicians who would not choose practice in a fair-sized town, if not a large city, in preference to a remote rural location. ${ }^{2}$ It is the difficulty of obtaining a foothold in the towns and cities that has sent the young graduate to the lone village, or has kept there the established practitioner who fain would leave. So long as there exists a degree of free competition in the medical profession, accompanied by an ample supply, the superior personal, professional and

\footnotetext{
1The terms town and village as used throughout the text represent classifications based on size and in no case do the terms conform to the legal definitions found in the various state codes. It is not possible to fix an exact population figure which will represent the division point between a town and a village. In general a settlement of less than $I, 000$ is thought of as a village while places having above $x, 000$ are classed as towns.

2It is recognized that there is a type of individual who greatly prefers rural to urban life, and that a substantial number of rural physicians doubtless are of this type. Their number is, however, relatively too small to affect the validity of the statement that the average physician is of the opposite type. Moreover, the statement has no reference to that group of self-taught practitioners once found in the remoter rural areas of the less developed states, and now rapidly disappearing. These were not physicians who located in the country, but countrymen who came to serve as physicians.
} 
social attractions of the town will unfailingly produce there a saturation, or, in the larger cities, a supersaturation of the demand; while the rural areas will attract physicians only to the extent that they offer a sufficiently superior financial prospect, and will retain what physicians they have only so long as the financial return is sufficiently great to outweigh the attractions of the town.

In this fact is to be found the chief explanation for the wide disparity which has always existed between town and country in respect to the number of physicians in relation to population. In a measure this disparity is explicable by the proportionately smaller demand for medical service in the rural areas, due chiefly to its greater relative cost; but this factor can account for only a minor portion of the disparity. ${ }^{1}$ The major part is manifestly to be accounted for only by the fact that in the rural areas the number of physicians has always been fairly well proportioned to the effective demand $;$ in the towns and cities it has always been and still remains substantially in excess of the demand. Only few physicians will long remain in the country, as thousands do in the cities, with professional income hardly in excess of expense.

But whatever be thought of the relative importance of

\footnotetext{
1An additional minor factor, of widely varying weight in the various sections of the country, is the much more extensive employment of midwives in the rural areas.

${ }^{2}$ This is not to say that all rural physicians have been, or are, at all times, assured of a reasonable income, or indeed of a modest livelihood. On the contrary, there has been at all times during the period under review a considerable fringe of rural practitioners whose practice has yielded but a precarious living even in the more favorable periods (for medical practice, like the economic life of the community on which it depends, is subject to wide periodic variations). Yet they cling to their village locations because, unremunerative as they are, the prospects in the overcrowded town are no better, or, if they are, the casbinecessary to finance the removal is not at hand.
} 
the two factors of demand and degree of oversupply, the fact stands unquestioned that a given town population yields support, or at least anchorage, to a substantially greater number of physicians than does an equal rural population.

\section{URBAN VS. RURAL POPULATION GROWTH}

The leading rôle which this basic fact has played in determining the changes in the distribution of physicians in the United States in the present century has not apparently received adequate attention. It is commonly assumed that if the whole number of physicians increases as rapidly as does the population as a whole, other things remaining the same, there is no reason why the relative distribution of physicians as between town and country should be in any wise disturbed. What is lost sight of is that for the present purpose it is not population in the abstract which increases-it is either rural population or urban population; and the rapid increase of population during the present century has been chiefly an urban increase. To maintain the existing ratio of physicians to population in the rural areas does nor require an increase in the whole number of physicians proportionate to the increase in rural population; for the ratio of physicians to population in the rural areas is less than in the country as a whole. Similarly, to maintain the existing ratio of physicians to population in the cities requires an increase in the whole number of physicians greater than is indicated by the mere proportion which the additional urban population forms of the whole population; for the ratio of physicians to population in the cities is greater substantially than in the country as a whole. 
Finally, by the same token, as the proportion which the urban population forms of the whole population increases-as it has been increasing from the beginning, and at an accelerated rate during the present centuryit requires more than a proportionate increase in the whole number of physicians to maintain the existing ratio of physicians to population in the towns and cities.

In the face of the pronounced population changes thus calling-if the status quo was to be maintained-for an increase in the number of physicians greater than proportionate to the increase in population, the number of physicians has failed during the present century even to keep abreast of the increase in population, and indeed latterly has been nearly stationary. ${ }^{1}$ Hence the existing ratio of physicians to population in the cities could have been maintained only by a concomitant reduction in the ratio in the country districts. Thus even if all other factors had remained unchanged, the greatly disproportionate increase of urban population during this period of itself inevitably tended to produce a substantial reduction in the relative number of physicians in the rural areas.

The conjuncture of statistical forces which has thus characterized the present century - a rapidly increasing

\footnotetext{
1See tables, pp. 159-160, and graph, p. 160 (in the Appendix). It is not to be assumed, however, that the failure of the number of physicians to keep pace with the increase in population is necessarily to be regretted. It is entirely possible that despite the relative decrease in numbers, the medical profession is still overcrowded to an undesirable degree; and such is indeed believed to be the case. See below, p. 5 I. It may be noted that despite its relative decline in recent years, the medical profession in this country is still relatively much more numerous than in Great Britain, France or Germany (the three European countries having relatively the greatest number of physicians) despite the fact that the more complete urbanization of those countries might lead one to expect there a higher ratio of physicians to populations than obtains here.
} 
urban population and a medical profession not increasing nearly as rapidly as that population or indeed as rapidly as the whole population-constitutes the most basic of all the factors which have affected the distribution of physicians during this period, the setting in which the economic and scientific factors have operated. ${ }^{1}$

In entering upon a review of these factors, it is essential to keep in mind that within any limited area, as regards the various locations, urban or rural, open to a physician in that area, the medical profession is highly mobile. There is of course a proportion-possibly even a large majority - of the physicians of the country, young as well as old, who may be regarded as permanently fixed in their present locations; but there is also a large proportion whose attachment to their locations is quite tenuous and who are prepared at short notice to make a change. The number of physicians in this class-composed to no small extent of confirmed rolling-stones-is quite large enough to give to the profession as a whole a considerable degree of local mobility, and to cause the distribution of physicians in any fairly limited area, within which knowledge of local opportunities may be expected to circulate, to respond with a considerable degree of sensitiveness to the changes in relative attractiveness of the various classes and types of locations.

INCREASED COMPETITION IN RURAL PRACTICE

The professional income of the average village practitioner of twenty years ago was a very modest one. With

\footnotetext{
1The incidence of these factors of population growth and growth of physicians has varied widely from one section of the country to another.
} 
a territory usually severely limited, a low scale of fees and a still lower scale of collections, and a population which even in the most prosperous rural areas regarded medical attention as an item of expenditure to be indulged in only under urgent compulsion, the run of rural practitioners earned only a modest livelihood. Many of them found it possible, and indeed, found it necessary, while practising their profession, to engage more or less actively in farming or trade. The opportunity to do so was the only thing that made it possible for a substantial proportion of the rural practitioners to exist at all.

But a factor which ameliorated greatly the financial rigors of the village practitioner's life was the modest standard of expenditure prevalent in the rural community. Between city and country there existed a wide gulf in standards of expenditure which enabled the country physician often to accumulate a competence on an income far less than sufficed for the bare living of his city brother.

Moreover, if the village practitioner's rewards were meagre, they were fairly certain. A crop failure might indeed compel him to defer for a year all hope of collections with the prospect that on a good proportion of his accounts payment would be indefinitely postponed; on rare occasions, he and his two or three colleagues, if he had any, might have to contend with an upstart competitor; but on the whole, almost from the day he opened his office in the village, especially if he had come to fill the vacancy left by the death or removal of another practitioner, he was fairly well assured of a comfortable monopoly, or the participation with his colleagues in a 
comfortable monopoly, of the medical patronage of the vicinity.

The coming of the automobile worked a swift change in this Arcadian scene. To the physician it brought at once a tremendous increase of earning capacity, and a great increase of expense, which made an increase in earnings imperative. ${ }^{1}$ Rural physicians were forthwith brought into much more severe competition than formerly. Territories formerly regarded as the exclusive preserve of the practitioner or practitioners in a given village were suddenly subjected to incursions from one after another of perhaps half a dozen surrounding villages.

The promptness with which the country people took advantage of their new-found ability to call upon or to call in a physician from a neighboring village in place of their customary physician is readily understandable. In thinking of the problem, we are prone to overlook those elements of human nature, and, more particularly, of rural human nature, which in reality lie at the very root of the matter; for few things are more personal than the search for a physician in whom one can place confidence, or, as some would have it, who will diagnose one's ailment as one would like to have it diagnosed. Here and there arose among the village practitioners of an earlier day a king among men whose skill, character and devotion to his mission exalted him to the position of

\footnotetext{
1The increased annual cost of operating an automobile-in terms of depreciation and maintenance-over the cost of keeping a horse and buggy, under the conditions of rapid depreciation encountered in rural practice, has been estimated at as much as $\$ 1000$. This is fully half as much as the gross income of many a rural physician twenty years ago. In addition, in a number of rural areas the physician must still provide for horses and buggy for use during the period, varying from a few weeks to three or four months, during which the condition of the roads makes the use of the automobile impossible.
} 
guide, philosopher and friend to all the countryside, ${ }^{1}$ but such were rare. Much more representative a type was the man of modest talents and limited knowledge, industrious and faithful, but not impressive, sometimes supplementing his professional income in the rôle of farmer, farm trader, or even on occasion, of village druggist and general store proprietor. With his professional conduct-more particularly what the laity deemed his professional mistakes and failures-his business affairs, and his personal life a subject of common knowledge and gossip in the village and roundabout, it was but part of the eternal constitution of things that a substantial portion of the residents of his territory should ordinarily be, if not actively dissatisfied with him, at least quite unenthusiastic about his merits, making use of his service only because no other physician was available. The city dweller can form a picture of the situation only by supposing that he were compelled by superior force to employ exclusively the physician who happpened to live next door. It is not hard to understand then how powerful an appeal this new-found freedom made to the village-dwellerfreedom to call in or visit any one of perhaps a dozen physicians.

The inevitable result of the greatly intensified and widened competition between rural physicians produced by the automobile was that an increasing number of practitioners found their locations either no longer ten-

\footnotetext{
'For a classical defense of the country physician of an earlier day see in John Brown's Essays (Horae Subsecivae, first series), "Our Gideon Grays" and "Dr. Adams of Banchory." The Scotch physician depicted by Ian MacLaren in "Beside the Bonnie Brier Bush," the chief exemplar in fiction of this type has recently been paralleled on the American scene by Theodore Dreiser in "The Country Doctor" (in "Twelve Men"2. In "A Country Doctor" (1884) Sarah Orne Jewett has portrayed rather woodenly a similar character. See also an excellently done if somewhat idealized, portrait of "The Pioneer Doctor of North Dakota," by Dr. Jas. Grassick (in University of N. D. Quarterly, March, 1023).
} 
able or so reduced in amount or security of return that they were constrained to seek new fields. Hence as the better rural locations became vacant through death or removal, they were promptly filled by physicians from other villages, whose own locations were tending to become profitless; this, at least, would seem to be the explanation for a very extensive inter-village migration, which has characterized the entire period under review. On the other hand, as a poorer location became vacant, the surrounding physicians promptly "closed in" on the territory served by it, making it wholly untenable for a newcomer. ${ }^{1}$ The villages which still retain their physicians represent, in a great many cases, the survivors of a decade-long process of competition between villages, in which the location of the village on a county or state highway has often been the strategic factor determining the outcome.

\section{INCREASED IMPORTANCE OF THE TOWN IN RURAL}

\section{MEDICAL SERVICE}

But for a large proportion of the rural practitioners the increased competition from neighboring village practitioners was by no means the most serious blow. It constituted indeed an invasion of the old-time monopolistic status of the village practitioner which was one of the chief compensations of his way of life; but it could be offset by a corresponding increase of his own range and his greater freedom to invade his neighbors' territory. No such offset could be found to the increasing competition of the town doctor. In the era of

\footnotetext{
1The fact that a given village has thus become untenable has been established, in many cases, only after two or three physicians in succession have attempted unsuccessfully to establish a practice there.
} 
the horse and buggy, a distance of even five miles rendered the competition of the town doctor in ordinary practice a negligible factor. With the acquisition of automobiles by the rural dwellers and the town doctors, village practitioners located ten, fifteen and even twenty miles from town were exposed to a competition with the town physician which was peculiarly damaging both to their incomes and to their morale. This competition affected every branch of medical practice, but it came to be particularly severe in the matter of nonemergent visits to the physician's office, in which the rural dweller could now patronize the town physician without extra expense as an incident to the occasional visit to town. Moreover, as trips to town became more frequent, and trips to the village less frequent, it might indeed become even more convenient to visit the town doctor than the village doctor, particularly as the former was more likely to be found in his office. ${ }^{1}$ And even when there was little to choose between the two as regards convenience, a trip to town was of course more enjoyable than a trip to the village.

The growth of the towns as trading and service centers at the expense of the surrounding villages has been well defined and well recognized as the outstanding development in rural life of the past two decades. Its progress has been checked only by the poverty of the farmer, hindering the purchase of the automobile on the one hand and improvement of the roads on the other. Thus the process has advanced much more rapidly in some sec-

${ }^{1}$ Moreover, in the case of an acute pain, or injury requiring minor surgical attention, the patient coming to town would be sure to find some doctor in, even if the doctor he preferred were out; not so if he went to the village. A similar factor often enters in calling the doctor to the home. Many a farm dweller has no telephone (see p. 8I) and is not accessible to one; and his method of calling the doctor is to go to his office. 
tions of the country than in others; and wide differences are to be found within a few hours' travel. ${ }^{1}$

To the automobile has been added, within substantially the same period, the interurban trolley and the spur trolley; and, latterly, the rural motorbus.

Needless to say, the effect of these developments on the outlying villages has been most pronounced in the case of the villages lying within easy distance-perhaps ten miles-of the town; but it has been felt more or less in all but the remotest villages, and, where transportation is good, villages even twenty-five miles from town have been greatly affected. ${ }^{2}$

The enormous increase in the number of rural dwellers brought within the town's sphere of influence by an increase in the ease of travel is not perhaps appreciated at first sight. If a town of $I, 500$ population be assumed, with a uniform density in the surrounding country of 40 persons per square mile, the total population in and within five miles of the town will be a little less than 4,500. If now the radius be increased to ten miles, no less than

\footnotetext{
1The characteristics of the process, and its results, were well and authoritatively described some five years ago, and since then it has been developing apace:

"With the wide use of the automobile by farmers, the nearby centers of population are made readily accessible for both commercial and associational purposes. Before the advent of the railway the ruralite visited the nearest trading place only occasionally, the county seat hardly at all, and more distant places never; before the advent of the automobile be went to town to trade weekly and to the county seat perhaps once or twice a year; now the nearest centers are within easy daily reach and the larger and more distant towns receive frequent visitation. To the farm family this has meant business convenience and the more frequent enjoyment of the amusement and cultural facilities of the town. To the neighborhood of the family having an automobile, especially if the town is not distant, it may mean a weakening of local associations and organizations by the transfer of patronage to town schools, churches and other organizations. . . . A wide use of the automobile and the extension of the trolley have likewise sharpened the competition between country towns and villages, the smaller places suffering a loss of patronage to the larger, which of ten decimates the population of the smaller." First National Conference on Country Life (rgrg). Report of the Committee on Means of Communication. Proceedings, pp. 146, 147 .
}

2It must be borne in mind that the village twenty-five miles from town was formerly 
9,500 people will be added-an addition of over 200 per cent. Put in another way, the number of people who can be served from or by the town on the basis of a five-mile travel radius is 4,500 , while the numberiwho can be served on the basis of a ten-mile radius is 14,000 .

Manifestly then the influence and importance of the small town, and correspondingly its wealth and facilities, have increased far more rapidly than is indicated by the mere increase in its own population; and the disparity in these respects between it and the village has widened correspondingly. ${ }^{1}$

At the same time that the difference between town and village doctor in accessibility to the farm dweller was being rapidly reduced, the difference in office equipment and facilities was being widened with equal or even greater rapidity. The development of mechanical equipment for the physician's office, whether for diagnosis, treatment, or merely asepsis, has proceeded apace in the past twenty years; and during the same period the installation of electric service in the small towns-those of over 1,000 inhabitants-has also progressed rapidly. So, also, has the installation of water supply and sewage systems. All these things, which are still almost unknown in the

the center for a considerable area lying between it and the town; and that the residents of that area, in deciding whether to go to town or to the village, would be choosing perhaps between a journey of as much as ten miles to the village, as against a journey of fifteen miles to the town.

In the decline of the country village the development of rural delivery and collection by the post-office has played no small part. The institution of this service in a farming area has often meant the discontinuance of the village post-office to which it was formerly necessary for the farmer to repair, both to receive and to send mail. The closing of the village post-office acts as a depressant to the entire business and social life of the village. This process is still going on; during the five years ended June 30 , 1922, there was a net reduction in the number of post-offices of no less than 2,398. (Report of the Postmaster General I922, p. I2r.) 
smaller villages, have made readily available for the town physician refined methods of diagnosis, and in some cases, improved methods of treatment, from which the village physician is either wholly cut off, or which he can employ only with great difficulty. Opinion may vary as to the proportion of cases in which the employment of these methods actually enables the town physician to do more for his patient than does the country physician; but for the present purpose this is hardly material. The indisputable fact is that the village or farm dwellers, particularly of the more prosperous sort, almost universally believe that the physician who has these things available can do more for them than the physician who has not.

Nor is it wholly, or perhaps even primarily, a matter of reasoned belief. It is as much or more a matter of atmosphere. Particularly is this true of mechanical appliances and equipment. It is not open to doubt that nothing is more surely calculated to impress the average lay mind with confidence in the occult skill of the medical practitioner than a judicious display and utilization of paraphernalia. Similarly, in addition to their value for strictly medical purposes, the conveniences made possible by a supply of electricity, gas, running hot and cold water and a sewage system, conduce to a better kept office, a better groomed physician and neater methods of workfactors all calculated to inspire greater confidence in the visiting patient.

It is easy to see how, in this setting, the town doctor tends to become, in the farm dweller's eyes, a more impressive figure than the homespun village doctor; and from a more impressive figure to a better doctor is a 
transition readily made. ${ }^{1}$ Thus has passed the era when after the country doctor's visit, "the wonder grew that one small head could carry all he knew"; it has given way to a day when the sophisticated farm dweller inclines to suspect that the physician who is content to remain in the village cannot possibly be abreast of the times. Nor have there been lacking town doctors who would assiduously encourage the countryman in this belief.

The declining confidence of the farmer and villager in the local village doctor has not merely rendered far less attractive the position of the established rural practitioner. Important as have been its consequences in that direction, it has perhaps been still more important as a deterrent to the taking up of rural locations either by physicians contemplating a change in field of practice, or by young graduates seeking an initial location. An established physician whose skill is known over the countryside may still hold his own against the town physician despite the presumption of superiority which the latter enjoys; but the newcomer starts with the odds against him. Only if he is very able, and opportunity promptly offers for him to demonstrate his ability-as in a bit of spectacular surgery in an accident-is he likely to overcome the odds within a practicable time.

To the superior equipment of the individual town physician has been added, in varying degree, in different parts of the country, another potent force for drawing patients from the outlying village practitioner-the town hospital. The small town hospital has developed rapidly

\footnotetext{
1This is strikingly illustrated by several instances which have been brought to our attention in which a village physician of long standing in the vicinage, feeling himself apparently losing the confidence of his fellow-villagers, moved to town to seek a share of its practice, only to find himself immediately in high favor with his former neighbors.
} 
during the last twenty years, and to-day in some sections of the country there is hardly a town of 2,500 inhabitants that does not have a hospital, or at least an institution which goes by the name of hospital. Many of the socalled hospitals are privately owned and managed by physicians. In a sense they are no more than elaborate extensions of the physician's ordinary equipment with a few beds added. But even these facilities have their influence and usefulness.

To the rural dwellers within a radius of from twentyfive to fifty miles and in many cases even more, the multiplication of these hospitals has brought hospital care for the first time within a distance at all practicable in the great majority of cases. In the most prosperous rural areas, many cases which formerly no one in the country would have thought of sending to the nearest hospital, perhaps two hundred miles or more distant, now go to the hospital thirty, forty or fifty miles distant as a matter of course. Among the better conditioned rural, village, and small-town population, even the deep-rooted prejudice against hospital care for maternity cases is breaking down.

Concurrently with the development of hospitals in the smaller towns has come, particularly in the towns which have acquired hospitals, an increase in the number of specialists. Data regarding the number and distribution of specialists in earlier years are unavailable; but it is a matter of common knowledge that great as has been the increase in the number of physicians in the large cities who hold themselves out as specialists, it has been relatively still greater in the small towns and cities. Many of the small-town specialists of course engage also in 
general practice, but for the purpose of the present discussion that fact is immaterial. Scores of towns in the 5,000-10,000 class could be cited which twenty years ago boasted not a single specialist, but which to-day have two or three-eye, ear, nose and throat, surgery and pediatrics being the favorite specialties. Against the lure of the supposedly, and in many cases really, superior service to be obtained from the town specialist, even the most skillful and well-esteemed village practitioner wages an unequal battle. The impression has gone widely abroad, among the country people as well as among the city dwellers, that the day of the general practitioner is past, and that real competence is to be found only among the specialists. That this view is questioned by some eminent authorities ${ }^{1}$ does not destroy its influence.

\section{DECREASED FINANCIAL ATTRACTIVENESS OF RURAL}

\section{PRACTICE}

It is of the highest importance to appreciate that the competition of the town physician, the town specialist and, in places, the town hospital ${ }^{2}$, to which the erstwhile vil-

1E. g: "General medicine as practised by the family physician enables the qualified practitioner to bring to the suffering patient practically all the benefits which modern medicine affords. . . The general practitioner who is qualified is able to adequately recognize and efficiently treat from 80 to 85 per cent. of the patients who may apply to him for relief." Dr. Frank Billings, Kentucky Medical Journal, May, 1922-vol. xx, p. 325.

'To these should be added, for some hundreds of towns, the town osteopath, chiropractor, sanipractor, etc. The distribution of the practitioners of these cults among the smaller towns is very irregular. Over most of the country they are seldom found in towns of less than 10,000 inhabitants; in the northwest and far west, particularly in Washington, California and Iowa, and also in Missouri, their number is relatively much greater, and they are not infrequently found in towns of not more than $r, 500$ inhabitants, though, on the other hand, there are towns with as many as 3,000 or more without them. It is doubtful whether outside of the states mentioned they can be regarded as a serious source of loss of income even to the physicians located in the same towns; while their effect on the practice of the physicians located in the surrounding villages, though it exists, is very inconsiderable. No comprehensive data are available as to the distribution of practitioners of medical cults in the several classes of cities and towns. 
lage monopolist thus with comparative suddenness found himself exposed, has affected him in precisely the most lucrative part of his practice. Naturally, it was only the better conditioned among his patients who acquired automobiles and became habitual visitors and patrons of the town, or who in case of serious illness could afford to go to the town hospital; and among the less prosperous it was the more profitable types of work-the surgical cases particularly - which went to the town physician and the town hospital. For the village practitioner there remained the long hard drives over the rough country roads, the night calls, the wearisome obstetrical cases in remote farmhouses, the charity cases and the struggling families found in every countryside who required long credit, obtainable only from their neighbor physician.

In the field of home visitation to the outlying farms, the village practitioner retains a margin of advantage over his town competitor. ${ }^{1}$ The practice, virtually universal, of charging mileage fees for trips into the country makes the visit of the town physician in most cases substantially more expensive than that of the local practitioner, so that only the more prosperous will ordinarily call him in, ${ }^{2}$ and, in the bad roads season, a trip from town may be quite impracticable. But as already suggested, this visitation is usually the most burdensome and least lucrative side of the village practitioner's practice.

'He has, however, largely lost one advantage which he had before the day of the telephone-that the farmer had to drive so much farther to call the town doctor. The farmer who has access to a telephone can call the one as easily as the other.

2Idle town physicians have, however, been known on occasion to make large concessions in rates to obtain rural clientèle. A Kentucky physician in one of the communications received denounces "raids" made by the town physician into the rural territory "at ridiculous low prices." 
Seriously aggravating the situation for the village practitioners in many localities is the fact that this enormous intensification in competition has taken place in the face of a relative and sometimes even an absolute decline in the number of his possible clientèle.

The degree and extent of the decline in population in the rural areas are not commonly appreciated. ${ }^{1}$ In many cases these declines do not reflect a decline in agriculture; on the contrary, they frequently reflect progress in the increased utilization of farm machinery, or in the better rotation and seasonal diversification of crops with the resulting need for fewer hands. But naturally all this is of only mild interest to the village practitioner affected.

In some areas, moreover, there has been a pronounced deterioration in the economic level of the farm population. The great increase in the price of farm lands, which characterized the war decade, resulted in these areas in a substantial increase in the proportion of tenant-farmers, and the removal to town of many prosperous farm owners. Finally, without entering here upon the vexed question of the changes in the relative income of the farmer in the economic confusion of the past decade, it is not open to doubt that in numerous rural areas the purchasing power of the average farmer's income bas declined over this period; and in such areas physicians have experienced difficulty in enforcing an increase in their fees at all proportionate to the increase in the cost of living. The failure of the fee in country practice to keep pace with the rise of prices is a factor mentioned with almost monotonous frequency by the physi-

'For details, see below, p. 43. 
cians who have stated to us their reasons for removing from rural locations. ${ }^{1}$

From another quarter altogether has come additional financial loss to the country physician. Within the present century two diseases, which formerly furnished a large and dependable source of income for the village practitioner, and indeed for many a town practitionertyphoid and malaria - have been brought in many areas so far under control as to be financially of negligible importance to the physician. The extension of the ice supply to the smaller towns and villages in many parts of the country, improved methods of food preparation and packing, and a wider dissemination of information on the subject have greatly reduced the incidence of food poisoning and related disorders. Other specific causes might, though doubtless with less confidence, also be cited, ${ }^{2}$ but the essential fact is clear that the population, and particularly the small-town and rural population, requires to-day less medical attention than it did twenty years ago. ${ }^{3}$ These developments have affected the town and indeed to some extent the city practitioner as well; but they came at a time when there were for him many offsets in the increase of urban population, in the general elevation of economic status of the urban dweller and in the enlargement of territory for practice. To the village

\footnotetext{
1The town physician has found much less difficulty in obtaining a suitably higher fee from his country patients-partly, no doubt, because he is in a better position to insist, partly because the rural dweller is accustomed to the rise in the price of everything he gets in town.

2Thus it has been suggested that early surgical interference to-day cures a large number of cases which in former days would have developed into chronic medical cases.

${ }^{3}$ See an excellent brief account of "Changes in a Small Town brought about by the Health Department" in Public Health Reports Vol. 38, No. 10, p. 456. March 9, 1923. The town referred to is in Virginia, and had a population in 1920 of about $I, 500$.
} 
practitioner they coincided in most cases with a period of precisely opposite character.

Nor has it been only in the amount of business "booked"-as the phrase of the profession is-that the village physician has suffered. Even more important in some cases has been the effect of town competition upon his actual collections. Almost everywhere, in rural practice, collection of fees has always loomed up as one of the prime difficulties of the practitioner. ${ }^{1}$ With much of his prosperous and prompt-paying clientèle going to town, the need of the village practitioner for reasonably prompt collection from what business is left him becomes increasingly urgent. But collections actually tend to become more difficult. As the rural dweller's respect for his local practitioner dwindles, his aversion to paying up often increases; the village doctor who has been carrying a family on his books for months with no apparent prospect of their becoming able to settle, sometimes has the experience of calling in a town physician for consultation, for whom the family somehow manages to find for his single visit a cash fee as large as the village physician's whole

\footnotetext{
1In some areas, particularly in the South, the farmer is wholly without funds until his crop is marketed; and physicians' bills are settled only at that time-once a year or in some localities twice. When the crop fails, the physician must expect to carry a large portion of his accounts over till the next year, when if conditions are exceptionally favorable some of them will be paid. If two bad years follow in succession, the physician may as well write off his old accounts. Where tenant-farming on shares is common the tenant is likely to move away without notice; and, if he remains, he is likely to have nothing on which the farmer can levy, even his share of the crop being in many cases mortgaged long before it is harvested to obtain advances of necessities, seed, etc. In many sections of the South this is a large factor in the collection difficulties of the rural practitioner. The suggestion has been made by a considerable number of the southern physicians from whom communications have been received, that the law should award to the physician's claim for medical service rendered a prior lien on the tenant's share of the crop, notwithstanding any agreement to the contrary made by the tenant with his landlord or merchant. The liberal homestead and kindred exemptions from execution granted by the laws of some states-e.g. Kentucky-are also attacked by several correspondents in the same connection.
} 
account. ${ }^{1}$ Nor is the village practitioner in as favorable a position as formerly for bringing pressure to bear on a dilatory debtor by withholding or stinting his service; for it is so much easier than formerly for the patient so treated to obtain the services of another physician. ${ }^{2}$

A final factor which should be mentioned, though it has played a part only in a very small proportion of cases, is that, owing to the increasing dearth of farm-hands, farming as a side-line is no longer so practicable for the rural physician as formerly. So also the decay of village centers has lessened the opportunities for profitable engagement in mercantile side-lines.

So much for the rural practitioner's income. Looking at the expense side of the account, we find the showing to be equally unfavorable. The heavy expense of maintaining an automobile at a distance from a garage and, because of exceptionally hard usage, of frequently replacing it, and, in some cases, of maintaining horses besides, has already been referred to. ${ }^{3}$ The cost of drugs, which many rural practitioners supply to their patients without charge, has mounted rapidly. The multiplication of medical equipment and medical literature and the elaboration of medical procedures have also placed an increasing financial burden upon the isolated physician who strives to "keep up." Finally, in the matter of the expense of educating his children, the rural practitioner of

\footnotetext{
${ }^{1} \mathrm{~A}$ few doctors even report the experience of going to town with such a patient, at their own expense, for a consultation yielding a large cash fee to the consultant, and returning to wait months longer for payment.

"The failure of rural physicians to get together and "blacklist" the "dead-beat" is a not uncommon subject of complaint in the communications received.

The heavy initial cost of an automobile-an absolute necessity for the physician in the rural areas-is undoubtedly a factor tending to deter some impecunious graduates from taking up rural locations.
} 
to-day who has a family growing up is, as compared with his city colleague, not merely at a disadvantage, due to the more frequent necessity of sending his children from home to attend school, but at an increasing disadvantage, because in every field the amount of scholastic training deemed necessary or desirable increases apace.

But perhaps equally important has been the change in the standards of price and expenditure that has come over so much of the countryside. To a very considerable extent the spirit of rural neighborliness and coöperation has given way to a relationship based on the cash nexus; and country prices for services and local products have tended to approximate town and city levels much more nearly than formerly.

The inevitable concomitant of the declining financial attractiveness of rural practice has been an unremitting nation-wide migration of rural physicians to the towns and an increasing disinclination of the younger graduates to take up rural locations.

In the large, the result has been an equalization, under which the greatly reduced number of rural physicians that remain are able to make, on the whole, doubtless as good incomes as did the more numerous rural practitioners of a generation ago-sometimes perhaps better incomes. But there are few indeed who, however fortunately situated, can earn, in their practice, more than a moderate income. ${ }^{1}$ The reason is plain. The amount of

'No attempt has been made to gather statistical data on the income of the rural physician. The only investigation of this subject of which we have learned is one conducted in 1922-23 by the Committee on Medical Economics of the New York State Medical Society, the results of which have been placed at our disposal by the Committee. Approximately one hundred returns, made by physicians located in villages having only one or two physicians, show an average gross annual income of $\$ 5,648$ and professional expenses of $\$ 2,305$, leaving a net income of $\$ 3,343$. It may be assumed that the physicians who made returns were at least as prosperous as 200 others who failed to do so. 
work the rural practitioner can do is severely limited; the proportion of office visits to bedside calls is almost invariably low; the time required not merely for travelling, but for the call itself, and in many instances for making the necessary arrangements for the proper care of the patient is excessively high; and the irregularity which seems inseparable from country practice consumes time. The fee-scale can never rise much above the minimum level, and a substantial proportion of uncollectible accounts is inevitable.

INCREASED FINANCIAL AND SOCIAL ATTRACTIVENESS OF URBAN PRACTICE

While the village practitioner's financial position has thus tended, except in the most favorable village locations, steadily to become more unstable, the financial opportunities of the town practitioner have increased. A prime factor in that increase has been his gain at the expense of his rural colleagues, ${ }^{1}$ already reviewed. But there have been other factors. The standard of living in the towns has in general risen more rapidly than it has in the country, bringing with it a greater relative demand for medical service. ${ }^{2}$ The rise in income level, also, has been greater on the whole in the town than in the country, and as a result the town physicians have had generally little difficulty in securing an increase in their fees proportionate to the rise in the cost and standard of living. The process has been greatly facilitated by the development

\footnotetext{
1Offsetting this in minor degree, there has doubtless been a slightly increased tendency on the part of the town patient to go to a still larger town.

${ }^{2}$ Rural areas where there has been a corresponding elevation of the standard of living and a corresponding increase in the demand for medical service are usually precisely those in which the competition of the town physician is most keenly felt.
} 
of the town specialist already referred to; for he has accustomed the townspeople to a fee scale by comparison with which the general practitioner's fees, even though larger than formerly, seem reasonable enough. Moreover, the cities and towns ranging from 50,000 down to as few as 5,000 inhabitants, and sometimes even less, in recent years have actually increased in importance at the expense of the larger centers. The hospitals and specialists developed in these towns have not merely gathered in patients from the countryside, who in former times stayed at home; they have kept in the towns patients who formerly would have gone to distant centers for treatment.

The serious effect which the development of specialists in the towns has had upon the income of the rural practitioner has already been mentioned. Conversely, the higher fees and easier conditions of work enjoyed by these specialists-many of them former general practitioners with little if any post-graduate training or hospital experience in their specialty-have become a standing incentive to the village practitioner, hardly known a decade before, to go and do likewise. The larger financial possibilities of the successful town practitioner have of course always been a feature in favor of town location; but the possibilities of the successful town specialist rise much higher still, creating in reality a wholly new level of medical earnings, and thus holding out to the rural practitioner a lure to the town far more powerful than formerly existed.

Moreover, curiously enough, for many a rural practitioner the development of specialism has actually facilitated his removal to town; for it has enabled him, after taking a short post-graduate course in a specialty, to prac- 
tise as a specialist in a town which has no other specialist of the type selected.

In addition, the larger towns, and particularly the larger cities, have been offering to the physician seeking a fixed income rather than the hazards of private practice an increasing number of opportunities. Particularly numerous have been the opportunities open to the recent graduate. Twenty years ago a contract practice in a coal mine or a lumber camp offered almost the only opportunity for earning a salary. A limited number of salaried posts there were, indeed, in public health work, but these were confined to the larger cities, and were seldom on a full-time basis. In the hospitals, so plentiful was the supply of new graduates, internes were readily procured for their keep in numbers sufficient to meet all the needs of resident service; and salaried posts were correspondingly rare. Analytical laboratories, $\mathrm{X}$-ray laboratories, and the like, were few and far between, and research laboratories were negligible. Thus, in proportion to the stream of new graduates which poured out of the schools - the majority without hospital experience, for they far out-numbered the available interneships - the number of available posts offering a salary, other than industrial contract practices, was negligibly small. The graduate eager to become an earner had virtually no alternative, other than an industrial contract practice, to a rural location; preferably one just made vacant by death or removal, but if none such were available, one which in the existing difficulties of transportation and communication gave promise of immediately engaging the patronage of the people in the village and vicinity.

It is indeed a changed scene on which the young physi- 
cian of to-day looks out. The number of salaried posts available in hospitals, in public health work, and in laboratories, both research and routine, has increased rapidly. Simultaneously opportunities for industrial contract practice have multiplied; and with the multiplication of specialists in the smaller towns, the opportunities for the young practitioner looking to eventual specialization to associate himself on a salaried or nearsalaried basis with a specialist have correspondingly increased. Altogether it would probably not be too much to say that in proportion to the number of graduates there are to-day ten posts, salaried or otherwise guaranteed, where twenty years ago there was one. ${ }^{1}$

With the steady deterioration of the financial reward of the village location, and the steady enlargement of the possibilities of the town location, it would seem that a sufficient explanation had been found for the migration to town of former village practitioners, and of the avoidance of the villages by the recent graduates, which have characterized the past decade or more. But there have been other factors than the financial-and factors of prime importance. In professional, personal and social attractions, too, the town has gained far more rapidly than has the country, and these attractions have worked powerfully, sometimes by themselves, sometimes in conjunction with the financial factor, to draw rural physi-

1On the other hand, the relative cost to the graduate in search of a location of establishing himself in a rural location has greatly increased; for an automobile is now indispensable in the country, while in the city the struggling physician may use the street-car. The large equipment which the conscientious beginner in rural practice to-day must possess, as compared with the beginner in the city, who can on occasion readily fall back on the equipment of his colleagues or of hospitals, has also increased the cost of setting up as a village doctor. 
cians to the towns, and to decide the young graduate in favor of the towns.

In respect to the personal comfort of the physician and his family the town has gained on the village or cross-roads location even more strikingly than in respect to income. Much has been made, and with good reason, of the great changes for the better in farm and village life which modern mechanical improvement has made possible. But too little emphasis has been laid on the fact that such improvements are within the means of, and have been availed of, by a relatively small portion of the farmers and village dwellers of the nation, and that large areas of farming country, and innumerable villages, are to-day, except for the automobile, little further advanced in the path of material development than they were a generation ago. ${ }^{1}$ On the other hand, the small towns have shared in that development to a very considerable extent. Paved streets, electricity, water and sewage systems are now the rule rather than the exception even in towns of 2,500 inhabitants; ${ }^{2}$ and where road improvement has come, it has come first, and often only, in the roads radiating from town. Thus the progress of mechanical improvement, much as it has done for the rural areas, has widened, not narrowed, the gap between town and country life.

\footnotetext{
1For an excellent authoritative exposition of this theme see Boyle, "Rural Problems in the United States" (I92I).

2"Many of the cities and villages having a population of less than 2,500 are characterized by city customs, methods and institutions in the realms of business, recreation and education. It appears also that this tendency of the comprehensive trading center to approach the manner of life of the larger centers of population is growing and will never diminish. Moreover, the housing convenience, public utilities and ease of transportation give to urban centers city characteristics which it is no longer possible to ignore." Report of the Committee on Legislation, First National Country Life Conference, rorg; Proceedings, p. 74. These remarks were part of the committee's criticism of the census classification as "rural" of persons residing in incorporated places of less than 2,500 inhabitants.
} 
From the standpoint of the rural physician, none of the town's growing improvements has made anything like so strong an appeal as has the paving of its streets and the improvement of the roads radiating from it; for the growing contrast in this respect between his own lot and that of his town brother is brought daily, indeed hourly, before the rural practitioner, riding for hours together over unimproved roads, and compelled, in the bad-roads season, literally to fight his way to his patients. It is true that the village physician removing to town must almost always continue to do a considerable amount of practice in the country, with its journeys over the back roads; but such journeys now form only a part, instead of the whole, of his day's driving; his duty to make them in all sorts of weather and for all patients becomes less imperative; and there is always the hope that as time goes on he will acquire enough practice in and immediately adjacent to the town to enable him greatly to reduce, or even to eliminate, the long drives into the country.

On its social and institutional side, the progress of town life in the past two decades, as compared with village and country life, has kept pace with material progress. In the towns, elementary schools, high schools, churches, amusements and social life have everywhere developed steadily. In the country notable progress in these directions has on the whole been limited to relatively few areas. ${ }^{1}$ The village physician with a family growing up finds to-day the apparent social and institutional advantages to be gained for his family in

\footnotetext{
IIn 1920 there were 189,227 one-room schoolhouses in use. The number of consolidated schools was 9,752, an increase of but 997 over the preceding year. Statistics of State School Systems (rgrg-1920). Bulletin of Bureau of Education, 1922, No. 29, p. 20.
} 
town far more numerous and marked than he did twenty years ago. Indeed, if the communications received by us be regarded às representative, the number of rural physicians who have removed to town in the last decade chiefly to obtain access to better schools and churches for their children constitutes a substantial proportion of the whole number so removing; and the proportion who cite the dissatisfaction of their wives and young people with the social isolation of the village is also considerable.

INCREASED PROFESSIONAL ATTRACTIVENESS OF URBAN PRACTICE

On the professional side, the drawbacks of village practice have also been keenly felt by the conscientious practitioner. At an earlier stage in the progress of medical science, the equipment needed for the practice of medicine was well within the means of the individual practitioner. "Every physician carried within himself his whole armamentarium. The use of the test tube, the microscope, and the Roentgen ray as aids to diagnosis at that time lay in the future. Medical books were rare, but they could be obtained and evidently were read as intelligently by the country doctor as by his urban brother. The great medical men of that era were those who were posted in the literature of medicine, were clear thinkers, and skillful practitioners-it mattered not whether they lived in small or densely populated communities." To-day the numerous books and instruments, particularly the latter, necessary for the conscien-

\footnotetext{
1Vaughan: Rural Health Centers as Aids to General Practitioners, Jour. Am. Med Assn., April 9, 1921, vol. 76, p. 983.
} 
tious practice of general medicine, are so costly that even the income of the prosperous town physician would hardly be equal to their provision; for the village practitioner, particularly for the younger man who is most keenly sensitive to the need, the expense is quite out of the question, even if the costly X-ray equipment be left out of account. ${ }^{1}$ Nor is it only a matter of expense. The rural physician, who, if not overworked, is at any rate condemned to irregular hours, finds it hard, particularly in the absence of electricity and running water, to do even those laboratory tests for which the required equipment is relatively simple and inexpensive; and like many a city physician he frequently does not trust his ability to do them. Increasingly it becomes possible for the physician in the remoter location to send specimens to town laboratories for microscopical or chemical examination, but the process is at best a cumbersome one, and rural patients have not yet become educated to the payment of the fee involved; while from X-ray diagnosis the rural physician is quite cut off, short of sending the patient to town.

There can be no doubt that the drawbacks under which the rural practitioner labors in these respects have been a material factor in the dissatisfaction with rural practice which has urged so many rural physicians to town, and perhaps even more in the reluctance of the more recent graduates to take up rural locations. If, however, one may judge from the hundreds of communications which have been received, both from physicians who have left village locations, and young graduates who have avoided

\footnotetext{
IIn addition to the $\mathrm{X}$-ray or other electrical equipment itself, an installation for the generation of current would ordinarily be required in the village location.
} 
them, the importance of these drawbacks of the country location has been somewhat overestimated by some who have discussed this subject. Despite the multiplication of diagnostic laboratories and X-ray installations in the last decade or two, the number of towns which have either is still so small, that, were attractive power limited chiefly to those towns, the resultant effect upon the distribution of physicians would be almost negligible. Thousands of rural physicians have moved into town without improving the professional equipment at their disposal in any respect other than obtaining access to electric current, and thousands of graduates of the second half of the last decade have located in towns in which this is the only scientific advantage over the villages which they have regarded with relative disfavor.

A factor closely related to the inaccessibility of laboratory and X-ray facilities in the rural areas is the lack of hospital facilities. Closely related as the two are, it is most essential in thinking of this problem to keep them entirely distinct - the more so because they have been so frequently confused. It is entirely possible to have laboratory and X-ray facilities and service without a hospital, though under current conditions few centers large enough to maintain a laboratory and X-ray installation are without their hospital. Similarly, it is entirely possible to have a hospital-in the common sense of the term as an institution for nursing carewithout any laboratory or X-ray equipment or personnel; and in point of fact a heavy proportion of the smaller hospitals of the country are lacking in these respects, in some cases wholly, in other cases in essential particulars. There is a proportion of cases in which under the best 
modern practice, the laboratory and the $\mathrm{X}$-ray are used during the whole progress of the illness to study the condition of the bed-ridden patient, and which accordingly can be so studied only if the patient is in a wellequipped and well-staffed hospital. But these classes of cases form but a minor, if not an insignificant, portion of the staple of general rural practice; and the inability to handle such cases in the most approved manner, where removal to a well-equipped hospital is impracticable, can hardly be regarded as an important factor in the unattractiveness of rural practice from a scientific standpoint. When it is said, therefore, as it so frequently is, that scientific practice is impossible in the country because of the lack of hospitals, it will usually be found that what is meant is not the lack of the nursing care under hospital control, but the lack of the laboratory, X-ray and cognate facilities and services which are ordinarily associated with the well-equipped and well-conducted hospital.

There is a much more important way in which the lack of local hospital facilities has increasingly contributed to the dissatisfaction of the rural practitioner who has a scientific interest in his profession. With the multiplication of hospitals in the small towns, as already pointed out, a large class of rural patients who formerly would have remained at home under the care of their local physician now seek the hospital. This almost always entails their passing completely from the hands of their local physician-either because he is so far distant from the hospital that frequent attendance there is impracticable, or because the hospital is a "closed" one, extending its privileges only to a limited list of physicians-fre- 
quently those having an ownership interest in it. ${ }^{1}$ The loss of the case, quite aside from the loss of fees entailed, deprives the rural physician of the opportunity to follow the progress of the disease; and in the main it is precisely the most interesting cases, from a scientific standpoint, which are thus lost to the rural doctor.

The difficulty of obtaining competent nursing service for rural patients-even for that limited portion of them who can afford it-is another source of professional dissatisfaction to the physician doing rural practice. In not a few cases, the recovery of the patient depends as much upon good nursing as upon medication or medical treatment; and satisfactory nursing in rural cases is often unobtainable.

Perhaps quite as important as the lack of material facilities in making rural practice increasingly unattractive to the physician with a scientific interest in his profession is the lack of contact with other physicians. There are few fields in which the rubbing of elbows with one's colleagues, not through the medium of the printed word, but in actual personal contact, discussion and observation, is so valuable and indeed so indispensable a part of the post-scholastic professional education as it is in the field of medicine. This has always been so; but as the progress of medical science swiftened its pace, it became increasingly so; and increasingly the village practitioner who is trying to keep abreast of the tide has become aware of the disabilities which his isolation imposes upon

\footnotetext{
1The "closed" hospital is found, however, quite frequently even among public taxsupported hospitals. Even where the law or ordinance under which the hospital exists provides, as is frequently the case, that its facilities shall be open to any licensed practitioner of the town or county, it may come about that the members of the appointed staff of visiting physicians in effect form a "ring," into which an outsider can enter only with difficulty.
} 
him and of the advantages in this respect which would come from daily contact with town colleagues.

The small-town hospital if properly organized and conducted furnishes to the town physician all the things which the rural physician lacks-laboratory and X-ray facilities and service, nursing service, and the opportunity for contact with his colleagues; and the possibility of obtaining access to a hospital consequently figures as an important factor in the lure of the towns. As already suggested, however, with reference to laboratory facilities alone, it is quite possible to over-estimate the importance of the town hospital in this connection; not only do a large proportion of the smaller towns which have attracted physicians in recent years have no hospital but in those that do have one, the hospital, in a large proportion of cases, furnishes no laboratory or X-ray service and little opportunity for intercourse among the physicians using its facilities. Moreover, it must be admitted that to judge from the communications received, in not a few cases where a desire to obtain access to hospital facilities has been assigned by a physician as a reason for his removal to town, the motive appears to have been fully as much financial as scientific-the desire to retain as his own the cases which need or seek hospital care.

It need hardly be said that the inaccessibility in rural practice, of the laboratory, the X-ray, and kindred facilities, has on the whole been felt most keenly by the younger physicians. To the older practitioners in many cases knowledge of these latter-day developments has come only in snatches as it were; and in some cases far from feeling their deprivation, they are more comfortable when they remain well in the background. With the younger 
man, on the other hand, familiarity with and reliance on these facilities have been an essential part of his education.

It is thus quite obvious that so far as this difference between the older and younger generations of physicians does exist, it is primarily to be explained by the different periods in the development of medical science at which they acquired their medical training; even if medical education had made no independent progress during the present century, but had merely kept abreast of the contemporary development in medical science, the more recent graduates would inevitably be on the whole more thoroughly schooled in those developments than those at least of the older practitioners who are located in the further places remote from contact with them. It is, however, at times asserted that the medical schools tend to over-emphasize the importance of mechanical equipment. Whether this be true or not, this is but one of several distinct counts in an indictment in which responsibility for the failure of the recent graduate to locate in the villages in the same proportion as his predecessors is laid at the door of the current régime in medical education; and discussion of the whole theme is reserved for a subsequent chapter. This postponement is warranted by the fact, shortly to be brought out, that whatever conclusion may be reached as to the contributing factors in the tendency of the recent graduate to avoid rural practice, the quantitative result of that tendency has to date been relatively minor.

The underlying factors which determine the distribution of physicians between town and country generally, 
and the special factors which have influenced the changes in that distribution in recent years, have now been reviewed. In the succeeding chapters the attempt is made to arrive at a summary view-correct only in its main outlines, for more is impossible in any general characterization of conditions of such infinite variety-of the actual disparity between town and country in the relative number of physicians, of the distance between physicians in the rural areas, the actual conditions of communication and transportation in the countryside, the economic and psychological factors that condition the availability of rural medical service, and the changes that have taken place in all these respects in the present century. Finally, the existing situation is examined from the standpoint of the "vacant" rural location-i. e., the village, usually the former home of a physician but now without one, in which it is alleged a physician is needed. 


\section{CHAPTER II}

THE DISTRIBUTION OF PHYSICIANS BETWEEN TOWN AND COUNTRY

As already pointed out, perhaps the most powerful of the factors which have brought about the extensive changes in the present century in the distribuition of physicians between town and country has been the progressively rapid growth of the urban population, with its disproportionately high requirement for physicians. At any time in our history this development must have caused a relative decline in the number of rural practitioners. Coming as it did in a period when the growth of the medical profession did not keep pace even with the increase of the population as a whole, much less with that of the urban population, its effects were all the more pronounced. It will be worth while, leaving for the statistical appendix ${ }^{1}$ all points of detail, here to review, in round numbers, the outstanding facts of these changes in the distribution of population between town and country and in the concomitant distribution of physicians.

\section{THE DISTRIBUTION OF POPULATION}

To view the problem of the distribution of physicians in its proper proportions, it is essential to have an approximate notion of the distribution of the population of the United States in and about the twenty thousand

1Pages 153 ff. 
or more cities, towns and villages in which one or more physicians are located. To form a more than approximate notion is extremely difficult, because of the impossibility of defining with any precision the areas of countryside respectively receiving their medical service from each of these thousands of places; or, even if those areas could be defined however accurately, of ascertaining their population, cutting as they do across all political subdivision boundaries, which alone form the basis of all available population data.

It is possible, however, to assume for each city, town and village having physicians an average number of persons who, though living beyond its corporate or recognized limits and therefore not embraced in its population figures as found in the census or other sources, ${ }^{1}$ look to it for medical service. ${ }^{2}$ In the nature of the case this assumption cannot be put forth with absolute confidence, but it nevertheless furnishes a reasonably correct approximation for the present purpose. ${ }^{3}$ The following may then be taken as reflecting with substantial correctness the proportions of the population (not including that of New England) ${ }^{4}$ resident in and about

IThe census gives the population of incorporated places only.

2The premise on which this assumed figure is based - that each dweller outside the town or village looks exclusively to only a single town or village for medical service-is notoriously at variance with the facts, but it is nevertheless sufficiently near the truth to warrant its use in the present connection.

${ }^{3}$ For the methods of deriving the figure in question, see Appendix p. I64.

"Owing to the practice which obtains in Maine, Massachusetts, Connecticut, and Rhode Island of incorporating villages or towns only when they attain a fairly large population (about 10,000), the population figures available for the smaller towns and villages in these states are incomplete and confusing and less reliable than elsewhere. For these reasons it has been thought best, in this and in the succeeding tables dealing with the smaller places, to exclude New England. Supplementary figures for New England, and for the whole country with New England included, will be found in the detailed tables in the Appendix. 
the various classes of cities, towns and villages having (in 1923) one or more physicians:

\begin{tabular}{|c|c|c|c|c|}
\hline & \multirow{2}{*}{$\begin{array}{l}\text { NUMBER } \\
\text { OF PLACES } \\
\text { HAVING } \\
\text { PHYSICIANS } \\
(1923)\end{array}$} & \multicolumn{3}{|c|}{$\begin{array}{c}\text { Percentage of Population } \\
\text { Reswing (IN I923) }\end{array}$} \\
\hline & & $\begin{array}{l}\text { IN AND } \\
\text { ABOUT } \\
\text { SUCH } \\
\text { PLACES }\end{array}$ & $\begin{array}{l}\text { IN CORPOR- } \\
\text { ATE OR } \\
\text { RECOG- } \\
\text { NIZED } \\
\text { LIMITS }\end{array}$ & $\begin{array}{l}\text { OUTSIDE } \\
\text { CORPORATE } \\
\text { OR RECOG- } \\
\text { NIZED } \\
\text { LIMITS }\end{array}$ \\
\hline $\begin{array}{l}\text { All Places } \\
\text { Places having (in } \\
\text { I920) a popula- } \\
\text { tion of: }\end{array}$ & 21,386 & 100.0 & 60.5 & 39.5 \\
\hline $\begin{array}{l}\text { Less than } 1, \infty 00 \\
1,000-2,500 . \\
2,5 \infty 0-5,000 \\
5,000-10,000 \\
\text { More than } 10,000\end{array}$ & $\begin{array}{r}15,724 \\
3,167 \\
1,227 \\
636 \\
632\end{array}$ & $\begin{array}{r}32.5 \\
11.3 \\
6.7 \\
5.6 \\
43.9\end{array}$ & $\begin{array}{r}3.4 \\
5.4 \\
4.5 \\
4.5 \\
42.7\end{array}$ & $\begin{array}{r}29.1 \\
5.9 \\
2.2 \\
1.1 \\
1.2\end{array}$ \\
\hline
\end{tabular}

It is apparent that the persons residing outside the town or village limits number about 40 per cent. of the entire population; and that of these nearly three-quarters are primarily dependent for their medical service upon physicians located in villages of less than 1,000 inhabitants, and almost seven-eighths upon physicians located in towns and villages of less than 2,500 inhabitants. For practical purposes, therefore, the problem of rural medical service may be regarded as the problem of supplying medical service from towns of less than 2,500 inhabitants, and, for the most part, from villages of less than 1,000 inhabitants-villages having on the average perhaps not much over 200 inhabitants, certainly not as much as 500 .

These basic figures must ever be kept in mind in discussing the problem of rural medical service from whatever angle. Thus proposals which would indeed give 
the countryside better medical service, but which cannot be developed economically, if at all, in a town of less than 5,000 inhabitants, are wholly inapplicable to all but a minor fraction of the rural area. True, the zone of service of the larger town can be measurably enlarged, perhaps in time greatly enlarged; but it needs but a glance. at the comparative numbers of the places of more and less than 5,000 inhabitants to force home the conclusion that even such enlargement, even if effected immediately, would bring the service of the towns to only a minority of the outlying rural communities.

Of the changes in population distribution which have conditioned the changes in the distribution of physicians in the present century, far the most important has been the disparity in the rate of increase between the urban and rural populations already reviewed. More striking, however, even if not so important, has been the absolute decline in population over extensive rural areas.

During the two decades 1900-1920 the population of the United States increased by nearly $30,000,000$-an increase of nearly 40 per cent. Of this vast increase only about $4,000,000$ occurred in the territory outside of incorporated towns and villages ${ }^{1}$-an increase of less than ro per cent. in that area.

But even this increase has by no means been uniform over the whole of the rural area. On the contrary, it represents the net result of great losses and great gains. The gains have come mainly from areas chiefly in the west, but in part in the settled states farther east, which have been largely opened to settlement only dur-

\footnotetext{
1This figure is based on the assumption that the approximately 5,000 villages incorporated since 1900 had in 1900 an average population of 200 .
} 
ing this period; and offsetting them are whole states nearly every county of which has declined in rural population in this period. Indeed, among the settled agricultural areas there are relatively few which have increased in farming population during this period, or which have even held their own. A glance at the map reproduced in the appendix ${ }^{1}$ will disclose how vast has been the area of rural population decrease. ${ }^{2}$

The rate of rural depletion has varied greatly from section to section, from state to state and from one part of a state to another; and available data do not permit of any classified presentation. It may be said, however, that, looking at the matter from the standpoint of the thousands of towns and village centers the country over, it is no uncommon thing for the rural territory within ten miles' ride of a town or village to have lost 20 per cent. in population since I900. This condition will be encountered frequently in New England, in New York and northern Pennsylvania and in all the states of the old northwest; all over the south (except in the Carolinas); and even west of the Mississippi in all the states east of the Rockies, except in northern Iowa and in Minnesota. Even in the newly settled areas the tendency of rural population to decline has very rapidly made itself manifest.

While the decline of rural population of course represents chiefly a decline in farm population, the small villages, for reasons indicated in the preceding chapter, have also for the most part declined in population. A

\section{Page 163.}

2The counties showing a decrease of total population from rgro to r920 comprise by area over $30 \%$ of the country. In the east north central section (Ohio, Indiana, Illinois, Michigan, Wisconsin) they comprise over $45 \%$. (I4th census, vol. x, p. 39.) 
proportion of them, perhaps as much as one-tenth of the whole, have been touched by the same economic influences that have caused the rapid expansion of the towns and cities during this era, and have themselves become thriving towns; but the remainder have in most cases failed to do more than hold their own in population.

RELATIVE NUMBER OF TOWN AND COUNTRY PHYSICIANS

Reasonably accurate data regarding the distribution of physicians in the United States among the smaller towns and villages first became available in 1906, with the publication of the first issue of the American Medical Directory. Nor for the purpose of the present study would it greatly profit to go much further back than r9o6, even were the data available. For in that year the nationwide movement for the elevation of the standards of medical education had hardly begun; the number of physicians, relative as well as absolute, had been steadily on the increase for over a decade; the automobile and the hard road had as yet made only slight progress in the rural areas, and were indeed minor factors even in the cities; and the rural telephone was still a novelty. Hence the distribution of physicians in 1906 may properly be regarded as the distribution which the country enjoyed at the culmination of the old order of medical education and medical practice.

In 1906, the cities of over 25,000 inhabitants contained about 28 per cent. of the population of the country and 40 per cent. of the physicians of the country. By 1923, such cities contained approximately 37 per cent. of the population of the country and over 50 per cent. of the physicians. For at least two decades, 
therefore, and doubtless from the very beginning, the people of the larger towns and cities have had at their service a substantially larger proportion of the physicians than has the population resident outside these towns and cities; and as will shortly appear, despite the widely current belief to the contrary, the inequality has increased but little during the interval.

The statistical presentation of the numerical relation between population and physicians in the several classes of places and their tributary areas encounters the basic difficulty already referred to-the impossibility of defining even approximately the boundaries of the rural area which receives its medical service from any given city, town or village, or, the area once outlined, however correctly, of approximating its population. ${ }^{1}$ Within

\footnotetext{
IIt may be well at this point to dispose of the genial notion so commonly encountered in the discussions of this theme that have appeared the last few years, that it is possible to measure the relative quantities of medical service available in the various portions of an area by computing the ratio of population to physicians in the several minor political subdivisions of the area, as townships or counties. It is difficult to imagine any form of measurement which will produce results less related to reality than this. Manifestly medical service bears no relation whatever to county, township, or other political subdivision lines, but flows from centers of settlement into the surrounding countryside in every direction regardless of political subdivisions. In some states where the counties are small (often not more than fifteen miles in any direction), it is perfectly conceivable that the population of a county might be entirely adequately supplied with medical service from bordering towns in neighboring counties though there were no single physician within the county. It is equally conceivable that the physicians in a county might bear numerically a very high proportion to the population, yet by reason of their being concentrated in one or two towns, a large portion of the county remote from these towns might be virtually without medical service. In short, political subdivision lines and medical service have not the remotest connection with each other, and any statistical study grounded on such a relation is worse than useless. Lest the point seem unduly labored it may be instanced that in the case of one state figures regarding the availability of med. ical service have been published from the state university medical school in which there is used as an infallible criterion of the sufficiency of medical service in the several counties, not merely the ratio of population to physicians in each county, but the ratio of area to the number of physicians, regardless of the number or distribution of the towns or villages in which the physicians are located or the distribution of the population with respect thereto - a proceeding so manifestly absurd as hardly to merit notice, had it not emanated from so respectable a source.
} 
these limitations, however, and with the qualifications already made in connection with the estimates just presented of the populations tributary to the several classes of places, the following table is believed to reflect with sufficient accuracy the relation between population and physicians in and about the several classes of towns, cities and villages in 1906 and 1923 , expressed in terms of the average number of persons to be served by each physician.

POPULATION PER PHYSICIAN, I906 AND I923 ${ }^{1}$

(NEW ENGLAND NoT INCLUDED)

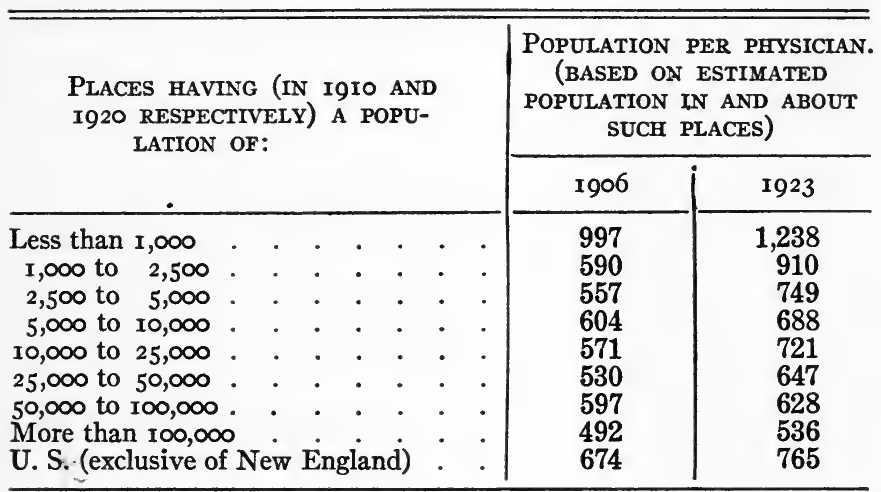

The extent of the difference between the various classes of places can perhaps more readily be seen by expressing the relative number of physicians in each class of places as a percentage of the relative number in the country as a whole, ${ }^{2}$ as is done in the following:

\footnotetext{
1A similar table showing comparable data separately for each section of the country may be found in the Appendix (p. 167). Limitations of space forbid its summarization or discussion here.

2The "relative number" used for this purpose is not of course the "population per physician" but the reverse or reciprocal figure, representing physicians per unit of population.
} 
RELATIVE NUMBER OF PHYSICIANS IN PLACES OF VARIOUS SIZES COMPARED WITH RELATIVE NUMBER

IN THE COUNTRY AS A WHOLE, I906 AND 1923

(New England Not included)

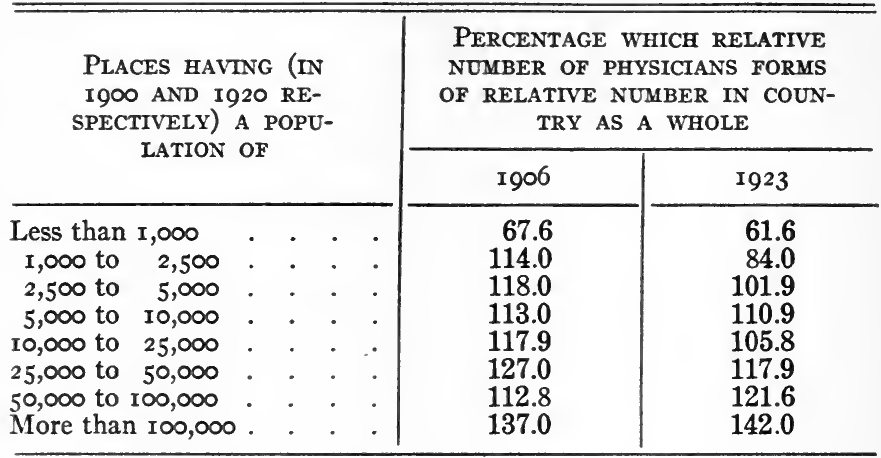

The essential conclusion to be drawn from these figures seems to be that the people in and about the smaller villages - the places of less than $\mathrm{I}, 000$ inhabitants-have long had relatively a much smaller number of physicians than the number indicated by the proportion which they form of the population; while for the people in and about the towns and cities of more than 1,000 inhabitants the number of physicians has been correspondingly larger than their proportion of the population would indicate ${ }^{1}$ - for the places of less than 100,000 inhabitants only moderately larger, and for the cities of more than 100,000 inhabitants much larger; and that, looked at in the large, these relations have remained fairly constant since I906,

\footnotetext{
${ }_{1}^{1}$ An exception must be noted in the case of the places of from 1,000 to 2,500 inhabitants. For 1906 the number of physicians is greater by about $15 \%$ than the estimated population in and about them would indicate, while for 1923 it is about an equal amount less. A possible explanation for the change is that places of this size have since 1906 in many instances lost their impartance in the countryside in favor of more distant towns of a somewhat larger size.
} 
despite an apparent tendency for the disparity between the smallest and largest places to increase.

What has really happened, the figures indicate, and what has given rise to the prevalent impression of a disproportionately great loss of rural practitioners, is seemingly not actually a greater decline in the relative number of rural than of urban practitioners, but merely a relative decline in the number of physicians everywhere, in the cities as well as in the smaller towns and in the country. In the cities, however, long oversupplied with physicians, their relative decline in numbers has caused no inconvenience and has indeed entirely escaped the notice of the average resident; while in the countryside, where even in the days of the greatest abundance of physicians it was often impossible to obtain medical service without hardship and serious delay, the decline has borne heavily on great numbers of farm dwellers and even villagers. Further, over large areas of the countryside the decline, in sharp contrast to the situation in the cities, has been not only relative but absolute. Most important, in the cities and towns the decline has meant at worst a mere reduction in the number of physicians in a given place; but for many a rural community it has meant the complete abandonment by physicians of the village to which the community has for years been accustomed to look for medical service.

In examining these statistical comparisons there must always be borne in mind the difference between town and country conditions, and between I906 and I923 conditions which tend to qualify the significance of the figures.

An obvious factor which the figures do not reflect is the difference in the proportion of physicians in town and 
country who have either retired from practice or do not devote themselves exclusively to practice. The proportion of those retired from practice is on the whole undoubtedly greater in the larger towns than in the villages, and the disparity in this respect has probably increased over the period under review. The proportion of physicians who follow a "side line," formerly considerable in the rural areas, has greatly declined during this period. Hence on both these counts, the disparity between town and country indicated by the figures may be regarded as somewhat exaggerated by comparison with the actual conditions, though the distortion is probably not considerable.

Another factor tending in the same direction is the increasing number of physicians in the cities and towns who are engaged in branches of medicine other than practice-as research work, analytical laboratory work, public health work, hospital administration, teaching, medical journalism and the like. Here, too, the number involved, though considerable in an absolute sense, is relatively too small to have more than a very minor effect upon the whole.

Far more important is the wide divergence in the conditions of city and country practice. At one extreme we have the physician in a congested urban neighborhood, whose practice is largely in his office, whose calls seldom take him more than fifteen minutes' ride or drive, who can keep in touch with virtually all his bedridden cases by telephone, and who has at hand analytical laboratories, drug stores, surgical supply houses and all other facilities, which enable him to do his work with maximum dispatch. At the other extreme is the lone practitioner of 
one of the more remote rural areas, spending long hours in drives over rough roads, unable to keep in touch with many of his patients by telephone, compelled to compound and dispense his own prescriptions, and forced in emergencies to improvise, at great cost of time and labor, all manner of appliances and even nursing expedients.

The difference in amount of available medical service represented by a given number of physicians at these two extremes, or at any points between, cannot be expressed numerically; yet it is obviously an indispensable factor in any valid comparison of the proportions of physicians to population in urban and rural areas.

On the other hand, it must be remembered that a disparity between town and country in the amount of medical service available by no means implies under ordinary conditions an equal disparity in the amount of medical service actually rendered. The disparity in the relative number of urban and rural physicians is of course in large part to be explained by a disparity in the demand for medical service by the urban and rural population; but even if this be admitted to be very considerable it is hardly sufficient to explain the very wide disparity in the number of physicians. That disparity can be fully explained only by taking into account also the far greater professional overcrowding in the urban than in the rural areas, with a correspondingly far greater proportion of the town physician's time spent otherwise than in rendering medical service.

A major element in the professional overcrowding of the towns and cities is the large number of physicians in them, graduated five or ten years ago, and in not a few cases even longer, who have not yet succeeded in securely 
establishing themselves and do not regularly find enough professional work to yield them a reasonable income. Less apparent, but perhaps even more important, however, is the enormous number of established practitioners who do regularly earn a reasonably good income, but whose time is seldom fully occupied. While no accurate estimate of the extent of this condition in the towns and cities is practicable, its magnitude becomes clear when one examines the fee scales prevailing in the average fairsized town or city. On such examination it becomes apparent that a physician whose time was more or less completely occupied in urban practice would readily earn an income substantially in excess of what, as matter of common knowledge, is earned by the average town or city practitioner.

If it be assumed that the profession may be regarded as over-crowded in any city or town in which the average practitioner does not ordinarily find his time fairly completely occupied, it may be safely said that there is hardly a single town of over 25,000 inhabitants in which the profession is not over-crowded. The degree of overcrowding, however, varies considerably from city to city. It tends to be greatest in those cities in which there are, or have formerly been, medical schools, resulting in a disproportionately large number of physicians locating there, and in which the growth of population has not been rapid.

While the over-crowding is greatest in the largest towns, it is by no means confined to them. There is, indeed, hardly a town of as much as 2,500 inhabitants, and in some sections of the country of even as much as 1,000 , in which the number of physicians may not be regarded as at least one or two in excess of the demand. 
Of this no better proof is required than the great numbers of physicians who are located in villages of less than 500 inhabitants. As the result of our studies, it seems conservative to assume that at least half of these physicians would greatly prefer residence in a town of even as few as 1,500 or 2,000 inhabitants and that the major proportion of them would promptly make the change did any of the towns with which they are familiar seem to hold out a reasonable assurance of a moderate income. Hence their continuance in their present locations may safely be accepted as an expression of their belief that the towns of even this size with which they are familiar are already supplied with physicians to the point of saturation.

\section{THE DECREASE OF RURAL PHYSICIANS}

For simplicity the changes since 1906 have been treated as a uniform process, without considering the relative rates of change at various periods in this interval. To go into detail on this head would be of slight value. In general it may be said that the period falls into two fairly distinct parts, with I9r6 as the dividing line. During the decade I906-I6 the proportion of physicians to population for the country as a whole remained nearly constant, declining only to a negligible extent; since I9I6 the decline has been substantial. Concurrently, the rate of urban growth became markedly more rapid about I9I6, due primarily to the war-time industrial expansion. Hence the decline in the absolute number of rural physicians has been much more marked since I9I6 than in the preceding decade.

The absolute reduction since 1906 in the number of physicians in places of less than I,000 inhabitants has 
been about 6,000 -from 33,000 to $27,000,{ }^{1}$ or about I8 per cent. Approximately two-thirds of this reduction, it is estimated, has been registered since IgI6.

This reduction represents the net effect of literally tens of thousands of individual changes. During the years 1906 to 1923 there have been, it is estimated, between seven and eight thousand deaths of rural physicians located in places of less than r,000 inhabitants, and perhaps twice as many removals to larger places. On the other hand, there has been a limited number of removals to these places of less than 1,000 inhabitants by men formerly located in larger places, and the initial location in them of new graduates to the number of perhaps I 5,000 . So that all in all, no less than perhaps 40,000 individual changes have entered into the net reduction mentioned.

Manifestly, even were complete records available, the extraction, transcription, arrangement and compilation of the facts regarding each of these tens of thousands of changes $^{2}$ would have entailed a labor wholly disproportionate to the result. What has been done, however, is the development of this information for substantially all such changes in a few selected states ${ }^{3}$; and the develop-

1These figures do not include New England. Moreover, they are approximate only, as no attempt has been made to determine the correction which should be made by reason of those places which had less than 1,000 inhabitants in 1910 and more than that number in 1920 .

2In addition there are thousands of removals from one village of less than 1,000 inhabitants to another to be recorded.

sThe method employed for each state has been the comparison, name by name, of a list of physicians in places of less than 1,000 inhabitants at a given date (compiled from the American Medical Directory) with a list of those in the state at a later date, and the ascertainment of the location at a later date, of all physicians not found at that date in the same place as at the earlier date, or vice versa. It will be noted that under this method physicians who, as not infrequently happened, removed two or more times during the interval would be recorded as removing only once-from the first to the last location. 
ment of data for other states which makes feasible a fairly accurate estimate of the number and character of the changes in those states as well. ${ }^{1}$ On the basis of data of these two types it becomes possible to determine with a sufficient degree of accuracy the relative importance in the reduction of the rural profession since I 906 and of the several types of individual changes mentioned.

The migration of rural physicians to town on a large scale appears to have set in somewhat before I9Io, but has proceeded at a substantially increased rate since I916, and has been slightly slowed up since I92r. The physicians who have migrated from the villages in such large numbers have represented all ages; indeed it is somewhat surprising to note the number of men who have thus migrated when past fifty. As was to be expected, however, the bulk of the migrants have been men who had been in practice, at the time of their removal, for less than twenty years, and even among them the tendency to migrate grows progressively stronger as one approaches the more recent graduates.

During the decade rgo6-19r6, the losses to the rural profession through deaths were about twice as great as the losses through migration; since I9I6, the increased rate of migration has resulted in losses equal to those caused by death.

The migration of physicians from places of more than I,, 00 inhabitants to places of less than that number has been too limited in extent to warrant separate consideration; but the fact that there has been found any movement at all in this direction is significant on account of

'Tables embodying these figures and estimates are given in the Appendix, pp. 190-192. 
the light it throws on the existence of professional overcrowding in the larger towns.

In view of the decline in absolute numbers of the physicians in places of less than $\mathrm{I}, 000$ inhabitants already described, it is needless to say that the number of new graduates settling in these places during this period has fallen far short of making good their losses by death and migration. In the decade 1906-I6 the number of deaths and removals was, it is estimated, about 9,000, and the number of graduates of those years settling in these same places was perhaps about 8,000 , of whom perhaps 1,000 again removed to larger places before the end of the period; so that, of the approximately 22,000 graduates of the decade, there were found in 19I6 in places of less than I,000 inhabitants about 7,000-a proportion substantially equal to the proportion of all physicians found in those places.

From I9I6 to 1923 the number of deaths in and removals from places of less than 1,000 inhabitants has approximated 5,500, and the number of $1916-20^{1} \mathrm{grad}-$ uates locating in those places has been perhaps $I, 600$, of whom I,425 were found there in I923. These graduates form only II.4 per cent. of the total number of graduates of this five-year period, while of the physicians graduated before I9I6 no less than 20.8 per cent. are located in these places.

\footnotetext{
1The graduates of 1921 and 1922 are omitted from consideration because with few exceptions they were not yet in private practice on their own account at the beginning of 1923, the date of the publication of the American Medical Directory for 1923 (the individual entries in which form the source of the data herein set forth). It was not deemed necessary to make a similar omission of the $191_{4}$ and 1915 graduates in the figures for the period 1906-15 because during that period, and particularly the first half thereof, the now virtually universal custom of serving an interneship of from one to two years or its equivalent before entering independent practice was by no means invariably followed, especially by those entering rural practice.
} 
However, even had the proportion of 1916-20 graduates located in those places been as great as was the proportion of physicians graduated before igr6 so located, the number of 1916-20 graduates so located would still have fallen nearly 3,000 short of making good the losses by death and removal since r9r6. The failure of the graduates of the years since igr 6 to make good, to any important extent, the losses which the rural profession has suffered by death and migration during those years is thus found to be due chiefly to the very small total number of such graduates, rather than to their relative avoidance of village locations. ${ }^{1}$

A recognition of this fact is of importance because of the oft-expressed view that it is the failure of the recent graduate to locate in the smaller villages in sufficient numbers that is the prime cause of the decline in rural practitioners. Indeed, seemingly implicit in some discussions is the notion that every village location made vacant by removal or death of an older practitioner ought promptly to be filled by a recent graduate. The unreasonableness of this standard becomes plain upon an examination of the facts. The graduates of the years I9I6-20 were barely more than sufficient in number to make good the losses of the profession through death, and hence were insufficient to make good the losses of the rural profession from both migration and death (unless, indeed, they correspondingly failed to fill the vacancies caused by death in the towns and cities) even had the

\footnotetext{
IIt is to be noted that in the southern section of the country the total number of new graduates graduated and locating in the section since rgr 6 has fallen off much more sharply than in the rest of the country. Inasmuch as the proportion of rural physicians $\mathrm{n}$ the South is greater than in the North this falling off has had a disproportionately heavy effect on the number of rural physicians in the country as a whole.
} 
rural and urban populations remained stationary or had both increased at the same rate. Under the conditions actually obtaining - a rapid increase in the urban population against a minor increase, or even a decrease, in the rural population-it was manifestly unreasonable to expect that even all the rural vacancies caused by death would be filled. Thus while it is quite true that the graduates of $1916-20$ are found in the villages of less than 1,000 inhabitants in little more than half as great numbers, relatively, as are the physicians graduated prior to that time, it is also true that even had these graduates located in the rural areas in abundant proportion there would still persist an absolute decline in the number of rural practitioners.

It is somewhat difficult to attempt a measurement of the effect which the decline in recent years in the number of graduates has had on the number of rural physicians; for there exists no theoretical standard of output against which the actual output of medical graduates may be measured. It may be illuminating, however, to compare the actual figures with those which would have resulted had the number of graduates in the period 1916-20 maintained the same proportion to population as did the graduates of the period I906-10, the last five-year period in which the number of graduates may be said to have been unaffected by the new requirements in medical education. ${ }^{1}$

The graduates of these two periods have numbered roughly 24,000 for I906-IO and 15,000 for I9I6-20,

1Substantial beginnings in the direction of increasing entrance requirements were indeed made during this period, particularly the latter part thereof, but they were virtually without influence on the number of graduates of this period, all of whom had matriculated by 1907 . 
giving a population per graduate of 3,665 and 6,818 respectively. Had the ratio in $1916-20$ been equal to that of 1906-ro, the number of graduates of I916-20 would have been greater by 85 per cent. Assuming that the proportion of these additional graduates who would have located in the villages of less than $\mathrm{r}, 000$ inhabitants would have been the same as the proportion which did actually so locate, the number of physicians in these villages would have been increased by some 4.5 per cent.; or looking at it slightly differently, the loss in physicians which under these assumptions the villages of less than I,000 inhabitants may be said to have incurred by reason of the falling off in medical graduates is slightly over 4 per cent.

To measure the extent to which the reduction in the number of rural physicians has been due to the smallness of the proportion in which even the small number of recent graduates have located in the rural areas is more difficult. For there exists no theoretical standard for determining the proportion of such graduates who might reasonably have been expected to locate there, against which the proportion actually so locating might be measured. For the sake of convenience, however, there may be taken as a standard the proportion of all other physicians located in these places. ${ }^{1}$

As already indicated, the proportion of $1916-20$ graduates found in 1923 in places of less than 1,000 inhabitants is only slightly more than half the proportion of earlier graduates so located. Had the proportion been the same, there would have been located in these

\footnotetext{
1That this standard is one of convenience only and has no inherent validity is pointed out in a subsequent chapter. See p. 146.
} 
places approximately 2,600 I9I6-20 graduates instead of the 1,425 actually so located. ${ }^{1}$ The difference again represents slightly more than 4 per cent. of the total number of rural physicians.

Combining both these assumptions, it appears that had there been proportionately as many graduates in 1916-20 as in 1906-10, and had these graduates located in the villages of less than $I, 000$ inhabitants in as great a proportion as did the graduates of earlier years, the total number of physicians in these villages would, in 1923 , have been greater by approximately 12.5 per cent. This figure may thus be regarded as representing the maximum quantitative influence of the graduates of 191620 upon the decline in the number of rural physicians since I9I6.

It need hardly be said that these figures are offered solely for the purpose of making possible an appraisal of the quantitative importance of the recent graduates in the current situation. Of themselves they furnish no basis whatever for an opinion as to whether the recent output of physicians has been too small, or whether the relative disfavor with which recent graduates have regarded the smaller locations bears any relation to their smaller numbers or to the character of latter-day medical education.

PROSPECTIVE NUMBER OF RURAL PHYSICIANS

The number of medical graduates during the current five-year period (I92I-25) will total approximately I 5,600 , an increase of about I,300 over the output dur- 
ing 1916-20. For the period 1926-30, while the estimate must necessarily be subject to error (as this is written the graduating classes of 1928 , I929, and 1930 have not yet matriculated), the number will probably be about 20,000 . During these periods we may therefore expect net increases in the profession of about 3,500 and 6,000 respectively (as compared with 2,600 during I9I6-20). The increase in the first half of the decade will thus fall considerably below the probable increase of population during the same period; during the second half it will doubtless be almost proportionate. As before, however, the rate of increase will fall considerably short of the rate of increase of the urban population, with the resultant difficulty in maintaining the existing ratio of physicians to population in the cities; so that this force tending to draw physicians from the rural areas will persist.

The extent of the migration of physicians during this period from village to town cannot be safely estimated. In $1921-23$, the unprecedented rate of migration established in 1916-20 seems to have fallen off somewhat, but whether this was merely fortuitous, or whether it indicates that a more stable relation between town and country has been reached it is impossible to say.

The rate of loss to the rural profession through death in this period will probably be beyond that of any previous decade. Indeed, as the last decade was one of depletion through migration, the present decade will doubtless be one of depletion through death; and there is a direct causal relation between the two. It has already been pointed out that the heavy migration to town in the last decade or more was primarily among the men who had been in practice less than twenty years, and that, on the 
other hand, the accessions to the country profession from the ranks of the recent graduates has been relatively less than formerly and absolutely very much less. Both these factors combined have resulted in a rural profession in which the older-age groups-the men who have been in practice thirty years or more-form a much heavier proportion than formerly. It is still somewhat too soon to observe any marked effect of this condition on the death rate of the rural practitioners, but that such effect will manifest itself unmistakably in the present decade is certain.

It is by no means certain, however, that many of the rural locations thus made vacant through death will not fairly promptly be filled by newly graduated physicians or indeed by men already settled in the larger towns near by. The older rural practitioners who have resisted the lure of the town represent extremes. Some have clung to their precarious cross-roads locations only because they felt wholly unequal to the struggle with the younger and more up-to-date men in the towns; others, however, have remained in their village establishments who would scorn the suggestion that they are not fully the peers of the town physicians, or that they might fail of success in the urban field. These men, well established in the respect and affection of the countryside which they serve, and frequently in receipt of a relatively good income, are the cream of the rural profession; and their locations are in many instances strategic ones, the occupants of which are, even in the face of all the forces which sap the value of the village location, virtually assured of at least a moderate financial success. As these locations become vacant through death or retire- 
ment, they will not, if the experience of recent years is repeated, fail to attract new men.

Clearly, one cannot confidently predict the net effect of the varied factors which will thus determine the increase or decrease of the rural profession in the years immediately ahead; though the indications point to the persistence, but somewhat less sharply, of the decline, both absolute and relative, characteristic of recent years. Even this tendency, however, may quite conceivably be checked fairly completely by the development by rural communities through community action of means for attracting and retaining physicians in their midst-a possibility discussed at some length in a subsequent chapter. ${ }^{1}$

The numerical facts regarding the rural physician which have been reviewed in the present chapter of themselves throw little light on the problem of rural medical service. Much more essential is it to ascertain the number and distribution of the towns and villages in which the physicians serving the rural population are located, the conditions of transportation and communication under which they work, and the economic level of the population they serve-in short, to measure, so far as practicable, the physical and economic accessibility of the physician to the rural dweller.

'See p. 106. 


\section{CHAPTER III}

THE ACCESSIBILITY AND COST OF MEDICAL SERVICE IN RURAL AREAS

The basic factor in the physical accessibility of medical service in any area is the number and distribution of the cities, towns, or villages having a physician.

Throughout the period under review (and the same is true today with negligible exceptions) every self-contained town of as much as 1,000 inhabitants has had one or more physicians. ${ }^{1}$ It is only when we pass below the $\mathrm{r}, \infty 00$ limit, and usually well below, that we find towns or villages without physicians, ${ }^{2}$ and it is only in this class of towns or villages that we find instances of complete abandonment by the medical profession.

Among the places of less than 1,000 inhabitants, only a small portion are incorporated, so that it becomes a matter of extreme difficulty to determine how many such places there are. Indeed an accurate determination is

1The total number of incorporated places of 1,000 or more inhabitants (exclusive of New England) was, in 1920 , very nearly 5,400 , while the number of places of this size having physicians was somewhat over 5,600 , the small difference being accounted for by the relatively small number of places which, though having over 1,000 inhabitants, were not incorporated.

${ }^{2} \mathrm{~A}$ few exceptions to this statement bave come to notice but they are to be explained in every case by special circumstances. Some of the exceptions are, moreover, more apparent than real, a population of over 1,000 claimed for a town without a physician being found upon investigation to be obtainable only by including large areas of countryside. In the absence of corporate limits, with corresponding census figures, the tendency of the local sources of information to furnish exaggerated estimates of population seems to be well nigh universal. On the average, each place of 1,000 to 2,500 inhabitants had, in 1923 , slightly more than 4 physicians. See, in the Appendix, p. 166 and p. 183. 
quite impossible; for at the lower end of the scale there are innumerable cross-roads which, while clearly distinguishable from the open country, possess so few structures as hardly to merit even the designation of hamlet. Some notion of the number of such villages is, however, given by the number of fourth-class ${ }^{1}$ postoffices, although the development of rural free delivery has in recent years deprived a number of villages of their post-offices. The number of such post-offices was in I923 about 50,000.

\section{NUMBER OF PLACES HAVING PHYSICIANS}

As against this figure, the total number of places of less than $\mathrm{I}, 000$ inhabitants which had one or more phycians was in 1906 over 25,000. By 1923 the number had declined to less than 22,000 , a decline of about 13 per cent. $^{2}$

The decline in the number of towns and villages having physicians has been experienced in all parts of the country east of the Rockies (west of the mountains the opening of new territory to settlement has resulted in a substantial increase in the number of towns having physicians); but it has displayed wide variations in

${ }^{1} \mathrm{~A}$ fourth-class post-office is one having annual stamp sales of less than $\$ 1,800$.

2It is probable that the reduction is slightly less than this figure indicates. In some cases the disappearance of a given village from the list of places having a physician is actually due not to the removal of the physician from it, but to the discontinuance of the village post-office and the inclusion of the village in a rural free delivery route emanating from some adjacent town or village, causing the physician to be listed with the physicians of that town or village though actually located perhaps as much as ten miles away. However, the careful endeavor made by the American Medical Directory in such cases to ascertain the precise location of the physician, and to list him under that location rathe: than under his post-office, has reduced the error from this source to the minimum. Moreover, there is an offset in the 350 towns and villages in the mountain and Pacific divisions, now having physicians, but which had none in 1906 . These are located for the most part in territory which in 1906 had not yet been opened to settlement. 
degree. In the section from which perhaps as much as from any other has come complaint of a dearth of rural practitioners, the south Atlantic section (embracing the seaboard states from Virginia to Florida), the decline has been least marked, totalling only 5.4 per cent., reflecting on the one hand no doubt the greater relative scarcity of physicians which has always characterized that section, and on the other hand the limited progress which has been made over most of this section in road improvement and the like. The greatest decline, 24.I per cent., is recorded in the east south central section, comprising, Kentucky, Tennessee, Mississippi and Alabama, and almost as great a decline, 2 r.6 per cent., in the east north central section comprising Ohio, Indiana, Illinois, Michigan and Wisconsin. It is notable that Kentucky and Tennessee in the east south central section, and Ohio, Indiana and Illinois in the east north central section, were the favorite homes of the medical diploma mills of the last generation (being outranked in this respect indeed only by Missouri) and enjoyed in consequence during that period the services of a disproportionately large number of physicians; while the extensive industrialization of the northern section during the past two decades, as well as its extensive motorization, undoubtedly furnish additional reasons for the sharpness of the reduction in the number of towns and villages in that section having physicians.

Aside from the south Atlantic section, already referred to, New England exhibits the smallest reduction during this period in the number of towns and villages having physicians, a reduction of 8.I per cent. The middle Atlantic section, comprising New York, New Jersey, 
Pennsylvania, Delaware and Maryland, is next with Ir.8 per cent., while the states between the Mississippi and the Rockies show a decline of 13.8 per cent., both the northern and southern groups in this region showing substantially the same rate of decline.

\section{DISTANCE BETWEEN PHYSICIANS}

In looking into the basic matter of the distance between physicians, it is useful to gain in advance a notion of the area required in the several sections to support a physician in an agricultural region of normal density of settlement. Such normal density varies materially from section to section, depending chiefly perhaps on the crop grown and its requirements of man power per acre. For the northern states east of the Mississippi, however (and for Missouri, Iowa and southern Minnesota), a density of 18 per square mile may be accepted as fairly characteristic; for the southern states, 25 per square mile; for the southwest, I5 per square mile; and for the grain states, Io per square mile. ${ }^{1}$ For the Mountain and Coast states it is difficult to establish a single figure, because of the irregularity of distribution of the settlement, and the diversity of the types of agricultural enterprises found in the rural communities.

Assuming, as a working basis, that ordinarily it will require as much as fifteen hundred rural dwellers to support a single physician, and employing the density figures just given, it appears that it will require some 80 square miles of rural area to support a physician in the north; 60 square miles in the south; I00 square miles in

\footnotetext{
1The figures given are derived by comparing the farm population with the acreage in farms given in the Fourteenth Census, vol. V. p. 34 .
} 
the southwest; and r5o square miles in the west. Assuming these areas in each case to be in the form of a circle, its center at the town in which the physician has his office, they correspond to a radius of from approximately 4.5 to 6.5 miles, distances by no means impracticable for the physician. Thus it would seem that given a reasonably uniform distribution of the rural population so that some approximation to the standard used is realized, a rural population of $\mathrm{I}, 500$, in any of the settled agricultural areas, should be able to have a physician within a readily practicable distance.

Even in 1906, there existed the widest variations, not merely as between the several sections of the country, but even as between areas fairly near to one another, with respect to the distances between physicians, depending of course upon the varying density and prosperity of the rural population, and the distribution of towns and villages suitable for serving as the location for a physician. Despite these great variations, however, it has been thought of value to determine, for the several sections, the average distance between physicians. It is found that in 1906, for the country as a whole, there was on the average for each town or village having a physician an area of approximately ir 6 square miles, corresponding to a practice radius of 6 miles, and indicating an average distance of $\mathrm{r} 2$ miles between physicians. For 1923, the average area per town or village is I34 square miles corresponding to a practice radius of 6.5 miles, and indicating an average distance of 13 miles between physicians.

The variations from section to section in the average distance between physicians is perhaps smaller than 
would be expected. ${ }^{1}$ For New England and the middle Atlantic states the average distance is approximately 7 miles, for the south Atlantic states about ro miles, for the states between the Appalachians and the Mississippi (both northern and southern sections) about 9 miles, and for the states between Mississippi and the Rockies (both northern and southern sections) about 13.5 miles. It is only when we reach the Mountain and Pacific states that we encounter an extreme variation-the average distances in these sections being about 33 and 20 miles respectively.

The increase in average distance which has been registered in all states east of the Rockies since 1906 has been fairly uniform over the whole area. The greatest increase has been in the east south central states-an increase of about I. 2 miles. The smallest increase has been in the south Atlantic states-an increase of almost exactly a quarter-mile.

While the figures of average distance for 1906 and 1923 are each of them of some significance, it would be manifestly fallacious to attach any significance to a comparison between the average distance in 1906 and in I923, or to the fact that the increase in distance during this period was relatively negligible. The increase is obviously the result not of a redistribution of places having physicians (except to a negligible extent), but of the total abandonment by physicians of a proportion of places. For most communities the distance to a physician has not increased at all; for some (approximately one-sixth of the whole) it has increased enormously.

As a further index of the actual distances between

1For exact figures see Appendix, p. I84. 
physicians, there were prepared for selected states, or portions of states (Maine, western Massachusetts, New York, Indiana, North Carolina, Kentucky, Alabama, Missouri, Iowa and South Dakota) maps ${ }^{1}$ on which a circle of ten miles' radius was drawn around every place having a physician in $1923,{ }^{2}$ and the territory falling outside such circles was examined. It is, of course, obvious that a circle drawn on a map, wholly regardless of topographical features or of the existence of roads, ${ }^{3}$ may in a particular case bear only a remote relation to the area actually capable of being served from a given place; and that in the mountainous areas places only a mile apart as the crow flies may be twenty miles or more apart up hill and down dale. Nevertheless, these maps serve as a rough index of the proportion of rural territory and population remote from a physician.

It is found that using a radius of ten miles, a large part of the area in all the states studied (except South Dakota) falls within two or more circles; that (except in South Dakota) all but a negligible part falls within at least one circle; and that where any substantial area (as an area as much as ten miles in its longest dimension ${ }^{4}$ ) falls outside the circles it is invariably found either to be virtually

\footnotetext{
1For illustrative purposes, a portion of one of these maps is reproduced in the Appendix at p. 197 .

2According to the American Medical Directory for 1923.

'Where, however, the circle would cut across an unbridged stream of appreciable size, it was not continued beyond the near bank.

There is not included in this statement a type of area not uncommonly found on these maps, of great length but little width, resulting from the presence of parallel railrnad lines somewhat more than twenty miles apart. The physicians in such areas being usually located exclusively in the railroad towns, the ten-mile circles described around those towns leave a narrow scalloped strip on either side of the median line between the two railroads.
} 
unsettled forest, marsh or mountain, or, as in South Dakota, to represent an extreme of sparsity of agricultural settlement.

Thus in Massachusetts, Indiana and Iowa ${ }^{1}$ there is no area, and in Maine and New York no settled area ${ }^{2}$ more than ten miles on an air line from a physician; and indeed in New York, outside the Adirondack and Catskill areas, there are but eleven areas, averaging less than 75 square miles each, when the distance is more than five miles on an air line.

In North Carolina, the state which, with South Carolina, has for many years had relatively the smallest number of physicians, and which has, in relation to its area, a substantially smaller number of places having physicians than any other state of comparable population density, the only substantial areas which are more than ten miles from a physician on an air line ${ }^{3}$ are the virtually uninhabited swamp areas along the eastern shore, and the extensive sand bar which forms the actual shore of the

1For Iowa this statement is subject to an exception so trifling as hardly to merit mentioning - an area perhaps two miles by three on the boundary between Osceola and Dickinson counties (in the northwestern corner of the state). It is altogether possible, moreover, that there may be in Iowa, or in the other states mentioned, a few other such areas of equally trifling size which have despite extreme care escaped attention; but if so, they are so few and so negligible in extent as not to impair in any degree the correctness of the statements made.

2The area in Maine more than ten miles from a physician, falls into two sections-the northwestern lake section (in Aroostook, Piscataquis and Somerset counties) comprising ro,000 square miles, and in the southeastern lake section (in Washington and Hancock counties) comprising 2,480 square miles. The area in New York more than ten miles from a physician also falls into three sections, the Catskill section (in Ulster and Sullivan counties) comprising 63 square miles, the Adirondack section (in Hamilton, Herkimer, Essex, St. Lawrence and Franklin counties) comprising r,8r8 square miles, and a small barren area in the center of Lewis county which, while not in the Adirondacks, is included in the total for the Adirondack section.

3There are in all sixteen such areas having a total area of about $\mathrm{r}, 600$ square miles, about $\mathrm{r}, \mathrm{r} \infty \mathrm{O}$ of which is contained in five swamp areas. The remaining areas (averaging about 25 square miles each) are none of them more than 5 miles wide. 
state. ${ }^{1}$ In the western mountains of the state there are no substantial areas, and indeed hardly any areas, more than so miles from a physician on an air line, but measured in actual road distance there are many places twenty and even thirty miles distant. In general, however, these places are inhabited, if at all, only by very few families, who live lives cut off not alone from medical service, but from all the ordinary services and facilities of American rural life.

Such being the situation in North Carolina with its relatively few physicians, it is not surprising that Kentucky, mother of doctors, and long possessed of a higher relative number of physicians than any other state except California, should equally fail to disclose any substantial areas of normal density of settlement more than ten miles from a physician. There are only five areas in the state outside the ten-mile circles, with a total area of some 350 square miles. All of them are in "the mountains" (the eastern quarter of the state) and all of them are areas with little or no population. Over the rest of the state (not excluding the unprosperous "knob" region in the central part of the state), even the areas more than five miles from a physician on an air line form substantially less than half.

In Alabama and Missouri the showing with regard to areas more than ten miles from a physician is much the same, though in both states these areas are more numerous and extensive than in Kentucky. Without going into details, however, it may be said that in both these states these areas constitute approximately only r.4 per

IFor discussion of the situation on these coastal sand bars, see p. 100, footnote. 
cent. of the total area of the state. ${ }^{1}$ An estimate of their population is difficult, but since they are, needless to say, less densely populated than even the average rural area in these states, it may readily be seen that their population is, by comparison with that of the whole state, quite negligible.

When we leave Iowa and Missouri, and come to South Dakota, we encounter for the first time the extremely low density of agricultural settlement which prevails over all the states west of the Dakotas and to some extent over the states directly to the south, a vast area the rough outlines of which can be readily discerned on the map by the simplicity of its railroad picture-the entire absence of the network of branch and connecting lines which characterizes even the least prosperous agricultural areas of the rest of the country. Eliminating the vast Indian reservations, ${ }^{2}$ and the almost uninhabited counties of the northwestern part of the state, ${ }^{3}$ the density of the rural population of South Dakota is about 8.5 per square mile. So low a density requires an area of not less than 125 square miles to support a physician; so that

\footnotetext{
1The number of such areas is 18 in Alabama and 17 in Missouri, and the total areas are estimated to be 697 and 977 square miles respectively. In Alabama almost all these areas are found either in the "cereal belt" or in the "black belt." In Missouri, while the smaller areas are scattered fairly generally over the state, the two distinctly large areas are found, not, as might be expected, in the Ozarks, but in the southeastern section of the state-one astride the boundary between Crawford and Washington counties, the other astride the boundary between Dent and Shannon counties.

2The Cheyenne River reservation, occupying parts of Dewey and Ziebach counties, the Pine Ridge reservation, occupying Washington and Washabaugh counties, and the Rosebud reservation occupying Todd county. There are also two smaller reservations not eliminated in the computations-the Coon Creek and Lower Brule reservations.

3Butte, Carson, Harding, Meade, and Perkins counties. The sout hern portion of Meade county bordering on Lawrence and Pennington counties, in which is located a portion of the Black Hills mining region, is well populated, but for the sake of simplicity the entire county has been eliminated from the computations.
} 
even were the rural population distributed over the state with substantial uniformity, the physicians serving them would not be much less than thirteen miles apart. Inasmuch as the rural population is in fact far from uniformly distributed, it is not surprising to find that in not a few places the physicians are more than twenty miles apart and there are accordingly areas outside the ten-mile circles. East of a line drawn north and south through Aberdeen, such areas are few and of negligible extent; ${ }^{1}$ between Aberdeen and Pierre they are extensive, aggregating nearly 6,000 square miles, or nearly one-third of the whole; while west of Pierre, excluding the reservations and the nearly uninhabited counties already referred to, substantially the same figures apply. A fair estimate of the population located in these areas would perhaps be I2,500 between the Aberdeen and Pierre meridians, and perhaps 7,500 west of the Pierre meridian.

If a radius of fifteen miles is substituted for the tenmile radius, east of Pierre the areas outside the circles in many cases disappear and the total of the areas remaining outside the circle is relatively small. West of Pierre, the areas outside the ten-mile circles while few in number are individually so extensive that the enlargement of the radius to fifteen miles would make little change in the figures of the area, though doubtless making a much greater change in the figure of population, were such available.

Because of the extreme irregularity of settlement in the Mountain and Coast states, no detailed examination has been made of any of them to ascertain the nature of the areas more than ten miles from a physician, but it is

1Except for the northeastern lake country in Marshall, Roberts and Grant counties. 
believed that the facts already presented adequately reflect conditions in the various types of areas and communities in these states, all of which have relatively an abundant number of physicians.

Despite the qualifications to which the showings made by these maps are subject, they seem to contradict rather conclusively the belief that has come to be fairly widely held that there are extensive areas of settled countryside many miles distant from a physician.

But physical accessibility depends not merely on distance, but on topography, road connections, road conditions and telephone service-factors which it is obviously impossible to present in statistical form; and physical accessibility is not the only factor to be taken into account. Equally important but equally impossible of statistical treatment are the cost of obtaining the physician's service, and the willingness of the physician to render service where pay is uncertain or deferred, or where considerable personal inconvenience is entailed.

Nor is it practicable to establish any standard of reasonable availability of medical service in rural areas by which conditions in any given area may be measured. ${ }^{1}$

Hence the impracticability of any categorical statement of the degree to which, under the present distribution of physicians, medical service is available to the rural

\footnotetext{
In some discussions the mere disparity between town and country in the relative number of physicians has of itself been regarded as warranting the conclusion that the medical service in a given rural area is unduly difficult to obtain. As already seen, however, the rural areas have at all times and in all parts of the country had relatively far fewer physicians than the cities; and this disparity has been and is due primarily to an excess of physicians in the cities, rather than to a deficiency in the country. In any event, a standard of reasonableness which can be satisfied only by a condition which Lis never existed is devoid of practical value for the present purpose.
} 
dweller. The best that can be offered is a review of the factors which affect that availability and the changes in those factors in recent years.

IMPORTANCE OF SEASONAL VARIATION IN ROAD CONDITIONS

It is essential to appreciate at the outset that in rural practice the demand for medical service and the amount of service a physician can render are subject to extremely wide variations, principally seasonal in character. Even in the cities, the substantial increase in the need and demand for physicians' services during the late fall and winter, due to the increase of illness during those months, is a well-recognized phenomenon; but in the rural areas, except in that small proportion of rural areas which have well-surfaced roads, this seasonal increase of illness is coincident with a deterioration of the roads which cuts down the ability of the local physician to visit the sick, sometimes almost to the vanishing point. If statements made to us by physicians are to be relied upon, the difference may, in extreme cases, reach a point where eight men would be required in the bad-roads season to cover a territory readily handled in the good-roads season by a single physician.

Hence it is that, except in the relatively small proportion of rural territory in which road improvement and maintenance have progressed so far as to eliminate seasonal variations, the question of the relation of the supply of medical service to need has, in the rural areas, two distinct phases, relating to the good-roads and bad-roads seasons respectively. Herein lies the reason for much conflicting testimony on the subject of the influence which roads have on the availability of medical service in the 
country. Some there are who make comparisons between former days and the present on the basis of experiences in good-roads periods. These naturally emphasize the greater range made possible by improved transportation. Others, practising in the same general type of country, may have been more particularly impressed with the hardship of some experience in the mud or snow, and these dilate on the difficulties encountered.

This disparity between conditions in good- and badroads seasons must be kept in mind in appraising the importance of a factor which is frequently cited as substantially ameliorating the reduction in the number of physicians in the all-rural areas-the reduction in the incidence of such illnesses as typhoid, malaria, diphtheria and diseases incident to food-poisoning. None of these diseases is peculiar to the bad-roads season; indeed, with the exception of diphtheria, they tend to coincide in their prevalence with the good-roads months. Hence it is that the effect of the reduction in these diseases in ameliorating the loss of physicians in the rural areas has not been so great as might be expected.

There are wide differences in regard to seasonal variation in the condition of unsurfaced roads, not only between the several climatic zones, but even within a fairly limited area, due to varying underlying soil conditions; so that no general statement is possible. Nor have there been collected any accurate data which would make possible a classification of the mileages of unsurfaced roads with respect to the degree of their passability for motor travel during the bad-roads season and the usual 
length of that season. The best that can be offered is that there exist numerous rural areas, particularly in the more backward sections of the South, and in the heavy snowfall zones of the northern states, ${ }^{1}$ in which for from two to four months automobile travel is so difficult that it must be wholly abandoned in favor of horse-drawn vehicles or horseback; and that there exist numerous other areas in which, during the corresponding season, the speed of the automobile must be so reduced as to lose the major part of its superiority to horse-drawn vehicles.

It is worth mentioning, too, in this connection, that variations in condition of unsurfaced roads are by no means entirely seasonal. There are many types of unsurfaced roads which, even during the summer, will be rendered virtually impassable for hours or even a day or two by a severe rainstorm.

One frequently hears the. delay and inconvenience experienced to-day in certain rural communities in obtaining the services of a physician, particularly in the bad-roads season, emphasized as if it were a hardship of recent development. In point of fact, as is well known, such difficulty and delay have always been common in the rural areas. Nor are instances of people dying in rural homes because no physician could be got to the house in time by any means a novelty in American history. The extreme contrasts encountered, in the typical rural area, between good-roads and bad-roads seasons, and the ex-

\footnotetext{
${ }^{1}$ Snow blocking affects the surfaced roads as well as the unsurfaced. So far as surfaced roads go, however, and to a considerable extent even for the unsurfacad roads, this is a condition which can be overcome by proper organization for clearing the roads. To date comparatively little progress has been made in this direction in most of the rural areas, but the movement to clear snow-blocked rural roads is rapidly gaining strength.
} 
treme and sudden enlargement of the immediate need for the physician's services, which is created by even a few simultaneous cases of accident, childbirth or acute infection, are conditions which in the nature of the case have always created temporary shortages in the supply of medical service.

The statements and opinions gathered indicate that even in 1906, and presumably for an indefinite period before, the number of physicians available for home calls in a given rural area was usually insufficient to meet the demands of emergencies in the bad-roads season. Exceptions were to be found in certain areas where the medical profession was overcrowded, and in particular instances where the uncommonly large number of physicians in a given area was to be explained by their being engaged in "side-lines"; but in general the statement will hold. The rural areas were dependent upon the smaller villages, which did not themselves have enough physicians to meet with reasonable promptness the needs for home visitation during the bad-roads season. The number of the physicians at any given village location was, in the large, about the number that could make a living there; and a physician who depended on his profession obviously could make a living in a rural location only if he was moderately busy during the good-roads season, which usually comprises at least two-thirds of the year.

Has the effect of the reduction in the number of village physicians ${ }^{1}$ and in the number of villages having physicians been compensated, or more than compensated, by

IIt should be pointed out that the reduction in the absolute number of country physicians has been compensated in a measure by the fact that a far smaller proportion of the rural physicians of to-day engage in farming and other side-lines than formerly. 
the development of the automobile, hard roads and the rural telephone? An answer to this question can be made only in the light of a fairly definite knowledge of the actual distribution of these improvements in the rural areas.

\section{ROADS, AUTOMOBILES AND TELEPHONES}

As far as visitation by the physician is concerned, the use of the automobile may now be regarded as virtually universal during the good-roads season, though numerous instances have come to our attention, particularly in the mountains of the South, in which the road conditions are such that the automobile cannot be used to advantage at any time and the practitioner still relies on the horse and buggy or, in extreme cases, horse and spring wagon, or even the saddle horse. ${ }^{1}$ So far as the visit of the patient to the physician's office is concerned, the use of the automobile is by no means so common. In I920 only a little over 30 per cent. of the farms of the United States had automobiles; even in the west north central section (comprising the states of Minnesota, Iowa, Missouri, the Dakotas, Nebraska and Kansas) the percentage was less than 60, while in the Southern states the percentage in no case ran over 16 and in some states was as low as 6 . Even making due allowance for the use by farmers of their neighbors' cars, it seems clear that there is a substantial proportion of rural families, especially in the South, to which no automobile is yet readily available for the transportation of the patient to the physician's office.

Unfortunately there are not available any recent ac-

\footnotetext{
II is possible that the rural areas of the South in which the physician still uses horse transportation exclusively number as many as two hundred.
} 
curate data regarding the extent of road improvement and its progress in late years, the last nation-wide survey of this field having been conducted by the Office of Public Roads in I9I4. Estimates made by that bureau indicate, however, that at the present time, of the approximately 2,500,000 miles of public roads in the United States, only about 300,000 are surfaced, and of these surfaced roads approximately one-half are surfaced only with sand, clay, gravel or water-bound macadam. While no statistical data on the point are available, it is a matter of common knowledge that surfaced roads are found principally in the neighborhood of the large towns or on through trails; so that if regard be had solely to strictly rural roads, the proportion of surfaced mileage would undoubtedly be very much lower. In addition there are here, as in the matter of automobiles, wide variations from one section of the country to another, so that in those sections which have made the least progress in road improvement the proportion of surfaced rural roads approaches very near the vanishing point.

The distribution of the rural telephone is even more irregular than that of automobiles. The proportion of all farms reporting telephones in 1920 was somewhat greater than the proportion reporting automobiles, reaching nearly 40 per cent. In Iowa, the leading state in this respect, no less than 86 per cent. of the farms reported telephones and in the North, as a whole, particularly in the Northwest, the percentage of farms having telephones is in most states over 50 per cent., and in a number of states over 60 per cent. In the South, however, the proportion is very much lower, the chief explanation being apparently the much greater prevalence of short-term 
tenancy, resulting in lack of incentive to organize local telephone companies. The percentage is lowest in the South Atlantic states, where it runs from 18 per cent. in Virginia to less than 6 per cent. in South Carolina. In Alabama, Mississippi and Louisiana, the ratio varies from 15 per cent. in the first named to 6 per cent. in the last. In Tennessee, Kentucky and Arkansas the ratio is about 25 per cent.

In the light of these facts it is clear that in the factors which tend to compensate for the reduced number of and increased distance from physicians, no less than in the actual incidence of such reduction in numbers and increase in distance, there are extreme variations, and that any attempt to embrace all these diversities in a single statement must be futile.

Plainly, for those portions of the rural population which look for medical service to the same towns as formerly, medical service during the good-roads season is much more readily obtained than formerly; even where the number of physicians located in the town has been reduced, the number that remains can usually accomplish far more with the help of automobile and telephone than the larger number could twenty years ago; physicians doing rural practice have estimated that the amount of work they can do has been multiplied as much as fourfold. ${ }^{1}$ Moreover, the residents of these areas, though still primarily dependent for medical service upon the same town or village as formerly, are able to go or send to more distant towns for service-towns which before

\footnotetext{
1Statements have frequently been made to us that owing partly to the reduction in disease, but chiefly to the automobile, two or three doctors in a town now take care of a territory which formerly required half a dozen or more; and that they have abundant leisure, where their predecessors worked incessantly.
} 
the day of the automobile were far beyond practicable distance. Particularly has this been the case where, by chance, several accidents or severe illnesses, coming simultaneously, or mayhap even a local epidemic, have overtaxed the local physician. In great numbers of cases of this kind, a rural patient, who in former years might have died for lack of timely attention, has been saved by a physician summoned from a distance.

In the bad-roads season, if, as happens in some areas, the roads are in such poor condition that an automobile can make little better progress than can a horse-drawn vehicle, an area of this character is still in most cases better off than formerly by reason of the telephone, which may be said to have been virtually unknown in 1900 . Wherever it has attained a widespread distribution, certainly, the rural telephone may be regarded, aside from all other factors, as having more than neutralized for the rural population dependent on a given town any reduction in the number of physicians in that town. ${ }^{1}$

For the population resident in and round about the villages which formerly had a physician and now have none, the change has, of course, been greater, but what is not commonly recognized is that it has been far greater for the bad-roads season than for the good-roads season. In the good-roads season the greater distance which one must now travel to reach the doctor, or which the doctor must now travel to reach the area, is more than neutralized on the whole by the greater speed of travel; or, where

\footnotetext{
${ }^{1}$ Where the rural telephone is common, it has made possible in many instances a tremendous saving of time in getting the physician to the farm by enabling the farmer, on telephoning the physician's office and finding him to be out visiting patients in the farmer's general vicinity, to locate the doctor by telephoning around to the several farms on his proposed route.
} 
this is not the case (as it manifestly is not for those villagers and near-villagers who formerly had their physician close by and now must go from four to ten miles for him) there is the substantial compensation of being able to call upon, or call in, physicians in any one of several more or less distant towns. These compensations again are offset by the increased cost of a call by the doctor, owing to the increased distance he must come, but from the standpoint of mere physical accessibility these compensations do exist during the good-roads season.

In the bad-roads season, however, the villager or farmer in many cases now finds himself definitely worse off than he did twenty years ago. He must go farther or send farther for a doctor, and there are fewer doctors to go to or send for; yet transportation is but little better, in these cases, than it was then. ${ }^{1}$ Only the telephone ameliorates the increase of distance. In specific cases this may indeed more than compensate for the increased distance; but generally speaking, it is an amelioration merely, and in no sense a complete offset.

The rural area whose nearest town still has a physician, and the area whose nearest town once had but no longer has a physician, thus present fairly clear-cut situations. Between these two types of areas lie others which the shifting about of physicians, the abandonment of some nearby villages by physicians and the taking up of others, have affected in complex ways.

But physical accessibility is only one factor, albeit the primary factor, in determining the availability of medical

IIndeed in certain areas, when road conditions become exceptionally bad and horses must be resorted to, the situation is definitely worse than formerly owing to the relative scarcity of horses. 
service in rural areas. ${ }^{1}$ Equally important is the factor of cost, and the willingness of the physician to serve.

$\operatorname{cosT}$

The country dweller, schooled to self-reliance in every phase of his existence, is prone to call in medical assistance only when things look serious. ${ }^{2}$ So long as there seems a chance that the patient will pull through without help, he is likely to put off calling the doctor. But this is not merely a matter of habit of mind. There are compelling economic reasons behind it. At all times medical service has been relatively more expensive in the country than in the city,-not only relatively to the cash income of the farmer, ${ }^{3}$ - but, so far as concerns visits to the home, absolutely as well. The practice which obtains everywhere in the rural areas of charging a mileage fee for calls made beyond the town or village limits is an old one, and while the mileage charge has in recent years generally increased somewhat it has always been sufficiently high

IIt is worth mentioning that in several communications received from physicians familiar with the difficulties of motor travel in the winter and spring, particularly in the zone of heavy snowfall, the development of a light motor car working on the caterpillar principle or on some similar principle, is suggested as a possible solution for those difficulties. No reliable information is at hand as to the progress thus far made by the manufacturers who are said to be experimenting in this field. Should a reliable vehicle of this type actually be developed the problem of physical inaccessibility of physicians would be largely solved.

${ }^{2} \mathrm{~A}$ common complaint among doctors who do rural practice is that the patient's family will do nothing all day (even letting the doctor ride by the house several times during the day without calling him in) but will summon the doctor post haste as soon as he is comfortably settled in sleep. The doctor charges this variously to the farmer's unwillingness to interrupt his day's ploughing to go for the doctor or to his irritation at having his own sleep interfered with by the patient. Probably a truer explanation is that during the day the family hopes the patient will mend before nightfall; but when evening comes and with it the prospect of a night's siege, the thing begins to look more serious, panic impends, and the doctor is sent for.

3Thirty or forty years ago it was not uncommon for the country doctor to receive much of his payment in kind; but except in the most remote areas this practice has disappeared. 
to make a call at the outlying farmsteads an expensive one $^{1}$ even judged by urban standards of cost; judged by rural standards it has been so high that even for the relatively prosperous farm families visited with prolonged illness, the extension of long credit by the rural physician has been a matter not of convenience but of absolute necessity.

In respect to visits to the physician's office, the contrast in cost between town and country has been less striking. The office charges of the country practitioner have usually been lower than those of the city or town practitioner (though probably never as low as in the poorer quarters of the great cities ${ }^{2}$ ); but they have nevertheless been higher in comparison to the free cash income of the farmer and indeed of the villager.

For the whole rural population, as for the urban population, the cost of medical service has risen in the past twenty years. The increase of cost in the country has not been as great as in the cities and towns; and has not been out of proportion to the general increase in all living costs. Since the post-war agricultural deflation, however, the rural population in many areas has been relatively

1The lowest mileage charge now current encountered in our study was 50 cents per mile (including going and return); the highest was $\$ 1.50$. The most common charge is $\$ 1 . \infty$. The mileage charge is of course additional to the regular fee charged for a visit to the home in town. No case has come to attention where the mileage charge was ever within the present century less than 50 cents. It need hardly be said that the practitioner perforce is frequently compelled to make concessions from this scale.

2In the larger cities, there have been for many years mutual benefit societies which furnish medical attendance to members at trifling cost, as well as the so-called "medical association"- a cut-rate medical service organized by one or two physicians in the guise of a voluntary society, whose members, on payment of a small fee, become entitled to the services of those physicians at greatly reduced rates. Moreover, there is not commonly found in the average rural area any provision for the indigent, corresponding to the dispensary and the free or near-free hospital of the cities; so that for rural families on the border line of poverty only the charity of the physician ameliorates the burden of severe or prolonged illness. 
less able to meet the increases in cost of medical service, at least the heavy cost entailed by serious illness or accident, than has the town population. ${ }^{1}$

So much for the rural population as a whole. For that portion of the rural population whose nearest physician is now farther away than formerly, the added distance has been another factor in increasing the cost of calling a physician to the home; and in the case of the villagers who formerly had a physician in their midst, and must now send five, six, or even ten miles for one, the increase in cost has been relatively enormous. It is this great increase in cost experienced by the village population so located rather than any real decrease in accessibility that has been the prime cause for much of the complaint of lack of physicians that has come from rural dwellers.

The raising of the fee scale in many places from 50 cents per visit to as much as one dollar and a half and the change from no mileage charge to a charge varying from 50 cents to a dollar a mile, together with the increase in the average distance for which mileage must be paid, do not, however, tell the whole story. Perhaps equally important, in some sections of the country at least, has been the increasing insistence of physicians on prompt payment for their services, enforced by a refusal to give further service to those who do not pay. In the case of calls at the home, particularly of a call requiring a long drive into the country at a late hour, this may take the form of a refusal to make the call, unless immediate payment is promised. In part this tendency is chargeable to the greater economic pressure on the rural physician

\footnotetext{
${ }^{1}$ Thexcorresponding difficulty experienced by rural physicians in enforcing an increase in their fee scale, and the influence of this factor in accelerating their removal to town, have been noted in the preceding chapter.
} 
himself, already referred to, making it increasingly imperative that he receive payment for his time-consuming and expensive drives into the country; in part, it is to be explained by the greater independence of the physician, and particularly of the town physician, now that he is no longer restricted as formerly in his practice to a severely limited area and clientèle. Finally, some would hold that it may be due to an increase of the commercial outlook and motive in the medical profession, and to a decline of the missionary spirit which characterized the rural physician of old, and which carried him, without thought of material reward, over hill and dale, in fair weather and foul, to whosoever might need his ministration. But whatever its cause, there seems to be little doubt that the tendency to insist on prompter payment does obtain and that its effect is equivalent in many cases to a large increase in the cost of medical attendance.

Physicians doing rural practice usually assert that what has happened in this respect is merely the result of increased unwillingness on the part of the physician to be put upon by "dead-beats," who will under no circumstances pay the physician for his services unless compelled to, and that the really deserving have no more difficulty than formerly in securing attention. A reasonable conclusion seems to be that in the bad-roads season, when in many areas the rural physicians of today are probably less able than formerly to take care of all the cases needing attention, the rural charity or near-charity patient has greater difficulty than formerly in securing attention, and that in the good-roads season the situation is not much different from what it formerly was. 
Finally, for the rural dweller, as for the city dweller, there has been an increase in the cost of medical service due merely to the elaboration of medical procedures.

Just as medical service is on the whole relatively more expensive in the country than in the city, so as between one rural area and another it is relatively more expensive in the more sparsely settled areas, and it reaches the extreme of costliness for the people located on the most inaccessible farms, ordinarily, of course, the people least able to pay.

The extent to which the increased cost resulting from these several factors works a hardship on the rural population, and the degree of hardship entailed thus varies widely from one area to another. Its incidence, however, is general enough to warrant serious consideration of the possibility of distributing at least a substantial part of the cost of medical attendance in all rural areas over the community generally.

Corollary to the unwillingness of physicians to serve when the pay is uncertain is noted a growing disinclination to make visits to the home in bad weather or at unseasonable hours even where the pay is quite certain. It appears that this tendency is not confined to country practice; it is encountered in the towns and even in large cities. ${ }^{1}$

In the light of the several diverse factors which have

1"To judge from known conditions in Chicago, there is a lack of the old-fashioned, resourceful family physician in the larger cities. Many private practitioners, whose chief practice a few years ago consisted of domiciliary visitation, now refuse to give this real obligation to the public and compel their patients who are too ill to visit the office to go to the hospital." (Communication from Dr. Frank Billings in Jour. Am. Med. Assn., December ro, r921, vol. 77, p. rgro.) So also, an editorial in Southern Medicine and Surgery, September, 1922 (p. 48r): "Even in cities where the supply of doctors is greatest, there is the universal complaint that it is so hard to find any doctor who will answer house calls." 
been reviewed, each varying widely in its applicability from one section of the country to another, and from place to place even within a limited area, it must be apparent that no single comprehensive statement is possible as to the changes in the availability of medical service in the rural areas in the past twenty years. In some areas, through improved transportation and despite the increased cost and other unfavorable factors referred to, medical service is at all times much more readily available than formerly; in other areas it is so except during the bad-roads season; in still other areas it is somewhat less available than formerly, even in the good-roads season; and much less so in the bad-roads season. Nor can any approximation. be made of the relative importance, in point of numbers, of the populations or places falling in each of these classes. 


\section{CHAPTER IV}

\section{THE VACANT RURAL LOCATION}

It is impracticable to lay down any quantitative standard, whether expressed in terms of population, distance, or what not, by which it will be possible to determine automatically whether locations which have been left vacant by the death or removal of physicians are today in real need of physicians to take their places. The same is true in the case of communities, having at least one physician, which are said nevertheless to be inadequately supplied at present. Topography, road connections, road conditions and their seasonal variations, the incidence of disease, the medical habits of the population-these are the essential factors which combined determine the need in specific cases. Obviously, these factors, of varying weight in varying situations, cannot be ensnared in a formula. Even if they could be, the point at which the inconvenience or delay now involved in any given area in securing the services of a physician becomes good ground for declaring an additional physician, or one more accessibly located, to be required or warranted is and of necessity always must be wholly a matter of opinion, with a wide gap between the points fixed by a generous and a severe appraisal.

For these reasons it would be quite impracticable, even if one were certain it would be useful, to attempt an exhaustive examination of the rural areas of the United 
States, in order to determine which of them need additional physicians. For practical purposes it will be sufficient to examine those locations in which it has been alleged either by local residents or by health authorities, or by physicians in adjacent towns, that a physician, or an additional physician, is needed, and those areas which on inspection of a map showing existing locations of physicians, disclose an unusually large territory apparently without a resident physician. Such an examination has been made, with some care, in the states selected for detailed examination. The total number of places investigated was about two hundred.

For these the authors gathered all available data regarding the number, if any, of active physicians in the place under investigation-usually a small village, the number in adjacent towns, and the distribution of population, and obtained from physicians located in neighboring towns (towns sufficiently removed, however, to reduce or wholly eliminate the possible influence of self-interest ${ }^{1}$ ) and from physicians formerly located in the town itself opinions as to the need of the town for a physician, or for an additional physician, and its ability and willingness to support one. It is, of course, impracticable to reduce the results obtained to statistical or tabular form; but they are believed to afford a sound basis for a reliable estimate of the situation the country over.

\footnotetext{
${ }^{1}$ The natural tendency of the physicians practising in a given rural area to reje $t$ the suggestion that the area needs the services of additional physicians has, of course, been kept in mind throughout in appraising the opinions obtained from such physicians. In general, however, opinion has been sought chiefly from physicians located in the county seat or other larger towns, who do but little practice in the outlying areas, but are yet fairly well acquainted with them. The large number of cases in which physicians practising in rural areas have stated that the medical service in those areas is inadequate, has, however, seemed to reflect a very general endeavor to respond to our inquiries with candor and sincerity.
} 


\section{TYPES OF VACANT LOCATIONS}

So regarded, the locations in question seem to fall into several distinct classes, which may be conveniently grouped primarily according to whether they do or do not already have a physician.

Among the towns or villages which already have one or more physicians, and are said to be in need of an additional physician, two distinct cases present themselves. In the one case, the physician already located there is in active practice; the allegation is merely that there is too much for him to do. Of such a location it can only be said that there may be a wide margin between a condition where there is too much for one physician to do, and a condition where there is enough practice to support two physicians. Moreover, in the average case the country over, if a town is the natural center of a population large enough to require and to support two physicians, it will in a short time have them. Such a location, small as it may be, will still be so far superior in attractiveness to the scores of villages found in all sections, in which lone physicians are struggling to wrest a meagre living from the countryside, that it will not, in the natural outworking of the competitive process, long lack a second physician. Needless to say the same will be even more true of a town large enough to sustain three physicians.

In a number of towns, however, the lone physician is partially disabled by age or infirmity and does not give full service to the locality, particularly in the way of home visitation. In such a case, the full services of an active physician may undoubtedly be needed by the neighborhood, yet it is clear that the location does not offer un- 
equivocal attractions to a physician seeking a field for practice; for, if the semi-active physician already there has a strong hold on the affections of his patients, the newcomer may find himself with chiefly the more disagreeable and less lucrative portion of the neighborhood's practice. In the aggregate, the number of villages where such a situation exists is undoubtedly quite large, and the problem presented is a vexing one. Manifestly, however, a case of this sort hardly warrants one in asserting that there is need for an additional physician in the town.

It is when we pass to towns and villages which have no physician, and which are alleged to be in serious need of one, that the really important part of our problem is reached; and it will be worth while, before entering upon its consideration, to take note of one or two fallacies which are quite commonly encountered in discussions of cases of this class.

Most common and most fundamental is the patently fallacious assumption that the mere fact that a community formerly had a physician is proof that it needs one now. Indeed, it is surprising to note how frequently the attempt to demonstrate that a community is in need of a physician is confined to the mere citation of the fact that it formerly had one. The profession may in former years have been grievously overcrowded in the region in question, so that many of its members were compelled to rely on farming and other side lines for a livelihood, or the physician who formerly resided there may have left, as in many cases actually he did, because he was unable to make a living there; but these tacts, to say nothing of the possibility that filth-borne and other diseases may have greatly declined in the area, that the population it- 
self may have declined, and that in many cases the improvement in transportation and communication now makes the physician of neighboring communities possibly even more readily available to many of the people in the locality in question than the physician in their own locality was twenty years ago, are forgotten. Nor is the fallacy confined to a single location. Quite frequently a whole county, or group of counties, is cited as having lost a substantial proportion of its physicians, and that fact alone is regarded as establishing a serious shortage in medical service.

A more subtle fallacy is found in the attempt to demonstrate that a particular village needs a physician by the citation of specific instances, strong in their appeal to the sympathies, of extreme hardship endured by persons living in or near the village through inability to obtain medical attention promptly. With the population scattered as it is in the average rural community in this country, there must always be a proportion of rural dwellers who depend exclusively on a single village for their medical service, a village capable of supporting only a single physician or at most two. It is readily apparent that where a scattered population must depend upon the services of one physician, well able to take care of it under ordinary circumstances, contingencies will arise in which it will be impossible for all the people needing his service to obtain it promptly. Such a contingency will be most likely to arise either in times of epidemics or when the roads are in unusually poor condition or blocked, or when the physician himself becomes ill or disabled; but they may occur even under normal conditions in consequence of the mere coincidence of several emergencies 
occurring at widely separated points in the area habitually covered by the resident physician. . But one is not justified in concluding that the area should have an additional local physician, merely for the sake of protecting the community against the possibility of temporary hardship in such unusual circumstances.

Finally, it is important to recognize that with perhaps 5,000 villages in which there is but one physician, the deaths, removals and retirement from practice of the physicians located in these villages will in the normal course of events annually create some hundreds of vacancies which cannot in the nature of the case be filled as soon as they occur. Hence there is at any given time a heavy proportion of vacant rural locations which are probably vacant only temporarily. Much could be done, it is believed, to expedite the filling of these locations by the development of a nation-wide system for the registration of locations seeking physicians and physicians seeking locations. A beginning toward such a system has been made in several states; in none of them, perhaps, has the work been given that fulbmeasure of publicity, either among the profession, or among the rural communities, which is essential to its complete success. What is needed is a well-developed system of registration in each state, with a national clearing house for exchange of information between the several state bureaus. The state bureaus might beoperated by the state health department (as is now done in New York), or by the state board of medical examiners (as is done in California and North Carolina).

Impossible as it is to formulate a rigid standard by which the adequacy or inadequacy of the existing number 
and distribution of physicians in a rural area can be automatically determined, it will be worth while to attempt to fix a standard to the extent of ascertaining the number of people who in the average rural area would be likely to occupy the entire time of a physician under the prevailing habit of mind of the rural population with regard to the necessity for the services of a physician. It has already been pointed out that the rural dweller is much less given to calling in medical assistance than is the urban dweller, and indeed there are wide variations in this respect even among the rural populations of various parts of the country and at different economic levels; so that any figure which is suggested must necessarily be regarded as subject to a large percentage of error when applied to a given case. With these qualifications in mind it may, however, be stated that the results of our studies indicate that in the average case it will require a rural population of not less than $\mathrm{I}, \infty 0$ to account for the full time of a competent physician, if he takes care of substantially all the ordinary illnesses and accidents occurring among the people in addition to substantially all the maternity cases.

It is to be appreciated, of course, that the extent to which the rural population makes use of medical service in turn depends largely upon the cost and convenience of the service. Hence the figure suggested has validity only if it corresponds with the condition to be found in those rural areas in which the present distribution of physicians is such that medical service is neither unduly costly nor unduly hard to obtain. Our studies of specific areas in which such may be said to be fairly the condition, as in the more prosperous sections of North Carolina and the 
moderately remote rural areas of Central New York and Iowa and Missouri, confirm the validity of the figure suggested.

It need hardly be said that exceptional isolated areas will be found which have a population of less than a thousand, but which can have satisfactory medical service only if they have a physician of their own. In general, however, no village or hamlet can be regarded as a logical location for a physician which is not the natural center, under the conditions of modern transportation, of at least. a thousand people.

The villages now without physicians, and alleged to be in need of one, fall roughly into several groups.

In the first we find the village which, while without a physician, is so near another village or town which has one that if both have physicians there will not be enough work for them to do. The required minimum population is not present. In some cases there is little to choose between the town or village which has the physician and the village which has none; about the only reason which can be offered for his living in one rather than the other is that he cannot live in both. In such a case it is entirely natural, even if quite unreasonable, that the people in the town without a physician, particularly if the distance to the physician is inconveniently great, as four or five miles, should feel that they are as much entitled to a local physician as the inhabitants of the more fortunate neighboring town. The fact that the average agricultural area remote from a large town needs a physician in only one of its four or five or six villages is frequently not appreciated by the dwellers in and about the four or five villages which have no physician: 
There is, moreover, a wide diversity of popular standards in this respect between one section and another, largely determined, apparently, by what the particular section has been accustomed to in the way of conveniently located physicians. North Carolina and Kentucky furnish an interesting example of contrast in this respect. Both have about the same area, but Kentucky has 40 per cent. more towns and villages having physicians. ${ }^{1}$ Yet complaints of lack of physicians, and requests for physicians to take up vacant locations, are much more numerous in Kentucky than in North Carolina. The explanation is chiefly that, relatively few as the towns and villages with physicians are in North Carolina, they have never been much more plentiful than they are today; in 1906 they were only 3 per cent. more numerous. In Kentucky, on the other hand, relatively thick as the towns and villages with physicians are, they are not nearly as numerous as they were; in 1906 they were 40 per cent. more numerous. It is not surprising then that the country people in Kentucky regard themselves as seriously deprived, despite the fact that, as compared with their neighbors across the mountains, they are very well off indeed. ${ }^{2}$

So much for those villages whose desire for a physician springs merely from a natural desire to have a physician as close at hand as possible, rather than from any serious inconvenience in getting one from a neighboring village. At the other end of the scale we find villages situated ten, fifteen or twenty miles from the nearest town having a

${ }^{1}$ North Carolina, 559; Kentucky, 782.

2The difference is to be explained partly by the relative absence of road improvement in Kentucky. 
physician and surrounded by a population equal to and not infrequently in excess of the minimum fixed, to which it is for the most part much more readily accessible than are any of the surrounding towns having physicians. In such a case the need for a local physician is evident; the advantages, from the standpoint of the population, of having their physician in the village instead of relying on physicians in the more distant towns roundabout are not to be questioned.

In our investigations we have been alert to seek out areas of the character described, and to ascertain their characteristics and the causes for their failure to attract or retain a physician. As a result of our inquiries we have to report that areas of this type are so few in number that they may and should properly be regarded as wholly exceptional, and as presenting a problem of their own distinct from the problem of the average run of rural districts; that such occasional areas are found virtually without exception in the most backward, topographically most difficult, and agriculturally least favored rural areas -for example, in the "abandoned farm" areas of New York and New England, in the tide-water swamp areas of the seaboard south from Cape Henry, in the southern mountains on both sides of the divide, in the "cut-over" lands of Michigan and Wisconsin. ${ }^{1}$

In most cases those having first-hand acquaintance

1A unique area which is worth mentioning separately is that comprising the sand-bars which form the Atlantic Coast line from Cape Henry to Savannah. These sand-bars are inhabited by the Coast Guard and their families, and by some thousands of fisher-folk living in almost complete isolation from the mainland. It is indeed surprising that the Government has made no provision for the medical care of the Coast Guard familieswho are, of course, drawn chiefly from the fisher-folk of the region.? Were such provision made, the service provided would doubtless be availed of by the population generally. Unless heavily subsidized, it is hardly possible that a physician would permanently exile himself in one of these communities. 
with the area ascribe the failure of the locality to attract or retain a physician to the poverty of the population, making a physician's livelihood precarious at the best, and to the ignorance and unprogressiveness of the population, with resulting lack of appreciation of a physician's efforts.

In a small proportion of cases the opinion is given that a physician laboring in the area would be fairly certain of a modest livelihood, the extreme isolation, the extremely poor condition of the roads, and in certain cases in the mountain areas, the extreme hardships of practice, being assigned as the ruling causes for the failure of these places to hold physicians. Cases of this sort are, however, rare, and the opinion that even a modest livelihood is to be had in the case of such an area is justifiably open to suspicion; ${ }^{1}$ for where roads are poor the amount of work the physician can do is correspondingly limited; and if in addition thereto the population is below the average level of prosperity, as it generally is in an area of this kind, the possibility of a living income is further reduced. ${ }^{2}$

\section{Between the numerous class of villages without a phy-}

\footnotetext{
IIn point of fact, in several of the areas of this class where an opinion was received from one physician of the neighborhood affirming the possibility of a physician's making a livelihood there, an equally positive denial of the possibility was received from another.

${ }^{2}$ Closely related to, yet quite distinct from, these relatively few instances of distinct communities remote from medical care is the much larger number of areas in which, though no considerable portion of the area or its population is excessively remote from a physician, the area as a whole has relatively few physicians-perhaps only one to two thousand inhabitants. Some of the areas of this class merely exemplify a fallacious method of computation by county or civil division. What is considered here is those areas in which the excessively low ratio of population to physicians quoted is found under a proper delimitation of the area, with reference to the towns and villages on which it depends for medical service. Areas of this type, which are to be found more plentifully in the South than elsewhere, while usually substantially in advance of the pauper areas just considered, are nevertheless almost invariably of a quite unpromising character. In such an area, it is not ordinarily a particular village or location that
} 
sician which quite clearly do not need one, and the more limited class of villages and areas which quite clearly do, come a large number of doubtful cases. A common type of village in this doubtful class lies near enough to larger or more strategically situated villages or towns having physicians to make reliance on those towns or villages for medical service quite feasible, though inconvenient and expensive; but it may have within a moderate distance roundabout a population sufficient to sustain a physician of its own. Quite frequently, too, it has demonstrated its ability in this respect by having actually supported a physician, or even two, over a considerable period, in days gone by.

In some of these cases there is doubtless room for difference of opinion, as to whether a comprehensively conceived plan for the organization of the medical service of the larger area of which the given community forms part would allot a physician to the village in question, or would regard the community as properly dependent for medical service on the larger though somewhat more distant town, on the ground that the inconvenience due to

is pointed to as being in need of a physician; the whole area is alleged to be short, and several locations are usually mentioned at any one of which an additional physician could advantageously be placed. The fact that no particular location is suggested as eminently suitable for the desired additional physician is significant; none of the villages in the area rises much above the cross-roads class. On investigation, it is usually found that there is serious doubt whether an additional physician or physicians would be likely to make a living at any one of the locations suggested, diametrically opposite opinions on this point being usually asserted by physicians in the county seat. In any case it usually develops that the territory naturally tributary to any one of the suggested locations is already covered more or less regularly by the physicians located at one or more of the other villages, and that these physicians are barely making both ends meet. In short, it is found almost invariably in areas of this type that while the resources of the population, as a whole, are doubtless equal to the support of one or more additional physicians, and judged by abstract standards, there should be work enough among so large a population to require such additional physicians, yet no unquestioned demand appears to exist for their services at any particular location, and in the current competitive organization of medical practice a newcomer has no reasonable assurance that support will be forthcoming. 
increased distance was more than compensated by the advantages gained by reliance on the town physicians. This is a question on which theoretical opinion will differ, and which will be discussed at a subsequent point. For the present purpose it may be assumed that any community of the character under discussion-a rural community, large enough to take up the full time of a physician, and with substantially all of its members more accessible to a village centrally located in the area than to any other village or town-may be said to be in need of a physician.

There are today undoubtedly some hundreds of such villages without a physician. The apparent reason, in nearly every case, for the failure of the village to attract a physician, the reason indeed, in many cases, for its having lost the physician it once had, is that despite its being the natural center of an area populous enough to give wholly adequate support to a physician, a physician locating there could not be certain of even a bare living; a substantial portion of the medical work of the area, and a still more substantial portion of the income, goes to the more distant yet wholly convenient town; ${ }^{1}$ so that a practitioner in the village would find his income hardly less precarious, and his professional position much less satisfactory, than the village practitioner located in a much poorer, but more remote, area. There exist the apparent need and the apparent ability to support; but the two are not correlated in such a way as to yield any assurance that the individual practitioner who attempts to meet the need will receive the support.

\footnotetext{
IIn not a few cases, as already suggested, the physician who formerly practised in the village is now located at the adjacent town and his hold on his former territary is likely to be especially tenacious.
} 
Despite the obtruding obviousness of the conditions described, there is no assumption so frequently made as that the mere statistical demonstration that there are in and within an easy distance of a given village a given number of people, say $1, \infty 00$, capable of occupying the full time of a physician and able to pay for his services, is equivalent to proof that a capable physician would make a good living in the community in question. Many a physician has made the same unfortunate error only to find after locating in the community-sometimes indeed at the earnest solicitation of a number of its residents-that his practice is confined largely to night calls and emergency calls during the few months of the year when the roads to town are impassable by reason of mud or snow. ${ }^{1}$

Summarizing, it appears that a substantial proportion of villages said to be in need of a physician cannot, under the régime of modern transportation, be considered as the logical exclusive center of an area sufficiently large to utilize the entire time of a physician, and are situated in territory which is already adequately covered from surrounding villages. A small number of remote areas sparsely settled but populous enough to require the entire time of a physician have not, owing to extreme poverty combined with extremely unattractive conditions, a resident physician but must depend for medical service on towns unduly remote, whose physicians are already fully occupied nearer home. A considerable number of rural areas fairly remote from a town, and of the less prosperous kind, but well above the pauper level

1For an illuminating first-hand account of a young physician's experience in a village of this type, see N. Y. State Journal of Medicine, March, 1923, p. 128. 
of the areas just referred to, appear to have an unduly low proportion of physicians to population, but are wanting in any particular village, now without a physician, in which a physician locating would have a reasonable assurance of earning a good living. Finally, there is a considerable number of villages in the more prosperous rural areas, now without physicians, which though located within accessible distance of a larger town, are logical and desirable locations for a physician, provided he could be assured of the patronage of the people for whom the village forms the natural center.

Our review of the situation has thus led us to the conclusion that only in comparatively few cases do the vacant locations apparently in need of a physician offer any reasonable assurance of a livelihood obtainable within a reasonable time; and that in the cases where such assurance is possibly present, the livelihood obtainable is frequently too meager to offset the extreme conditions of isolation and hardship found in those areas.

Does it follow that if an assurance of a reasonable livelihood were provided in these locations, such assurance would induce physicians to locate in them? The answer depends upon an appraisal of the existing degree of competition and economic pressure in the medical profession -an estimate of the number of struggling practitioners in city and town to whom the assurance of a livelihood, even though in a remote location, would make an effective appeal, and the number of recent and current graduates whose need for immediate income is urgent. Such an appraisal and estimate must necessarily be matters of opinion only. It is our opinion that for the present, and for the immediate future, the state of economic pressure 
in the profession is and will be such that the provision of assurance of a fair income for the physician taking up a given location will in almost every case attract a physician to it.

How correct this conclusion is, and in what proportion of cases, no one can say with absolute assurance; but only after a given village has taken action to give a physician locating in it reasonable assurance of a fair income, and has nevertheless failed to obtain a physician, can our conclusion be held to be incorrect.

Hence it would seem self-evident that the problem of inducing physicians to locate in or remain in the villages now without physicians or threatened with the loss of their physicians, cannot be said to have been seriously presented in any community unless and until that community has taken action, within the limits of its financial ability, to give to the physician whose service it seeks a reasonable assurance of a moderately good income.

\section{SECURING PHYSICIANS BY COMMUNITY ACTION}

From time to time, the fact that the people of a particular community have taken, or are said to have taken, concerted action to offer a subsidy or a guarantee to a physician locating among them, is cited as evidence that an alarming condition exists in the field of rural practice; but it is difficult to understand why a proposal of this sort should give any cause for alarm. On the contrary there is more than one standpoint from which it may be viewed as a very healthy symptom. For one thing it indicates that the people of the community have recognized the provision of local medical service to be a com- 
munity responsibility, and not a responsibility of the medical profession. Again, it will be admitted that a community is likely to respect its physician more when it has sought his presence, offering tangible evidence of its desire for him, than when he has come to it as a prospector seeking a living; and that whatever increases the standing of the medical profession, whether in the rural areas or elsewhere, works for the selection of a higher type of individual in the profession. In short, the fact that a condition may have come about, or is likely to come about, in which the normal play of competition will no longer bring physicians to a certain class of villages, but must be supplemented by community action, is of itself no occasion for alarm. Only if it be found that the type of community action called for is economically unsound or impracticable will there be cause for misgiving.

Indeed it has already been suggested that the cost of medical service in a moderately serious illness, even in those rural areas which have a local physician, is relatively so heavy as to raise the question of the appropriateness of some method of distributing at least part of the cost over the whole community; so that the suggestion of community coöperation in offering monetary inducements to a physician to locate, far from evidencing a dangerous condition in the rural area involved, may be viewed as representing an advance in the recognition of the community's responsibility for the health of its members.

Community action in this field may take one of several forms. The most obvious is that of outright subsidy to a physician, the amount being fixed with a view merely to supplementing the physician's income, which will be 
derived for the most part in the regular way. Another form is that of a guarantee, under which the community undertakes to make good any deficiency in the physician's income below a given figure. Finally, there is the possibility of outright employment of the physician by the community on a full-time basis. Unfortunately, little has been done in this country to test the possibilities or merits of any of these methods of community action.

The only authenticated instances which have come to our attention, in which a physician has been subsidized by community action, are found in a few of the more remote areas of New York and New England. In New York, by an act passed in rgr6 at the instance of the State Department of Health, the town board of any town (the term used in New York for what is in most states called a "township") in which there is a village or hamlet without a physician, may establish the office of town physician at such salary as may be fixed by the town board. Towns may also combine for this purpose. In return for the salary, the physician is required to treat any of the indigent sick of the town who may be referred to him by the proper authorities. Up to June, I923, only two towns had taken advantage of the authority thus conferred. Both of these towns are located in regions of extreme sparsity of population in the Adirondack Mountains.

Despite the smallness of the salary offered, and the remoteness of the locations, no difficulty appears to have been experienced by either of these towns in obtaining physicians willing to locate in them; and it may be remarked that both of the physicians now working under 
these subsidy arrangements are graduates of recent years.

In Vermont and New Hampshire, by laws passed in I92 I and I923, respectively, provision similar to that found in New York has been made, a limit of $\$ 500$ per annum being fixed in the Vermont law, however. So far as available information goes, no Vermont town has yet taken advantage of the law, while in New Hampshire one town has done so. ${ }^{1}$

In Massachusetts there is no specific provision of law which empowers a local unit of government to subsidize a physician. In one instance, however, a town in western Massachusetts ${ }^{2}$ has for this purpose taken advantage of its authority to employ a health officer and a school physician, by providing for those posts a compensation so much in excess of what ordinarily attaches to them as to constitute for the single resident physician in the town, who occupies both positions, a substantial subsidy; and such is the mutual understanding of the arrangement. The combined fees thus provided total only $\$ 600$ per annum, but the amount is slightly increased by compensation for services as school physician in several neighboring towns. Still more important, however, is the fact that the town provides the physician with a house, rent free. The town in question is located in the remoter hills of Massachusetts, about twenty miles from a railroad station and about ten miles from the terminus of a trolley line, which connects with the railroad town. The total population ordinarily within reach of the physician

\footnotetext{
1The town of Deerfield. No information regarding the details of the arrangement is available.

2The town of Chesterfield, in Hampshire County.
} 
located in this town is hardly 1,000 and conditions of winter practice are extremely severe. The arrangement referred to was first put into effect in I9I9 and appears to have met very satisfactorily the problem faced by this isolated community.

In the Province of Saskatchewan, Canada, there is found legal provision similar to that of New York, and two or three localities there now have physicians under subsidy.

From time to time one hears of additional instances in which subsidies have been or are being offered to physicians to locate in a particular community, but on investigation it usually develops that the matter has gone no further than a suggestion and that definite action has either failed to result in approval of the suggestion or has indeed resulted in its rejection. ${ }^{1}$ No systematic attempt has been made to collate all such instances, but there is not believed to have been any considerable number. None has come to attention in any of the states selected for detailed study, except as already mentioned. ${ }^{2}$

Only one reported instance has come to our attention in which a rural community in this country has adopted a plan of guaranteeing the physician's income. The community is reported to be located in Nebraska. Unfortunately authentic details of the ar-

\footnotetext{
1An instance is that referred to in a publication of the Public Health Service, Public Health Reports, April I6, I920, "The community without a physician," regarding a township in Wisconsin, which was reported to have adopted a plan for offering a subsidy. Correspondence with the Public Health Service, however, disclosed the fact that the voters of the township had rejected the plan.

2It has been stated to us by the Health Officer of Virginia that in several instances in which rural communities have applied to him for assistance in securing a physician, he has proposed to the community the subsidizing of a physician, who would also perform the functions of the local health officer, but that in no instance has his suggestion been adopted.
} 
rangement adopted are not obtainable ${ }^{1}$ but it is stated that the amount guaranteed was $\$ 2,500$ per annum for a period of five years, the guarantee being made by a large group of citizens, and that the arrangement resulted in the physician's obtaining a lucrative practice in the town, the residents of which had formerly been given to patronizing the physicians in neighboring larger towns to such an extent as to make the location in question an impossible one.

In the Province of Saskatchewan, in which, as already seen, the law permits the subsidizing of a physician, rural municipalities are also authorized to guarantee the income of a physician. The law provides, however, that no such guarantee is to exceed the amount required to bring the physician's income up to $\$ \mathrm{I}, 500$ per annum, an amount so small that the provision would seem of negligible value; and indeed there is now no physician under such a guarantee arrangement in the Province.

The amount of subsidy or guarantee, which, in the average case, the rural community will be called upon to provide, will vary considerably, not only according to the nature of the conditions surrounding the location in question, but according to the arrangements made for reimbursement of the community by the patients treated. Inasmuch as whatever is provided represents in the main a corresponding saving in the aggregate amount expended by the members of the community for medical service, there is no reason why the provision of such an amount should in the average case offer any serious difficulty. It may be readily admitted, however, that there

\footnotetext{
1The instance referred to was mentioned in a letter to the Journal of the American Medical Association appearing in the issue of March 4, 1922. The writer of the letter is unable to give the name of the town, having obtained his information merely from a casual conversation with the physician working under the arrangement.
} 
are a limited number of remoter areas corresponding roughly with the areas described as being either too poor or too unattractive to hold a physician, in which difficulty will be found in providing locally an amount sufficient to induce a physician to locate in the area, particularly since that amount will have to be sufficient to offset the reduced amount which may be expected from fees in a poverty-stricken area or one difficult to travel, or to overcome the environmental drawbacks found in the type of area under discussion. In districts of this kind it is probable that the requisite subsidy could be provided only with state help. This does not mean, however, a gigantic program of state expenditure. It is hardly likely that there are to be found in any state over twentyfive areas of this kind-certainly not over fifty, nor is it probable that the contribution required from the state in the average case would run much over $\$ 1,000 .^{1}$

The provision of a subsidy by a community to induce a physician to locate in its midst is by no means to be regarded as being wholly an additional burden on the community; for, having a physician near at hand, the members of the community save the extra cost that would be entailed by sending to a more distant place for a physician. Looked at in the large the subsidy may be regarded as a method of absorbing as a social charge the excess

\footnotetext{
'Such state aid is found in the provinces of Saskatchewan and British Columbia. In Saskatchewan the Province subsidizes physicians in two instances to the extent of about $\$ 100$ per month, these cases being in unorganized territory. In the Province of British Columbia, these grants by the Provincial Government are found on a fairly extensive scale. The practice of paying subsidies to physicians of the remote parts of the Province dates from 1883 and there are now no less than 23 physicians so subsidized. The grants, however, are quite small, varying from $\$ 200$ to $\$ 900$, with the average between $\$ 300$ and $\$ 500$ per annum; but in some cases, these subsidies are supplemented by grants from the Dominion Government for medical care rendered to the Indians in the vicinity.
} 
cost of obtaining medical service previously borne by the individual members of the community who happen to need such service. The same may be said of any sum for which the members of the community may be called upon to make good a shortage in the physician's income below a guaranteed minimum.

It is of the highest importance to appreciate that a plan of subsidy or guarantee, in addition to its financial attractions for the physician, offers equally important attractions to him in another fundamental matter, that of professional prestige. It has already been pointed out that the serious loss of prestige which the rural practitioner has suffered since the opening years of the century has been one of the prime factors in his dissatisfaction with the rural location. It is safe to say that the oldtime prestige of the rural doctor among his neighbors can never be regained by any physician who under modern conditions comes to the sophisticated rural community in the position of a seeker for clientèle. The villager who has ceased to respect the established practitioner of long standing will have but little regard for a newcomer who in his search for a practice location has been content to settle upon one of such limited possibilities. It seems altogether likely, however, that were the positions reversed-were the community to seek the physician-the physician, now in the position of the one sought after, one who must indeed be offered substantial inducements to be obtained, would fill a far larger place in the estimation of the average member of the community. Such a position would not merely be attractive to the physician of itself, but would redound also to his professional as well as to his financial satisfaction; for it is 
not unlikely that a proportion of the more difficult and interesting cases which under current conditions pass by the rural practitioner into the hands of the town physician would come to him.

Both the subsidy and the guarantee plan carry with them the possibility of some regulation by the community of the fee scale of the physician who receives the subsidy or guarantee. It is believed that such regulation could not in the long run be other than helpful to the physician involved, for it would give to his fee scale a sanction of lay opinion which it now lacks and in the absence of which it quite frequently seems excessive to the rural dweller.

No instance has come to our attention of a state statute authorizing the direct full-time employment of a physician by a local unit and his compensation out of public funds. In the Province of Saskatchewan, however, rural municipalities are empowered to engage the services of a legally qualified medical practitioner for the municipality at a salary not to exceed $\$ 5,000$ per annum. It is noteworthy that the law requires that action under this provision can be taken by a rural municipality only after a favorable vote of the electors; whereas, action under the subsidy or guarantee provisions of the law may be taken by the council without reference to the electors. There are now two rural municipalities in the Province which have taken advantage of this provision of the law, the salary paid being in both cases $\$ 4,500 .^{1}$ In one of these municipalities the physician employed gives his

\footnotetext{
These are the municipalities of Sarina and Craik, the physicians being located in Holdfast and Aylesbury respectively. Medicines and dressings are furnished by the physicians at cost. The patient does not reimburse the municipality in any way for the service rendered him. The physician's salary is included in the general tax levy.
} 
services free to all patients in the municipality, except in confinement cases, in which he receives an additional fee usually amounting to seven dollars. ${ }^{1}$ It is notable that both of the physicians thus working on a salary basis have commented in correspondence which we have had with them on the gratifying absence of any tendency on the part of their patients to call them in for trivial reasons - a tendency which might perhaps have been expected.

Only one instance has come to notice of the direct employment of a physician by a community organization in this country. The community is that of Sharon, Kansas. Sharon is an incorporated city of three hundred and twenty-five inhabitants. Owing to the difficulty experienced in retaining a physician in the village, a number of citizens in and around the town formed an association for the purpose of employing one. The membership of the association comprises about two hundred families, and the membership fee is \$I 5 per annum for each family, regardless of its size. There is thus provided a fund of about $\$ 3,000$ per year, which is paid as salary to the physician employed by the association. For this salary he gives medical service to all members of the association without charge, except for a small charge for calls. ${ }^{2}$ This arrangement was inaugurated in October, 1922. It is reported to be highly satisfactory both to members and the physician.

Neither the guarantee arrangement cited above nor

\footnotetext{
In one of these municipalities an extra charge of $\$_{5}$ is also made for fractures and $\$ 2$ for the initial visit to a family.

2The statements here made are based upon a newspaper account issued by the Central Press supplemented by correspondence with the physician now working under the arrangement described, Dr. E. S. Hawarth.
} 
any of the subsidy arrangements involve any attempt to relieve the physician of the responsibility for collections. The uncertainty of payments is notoriously one of the chief ills of the rural physician's lot and the making of collections doubtless one of the most disagreeable features of his practice. A plan which would relieve the practitioner of concern for collections and assure him of payment by the community for all services rendered, leaving to the community responsibility for enforcing collection from the patient, would, regardless of its other features, represent a tremendous advance in the conditions of rural practice. Indeed it is not too much to say that in a large number of the rural areas now without physicians the adoption of this plan, and nothing more, would be effective in attracting a competent physician to the area.

There is another phase of the rural practitioner's position for which relief should be provided in any plan which seeks to retain competent physicians in the remoter rural locations. It is essential that the physician be enabled to take every year or two a vacation both for recreation and for the opportunity afforded to visit the larger centers and refresh his knowledge of medicine by personal observation and contact with its current developments. It is difficult to over-estimate the importance of this factor. There are large numbers of physicians who would be content with the isolation of village practice and with its hardships, were they afforded an opportunity periodically to interrupt the arduous and confining routine of their lives; but for the average rural practitioner under current conditions this is out of the question, both because of its expense and because in many cases absence for even a month or two would weaken the hold, already 
too tenuous, which the physician has upon his territory. Were a sufficient guarantee or subsidy provided, both factors would cease to have much influence; while there would be no great difficulty, during the months of little illness and easy travel, in arranging for temporary service to the community either by engaging a substitute from among the younger unattached members of the profession, or by apportioning the territory among the physicians of the surrounding towns.

A community contemplating action along any of the directions indicated would, it is believed, do well to include as an additional item in its program the provision of suitable quarters for the physician. At all times, but more especially since the shortage of housing incidental to the war-a shortage which has affected, in a measure, even some village communities - the problem of obtaining desirable quarters has always been an important one for the physician taking up a village location. ${ }^{1}$ The number of houses in the average village suitable for a physician is severely limited and they are usually owned and occupied by the more substantial citizens of the village, and are not available on a rental basis; moreover, if one happens to be for sale, the physician, even if he has funds available, is naturally reluctant to purchase in a location which must be regarded as experimental. A subsidy or guarantee provision would, of course, tend to make the physician measurably more certain of his per-

\footnotetext{
1In one of the southern states the failure of a certain rural location to obtain a physician was explained to us as being due solely to this factor; the physician who formerly lived there and had moved to the larger town some ten miles away was said to be the owner of all the houses in the village, only three or four in number, suitable for a physician's residence; and it was alleged that he refused to sell or rent to a physician, thereby preventing the establishment of a competitor in the village in which he still did a large practice.
} 
manence in the location; but even so, the provision of a suitable house would constitute a strong attraction.

Particularly would this be true were the house provided with such conveniences as running water and electric current, which are so frequently absent even in the better village houses, with a modest laboratory equipped for the performance of the simpler tests, and possibly also with two or three rooms suitable for sick rooms, to which the physician might on occasion bring patients. The latter provisions would make it possible for the physician to handle under reasonably good conditions those occasional emergency cases which cannot be properly treated in the home, and would also tend in seasons of extremely difficult travel to eliminate home visitation to patients unduly remote and requiring frequent visitation, who could more conveniently be brought into the village. These provisions would not entail a permanent nursing or ambulance service; nursing could be done either by a member of the patient's family who might stay in the village during the period of the illness, or by a "practical nurse" living in the village. In short, there need be no attempt to provide hospital facilities or care, but merely a reasonably good substitute in selected cases for the type of care usually received by the bedridden patient in the rural home.

\section{THE COTTAGE HOSPITAL}

In the vision of some of its proponents, the modest plan just suggested expands into a "cottage hospital" in which virtually all of the illness of the circumjacent rural community will be treated; and the establishment of these hospitals in rural areas, with the help of state funds if necessary, has been advocated in New York by the state 
health authorities as the best means of inducing physicians to locate in the rural areas. The cottage hospital would attract physicians, so runs the argument, on the one hand by providing them with the facilities necessary for high-grade work, and on the other by greatly reducing the amount of home visitation; for while a certain amount of visitation would still remain, a case requiring or threatening to require additional visits by the physician would promptly be moved into the hospital. ${ }^{1}$

The program suggested would undoubtedly economize the time of the physician and its attendant cost by permitting him to care for a larger population; but partly offsetting this gain would be the expense of an ambulance service, a type of transportation relatively more costly than that employed by the physician in making his visits. ${ }^{2}$ The project substitutes, moreover, for

1The subject was first introduced by the Health Commissioner of New York at a conference held at the call of the Governor, February 26, 1923. In his message to the legislature, sent as a result of this conference, the Governor states that "small community hospitals to serve rural districts where a physician would have the advantages of being able to take care of several patients at a time, and thus avoid the long rides in the winter time over difficult roads to scattered homes, are looked upon as a helpful solution of the need. Such small hospitals would provide laboratory and other facilities that would stimulate the interest of the physician and assist in attracting him to remain in such communities. Many counties and other smaller communities are going forward with the establishment of such institutions. . . . I would therefore suggest that . . . when the county supervisors of counties having no first or second class cities. . . . make an appropriation . . . for small community hospitals in the rural districts - . . the State shall appropriate a similar amount, dollar for dollar." It would seem that there is here some confusion of the "small community hospital in the rural district" (doubtless equivalent to the "cottage hospital" proposed by the Health Department) with the county hospital, located at the county seat, the possibilities of which are discussed in subsequent pages. The Governor's recommendations were adopted by the legislature (Laws of 1923, chap. 662).

2The vehicle must be more expensively constructed than the ordinary passenger car, and the speed over difficult roads slower; more important, a separate trip must be made for each patient. On the other hand, only a single trip, or at most two, is required for each patient as against a possible large number of trips by the physician. 
the home nursing of the bedridden patient, a service in which fixed charges on capital outlay, maintenance costs (including heating, cleaning, laundry and commissary service) and trained nursing service all enter. No attempt has been made so far as we are aware to estimate carefully the precise size of an institution such as that under discussion, the amount of ambulance, maintenance and nursing service required for its operation, or the cost of the institution and the proposed services. Nor has any estimate been made of the ability of the average rural community to finance even the maintenance of an institution of this character, to say nothing of providing for the initial outlay. It is a question, however, whether in the cases where the hospital would be most needed, much the larger part of the necessary funds would not have to be furnished by the state. That this was recognized by the proponents of the plan in New York would seem to be indicated by their emphasis on a state subsidy for the proposed hospitals.

There is, moreover, apparently much conflict of opinion as to the completeness with which, in the present state of rural roads, hospitalization of the bedridden could be effected without injury to the patient. The opinion of the average experienced rural practitioner would seem to be that the percentage of cases which could not be moved would be quite high; on the other hand, there is support for the view that the injury to the patient would be on the whole less than that suffered under present conditions, due to remoteness from medical attention and lack of facilities for proper nursing care at home. In a proportion of rural areas, how- 
ever, including some of those in which the greatest difficulty is now experienced in obtaining medical service, the condition of the roads is such that in bad weather the transportation of a seriously ill patient is quite out of the question.

The cottage hospital proposal is here considered not primarily as a rural health measure, but as an item in the program of attracting additional physicians to the rural areas. Viewed in this light, we are convinced that in the present and immediately prospective state of competition in the medical profession, the proposal goes considerably beyond what is necessary. Our studies have led us to believe that any rural community which provides a moderate subsidy and possibly quarters, and which will relieve the physician of the responsibility for collections, will have little difficulty today-and probably for some years to come-in securing the services of a competent physician.

A line of action which would doubtless have a measure of influence in making physicians, particularly younger physicians, more willing to locate in the rural areas, is the development by the state health departments of improved diagnostic laboratory service for the rural practitioner. A partial service of this kind is already furnished by a number of state health departments; but complaint is fairly general that the service is incomplete and slow-moving. The establishment of branch laboratories at convenient points, in lieu of the customary arrangement by which all work is centralized in a single state laboratory, has been suggested.

The suggestion is sometimes advanced that there should be made available medical school scholarships to 
be granted on condition that the recipient upon graduation choose some rural district for a practice location and remain there for a given length of time. The proposal contemplates action by the state or local community in making the scholarship award. ${ }^{1}$ It is difficult to see how the agreement with the scholar could be enforced unless assurance of a reasonable living were added. But if this assurance could be given it is questionable whether a scholarship provision would be necessary, although it might serve as a desirable supplement.

The provisions of guaranteed compensation and living quarters practically exhaust the possible methods of making a direct appeal to the physician to locate in a given rural area. ${ }^{2}$ All other suggestions which have been advanced look to a general improvement of the rural area itself. The thought is that when an improvement is realized the natural professional and living advantages of the rural areas will reassert themselves in a degree suffcient again to attract physicians, without the offer of specific inducements directed exclusively to the physician. Aside from the financial or professional aspects, the chief counts in the bill of complaint against the rural areas as locations for physicians which has been drawn in the preceding pages have been the difficult roads and the absence of schools, churches and social life; so that proposals

\footnotetext{
1The only specific proposal in this direction which has come to our attention is one introduced in the Virginia legislature in 1922 but not adopted. It called for an award of an annual grant of $\$ 500$ to a medical student for each of the ten congressional districts of the State, on condition that the recipients return to a rural location in their respective districts.

${ }^{2}$ Mention should be made of a proposal advanced in 1922 in Kentucky by the state health department for the establishment in the department of a fund for making loans to indigent city practitioners to enable them to set up in vacant rural locations. Nothing came of the proposal.
} 
directed to the improvement of the rural environment to a degree adequate to attract physicians must attack these factors. It will be seen at once that such a program of action by a rural community, or by the state in coöperation with the rural communities, is far too extensive to be entered upon merely for the purpose of attracting a physician. A community which is indifferent to the primary values of good roads and schools and to the advantages of local social life, is not likely to be stimulated to comprehensive action in these directions by the comparatively minor additional incentive that improvements of this sort may make it less difficult to attract or retain a local physician. From the standpoint, therefore, of a practical and relevant contribution to the solution of the problem of attracting and retaining physicians in the rural areas the statement that roads, schools, churches and social life must be improved, while true enough, so far as it goes, must be considered valueless. ${ }^{1}$ It. is important to note, moreover, that the improvement of roads, instead of making it easier to attract and retain physicians in the rural areas, may often render it much more difficult. The improvement of roads has already been seen to be one of the primary factors in the decay of rural practice by reason of its enhancement of inter-village and town competition. It is only, therefore, in those extremely rare locations in which the poor condition of the local roads constitutes practically the sole drawback to an otherwise wholly desirable location that road improve-

\footnotetext{
1The lack of immediate value of suggestions of this character is emphasized by the fact that in a considerable number of areas, as already seen, an outstanding drawback from the standpoint of the physician seeking a location is the backwardness and in some places indeed the illiteracy of the population. A condition of this sort must for the present purpose be taken as it is found.
} 
ment can be expected to make easier the task of obtaining or holding a physician.

It has already been mentioned that, in the view of some, all the foregoing discussion, directed as it is to the placing of additional physicians in the rural areas, is wide of the mark. The persons in question urge that the declining number of physicians in the rural areas and the desertion by physicians of the country villages reflects merely the working of powerful economic and social forces, and that the attempt to run counter to this drift is unwise as well as futile. What should be attempted, so runs the argument, is not a perpetuation of the old type of rural practitioner, but a program which will extend the services of the towns more fully into the rural areas, thereby making the rural practitioner unnecessary. It is in our judgment open to question whether this view is valid, even from the standpoint of ideal theory. Given a town of, say, 2,500 inhabitants, with a population of perhaps 10,000 in the countryside for ten miles about, it is not altogether certain that even under a régime of superlative roads and universal telephones, and with an insurance system in operation which would distribute over the community the cost of medical service, a more efficient organization of medical service would be secured by locating all the ten or twelve doctors which a community of this size would require in the town, than would be obtained by locating perhaps one-half or three-fourths of them in the town and the remainder in one or another of five or six villages lying round about, perhaps five or six miles from town. There are advantages in either arrangement and a worthwhile opinion as to which arrangement was better in a given case could be reached only after consideration 
of its specific conditions. Obviously no such balance of considerations is to be found in the average rural area today, in the present state of road improvement and in the absence of any development in the direction of distributing over an area the high cost, under present condiditions, of medical service drawn from a distant center. We are of the opinion that except in the most highly developed rural areas - the very areas in which the provision of medical service has ceased to be a problem-the proposal that medical service be still further centralized is unsound.

THE TOWN HOSPITAL

The proposed establishment of a more centralized medical service for rural areas is, however, commonly presented in connection with, and indeed not infrequently merely as an incident to, an argument for the development of hospitals in the towns, designed to serve the rural areas and villages for a considerable distance about. ${ }^{1}$

The town hospital plan contemplates, of course, a reduction of the amount of home visitation through prompt removal into the hospital of all cases requiring repeated visits by the physician; but it cannot eliminate home visitation. Physicians experienced in rural practice are in accord in the view that, even with a hospital available, only by a home visitation service which is obtainable with reasonable promptness and at reasonable cost, can early diagnosis of serious or infectious diseases be assured, and those cases which call for hospital care be distin-

\footnotetext{
1In general, the type of town and size of surrounding area had in mind correspond substantially to the average county seat and county so that the proposal is practically equivalent to the county hospital program, statutary authorization for which is now found in some fourteen states.
} 
'guished from those in which hospitalization would entail needless hardship and expense. Moreover, even for ambulant cases, the distance to town from the remoter areas is likely to be so great ${ }^{1}$ that a journey to town merely to consult the physician would be unduly burdensome.

On the cost side the town hospital encounters the same general difficulties as does the village hospital, but they are considerably reduced in degree. On the one hand, owing to larger size, the relative overhead costs may be greatly reduced; and, on the other hand, the cost of the institution, so far as it is not self-sustaining, is distributed over a larger area in which it is likely that the average taxable value will be higher than in the remoter village and surrounding area for which the village hospital is more particularly suggested.

A suggestion that seems practicable, though its realization doubtless lies rather far in the future, is that the entire profession of the area served by the town hospital should reside in the town, be organized around the town hospital and connected with it, and that the physicians so organized cover the outlying areas both for office consultation and home visitation, either in rotation or by an allotment of territory. This would in effect represent an equal distribution of the burdens of rural home visitation over the entire profession of the area, in place of the unequal distribution at present obtaining, in which the physicians located in the outlying villages do a disproportionately large part of the rural home visitation, and

\footnotetext{
IThe typical county in the settled agricultural region of the country has an area of about 750 square miles, so that if the county seat be assumed to be centrally located, the distance to the farthest parts of the county as the crow flies would be about fifteen miles. In many cases the actual road distance, due to irregularities in the shape of the county, amounts to as much as thirty miles.
} 
particularly of the more disagreeable and arduous rural home visitation; and, correspondingly, would represent a more equal distribution of the more lucrative and more agreeable town office consultation work. The proposal encounters a serious psychological difficulty in that the rural dweller is in effect, so far as home visitation is concerned, deprived of the physician of his choice. But this objection is perhaps not as serious as it seems at first sight, inasmuch as the proposal contemplates that bedridden cases requiring or threatening to require treatment for anything beyond a day or two shall be promptly moved into the town hospital, where, presumably, the patient would be under the supervision of the physician of his choice.

For the present, however, all this is more or less speculative. As is well known, hospitals corresponding substantially with the type outlined are found here and there, chiefly in those states in which the law authorizes or encourages counties to construct county hospitals. In no case, however, has any attempt been made to make such hospitals the core of an organization of the profession of the county for purposes of home visitation and office consultation, as well as for hospital treatment and care. For the present, consequently, these hospitals figure merely as an additional facility for treatment and care confined largely to surgical and serious medical cases, leaving the organization and operation of the profession for the run of common ailments and obstetrics substantially unaffected. Nothing would more helpfully illuminate the problem of rural medical service than a consistent and well-grounded attempt on the part of one of these county hospitals to organize about itself a complete, comprehen- 
sive and exclusive medical service for the county, in which every practitioner in the county would be included. There are manifold and serious questions that the attempt would raise, particularly in connection with the adjustment of the financial and professional interests of the physicians involved. Upon a satisfactory solution of these questions would largely depend the success of the entire effort; but the attempt is one well worth making. 


\section{CHAPTER V}

MEDICAL EDUCATION AND THE SUPPLY OF RURAL PHYSICIANS

The view has been taken in the preceding chapter that, for the present and the immediate future, in the existing and immediately prospective state of competition and pressure in the medical profession, rural communities will be able to obtain and hold physicians by the provision of relatively simple and inexpensive inducements. It remains to consider the outlook for the more distant future. Particularly are we concerned with the outlook as affected by the current régime of medical education; for in so far as the character of medical education conditions the number of physicians, and the outlook of the physician in estimating the relative attractions of urban and rural practice, it becomes a primary factor in determining what will be the supply of physicians to the rural areas.

Needless to say, the degree of economic pressure in the profession, and the outlook of the medical graduate, are not the sole factors which will determine the future supply of physicians to the rural areas; at least as important, if not far more important, will be the further changes in rural life and distribution of rural population, in the relation of town and country, and in the conditions of medical practice, which the years ahead will inevitably witness. But those changes lie in the realm of speculation and outside our present purpose. 
It is important to recognize, moreover, that the degree of economic pressure in the profession is by no means determined solely by the absolute number of physicians. Doubtless it may be true that, all other things remaining the same, the degree of economic pressure in the medical profession for some time to come will be determined solely by the numbers of the profession; but no one of the other things will remain the same. The incidence of disease, the medical habits and outlook of the population, the development of institutional medical care and of one or another form of sickness insurance -in these and possibly other important respects the economic bases of medical practice must inevitably experience changes during the years ahead. Quite chimerical, therefore, is the notion that the degree of economic pressure which is to obtain in the profession some years hence may be predetermined solely by regulating the number of medical graduates-and no less than this is the object of some of the suggestions which have been made looking to a change in the current standards of medical education.

Finally, even in so far as the number of graduates does enter as a factor in determining the economic pressure obtaining in the profession, it is erroneous to assume, as is often done, that that number is determined wholly by the severity of the requirements for the medical degreethat a lowering of requirements necessarily brings with it an increase in the number of students, and a raising of the requirements a decrease. It is plain upon even the most casual reflection that the youth considering the study of medicine considers, not only the length and cost of the course, but also the prospect of establishing himself with reasonable promptness after graduation. If at- 
tractive prospects do not exist, the mere reduction of requirements will do little to attract students; if they do exist, the addition of a year or two to the course will discourage but few students.

\section{RELATION OF MEDICAL SCHOOL REQUIREMENTS TO NUMBER OF STUDENTS}

The notion so widely current, in medical circles as well as out, that the standards of medical education alone determine the number of medical graduates, is usually found on inquiry to be based on the apparent experience of the past two decades - the sharp falling off in the attendance of medical schools concurrently with the elevation of their requirements. So direct does the connection seem to be that it is usually accepted as self-evident. On closer inspection, however, it develops that there are good reasons for doubting whether the connection is as direct as it looks.

The decline in attendance at medical schools began in 1905. The preceding twenty years had, however, been a period of abnormal growth in attendance, which had increased far more rapidly than did the population. The number of medical graduates in the United States during the five-year period, I 886 to I890, was I9,284. In the next five-year period (I89I-I895) the number rose to 24,363 , in the next (1896-1900) to 26,238 and again (I90I-I905) to 27,398 . This growth was promptly reflected in the heavy increase in the number of physicians recorded in the 1900 census ${ }^{1}$-an increase particularly heavy in the northern states, resulting in an overcrowding of the profession admittedly extreme. It is consequently

1See table, p. 159, and graph, p. 162 (in the Appendix). 
more than likely that had there been no change whatever in the requirements for entrance to medical schools and for graduation there would still have developed, not long after I904, a substantial reduction, relative if not absolute, in the number of medical students.

It has already been pointed out that, close on the heels of this decade of inflation, so to speak, in the number of physicians, there came the automobile, with its enlargement of the working capacity of the physician and the resultant intensification of the already severe pressure consequent on overcrowding. It is fair to assume that these conditions were effectual in discouraging, in the early years of the last decade, a not inconsiderable number of prospective or potential medical students who might otherwise have entered on the course.

Moreover, during the years in question not only have entrance standards risen, but the number of schools has sharply decreased. There were I 50 medical schools in the United States in I9ro; there were about 90 ten years later; and the schools that disappeared were schools that employed flagrant advertising methods. The drop in attendance is partially explicable by this fact.

It will thus be seen that there are several major factors in addition to the elevation of medical standards which must be taken into account in explaining the decline in medical school attendance of the past two decades. ${ }^{1}$

'So far, moreover, as that decline is properly chargeable to increased requirements for admission and graduation, it is to be remembered that this has been a period of very drastic change in requirements, entailing an unprecedentedly large amount of readjustment on the part of the body of prospective medical students. Such readjustment to increased standards necessarily retards the entrance of a large proportion of prospective students and completely discourages a great many more. The readjustment to advanced standards was particularly drastic in the South, where the former standards of medical schooling had been, with few exceptions, low, and where the existing high school and college system was such as to make difficult the attainment of the higher entrance requirements by the sțudents. 
Finally, the yedrs since I9r4-I 5 (when the low mark in new matriculants was reached $^{1}$ ), though a period of increasing severity in entrance requirements, have witnessed not a decline, but an almost uninterrupted increase in the number of new entrants upon the medical course. An increase of almost 500, or about i4 per cent., was registered in 1916 , and an additional substantial increase was made in I9I 7. In I9I8, due doubtless to the fact that many prospective students were in the military service, the number of new matriculants dropped far below that of any previous year; but in I9I9 it returned to approximately the figure of I9I7. In 1920 and I92I successive annual increases of approximately 600 were registered, so that the I92 I figure exceeded that of any year since $1903 .{ }^{2}$ In 1922 the number showed a reduction of some 250 , apparently as a result of a reduction in medical school capacity; and in 1923 the number was almost exactly the same as in 1922 . The current situation thus seems to be that the number of new matriculants is no longer determined by the entrance requirements but is limited by the capacity of the medical schools.

All this has been said largely by way of counterweight to the impression so widely current that it is the standard of medical school requirements which alone determines the number of students and the resulting number of physicians. There is no intention of implying that within limits the number of students is not largely in-

\footnotetext{
'Except for the year 1918, referred to below. The actual figures are: 1914, 3,373; r915, 3,582; and r918, 3,104.

2This statement is based on an estimate of the number of new matriculants in each year, computed from the number of graduates four years later. Exact data regarding new matriculants are not available for any year prior to 1911 .
} 
fluenced by the severity of the requirements, or of denying that at the present time a relaxation of the requirements (together with an enlargement of the capacity of the medical schools) would probably produce an increase in the number of matriculants.

How large that increase would be is wholly problematical. It is worth noting, however, that the proponents of a reduction in the entrance requirements-for it is against the entrance requirements rather than against the four-year course that the advocates of lower standards direct their attack-do not propose a level of entrance much below high school graduation. ${ }^{1}$ As against the present standard entrance requirement, which calls for two years of college work, their proposals would represent a saving of not much over two years. It would seem that the increase in the number of matriculants which this saving might produce would hardly be significant; for it would have to overtop an increase which even under present standards promises to be very rapid. The fact seems to be that the proponents of a reduction in medical school requirements (among whom are not a few physicians of the old school) while actually favoring only a relatively minor reduction in requirements, expect an enormous increase in the number of medical students, comparable to the tremendously swollen numbers of the '9o's.

In connection with the current and prospective increase in the number of medical students, attention should be called to the unprecedented increase, since the war, in the number of high school and college students the country over, an increase which has already excited wide-

IIn Kentucky and Missouri. 
spread interest and comment in other connections. It is manifest that, with this enormously increased high school and college student body, the number of potential medical students who are capable of satisfying the current entrance requirement is correspondingly increased; and indeed it is now quite plain that it is neither entrance nor graduation requirements, but rather the capacity of the medical schools that will be the measure of the number of medical students in the years just ahead.

Moreover, looking into the matter more concretely, a weighty additional reason appears for doubting whether the reduction in medical school standards which is urged in some quarters would produce an increase in the number of students. It is manifest that any action looking toward reduction can at this time be anticipated if at all in only a limited number of states. A student entering upon a course at the reduced requirements level would thus be deliberately barring himself from any possibility of practice in the majority of the states-and these the wealthiest and most highly developed. ${ }^{1}$ With the very general publicity which, thanks largely to the Council on Education of the American Medical Association, facts of this kind nowadays receive among prospective medical students, it is open to serious question whether the number of additional students who would be attracted by a reduction of requirements would be nearly as large as is assumed by those who advocate reduction. It is true that a few "outlaw" schools continue to maintain a student body of fair size despite the fact that their graduates are barred from practice in all but three or four

\footnotetext{
1The states retaining the present standards would of course be compelled in self-defense to deny license to physicians licensed in low-standard states.
} 
states; but these institutions are notoriously catch-alls for the rejects and misfits of the medical student body. It is doubtful whether letting down the bars to their graduates in a few additional states would mean a proportionate increase in their attendance.

So far, however, as a reduction in entrance or graduation requirements would actually produce an increase in the number of physicians, the extent to which an increase would result in taking up by physicians of rural locations now vacant is a very problematical matter. What the plan contemplates when reduced to its simplest terms is nothing more or less than that the supply of physicians should be increased to a point where competition in the towns will be so severe that a larger proportion of physicians than at present will be compelled to seek a living, however meager, in the country, and the resulting increased competition in the country will force physicians into locations now vacant, despite the unattractiveness and unprofitableness of those locations or will force additional physicians into locations now supporting only one or two physicians.

Merely to state the plan in these terms is sufficient to condemn it. The larger towns and cities are already super-saturated with physicians, engaged in an incessant and vigorous competition. The imagination shudders at the thought of intensifying this already far too keen struggle for clientèle by a wholesale production of additional physicians merely in the hope of forcing a few additional practitioners into the country. Beside this project, the historic expedient of burning down the house to roast the pig deserves to rank as an exalted type of wisdom.

But, in addition to its fundamental viciousness, the 
proposal has the equally serious defect that it will not work. No matter how severe the competition in the medical profession may become through increase of numbers, it will not compel a physician to live in a place where a living can not be made; and these we have seen are, in the main, places now seeking physicians. Increased competition indeed could only make the livelihood of a physician locating at most of these places even more meager and precarious than it would be today; for the increased pressure transmitted from the larger cities to the towns and so on down through the smaller places would compel the physicians surrounding these now vacant locations to encroach still further on any prospects of practice which a physician taking up one of them today might have.

It remains to consider whether, entirely aside from their effect on the number of physicians and hence on the state of economic pressure in the profession, the current standards of medical education are likely to result in a body of medical graduates unduly averse to the rural location-either through the type of matriculant initially selected, or through the character of the instruction and the environment of the medical course. That in both these respects the current régime of medical instruction is tending to produce a body of graduates unduly averse to rural practice is a view which finds widespread expression in medical circles.

CURRENT REQUIREMENTS AND THE POOR BOY

With reference to the effect of current requirements upon the initial selection of medical students, the statcment is commonly made that these requirements, by 
reason of the prolonged course of study they entail, have eliminated the poor boy ${ }^{1}$ and admittedly it was in former days chiefly students of small resources who, in immediate need of funds on graduation, were willing to accept the hardships and isolation of rural practice for the certainty of immediate returns.

Whether in point of fact the "poor boy" forms any smaller proportion of the medical student body of today than he formerly did is a question on which no reliable data have been, or indeed well could be, assembled. So far as the belief has foundation in actual observation of the medical student body over the past twenty or twentyfive years, it must be borne in mind that the general economic level has risen substantially in this period, carrying with it all classes, and, correspondingly, all classes of medical students.

If this factor be discounted and it still remains true that the general economic level of the student body is higher today than it was twenty-five years ago, it must be remembered that any reduction in medical school requirements which is at all conceivable today could hardly be expected to reduce to a significant extent the level of economic ability at which the medical course seems feasible. At most such a reduction would mean a saving of two years; the graduate would be ready for practice at twenty-two or twenty-three, instead of at twenty-five. It seems altogether likely that in the great majority of cases the student with purpose sufficiently serious to pursue his course despite financial hardships till the age

\footnotetext{
1An extreme form of this statement not infrequently encountered is that only "rich men" now send their sons to college. That this statement is devoid of truth is a matter of common knowledge among all who have first-hand contact with the medical student body of today.
} 
of twenty-two or twenty-three will find means of continuing it a couple of years longer. For the proportion of students at the absolute margin, to whom this difference is the difference between the possible and the impossible, the solution is manifestly to be sought in the development of scholarships or loan funds, rather than in a general reduction in medical school requirements.

It must be emphasized that there is no more certain way of enabling the poor boy to study medicine than by maintaining conditions in medical practice which will give the prospective student a fair assurance that he will become self-supporting within a reasonable time after graduation. Without that assurance a fairly wealthy youth may well shrink from the prospect; with it, even a young man of very slender means may find ways to finance his course, secure in the knowledge that he can, with reasonable promptness after graduation, begin to repay his obligations.

Hence it is that the provision, by any considerable numbers of rural communities, of the subsidy and auxiliary facilities outlined in the preceding chapter would in itself undoubtedly be a far greater encouragement to the poor boy contemplating the study of medicine than would be a reduction in the entrance or attendance requirements of medical schools.

It is worth noting further that the proponents of a reduction in standards almost without exception attack that particular part of the process of medical preparation which is least burdensome from the standpoint of cost. One hears indeed from time to time a defender of the old order in American medical education aver that the twoyear course which produced the old masters is good 
enough for him; but almost universally it is admitted that the four-year course is none too long, while the desirability of the intern year receives almost universal acceptance. What is almost invariably attacked by the proponents of lower standards is the entrance requirement of two years of college work.

In the long process of preparation which the prospective physician must face before he becomes self-supporting in the practice of his profession, the pre-medical years are precisely the least burdensome from the cost standpoint; for during those years not only are tuition fees low but there is considerable opportunity for part-time remunerative employment. It is the years at medical school, with their relatively high tuition fees and expenditures for books and accessories, and their almost complete absorption of the student's time, precluding outside employment except for the aptest of mind and strongest of physique, and the two or three or four years after graduation, when expense equals or exceeds the slowly growing income of the practitioner-it is the prospect of these years that gives the potential medical student pause. So relatively minor indeed are the burdens of the college course that large numbers of students annually complete not merely the first two years but the whole of the college course without having come to any definite decision as to what profession they will enter.

In this connection it is worth pointing out that the current requirements in medical education, while undoubtedly high, are not so much higher than the requirements in other fields as might be thought. The medical requirement entails six years of study after graduation from high school, and an additional year of internship, 
in which the graduate at least earns his keep. If the internship year be for the moment disregarded, we have a requirement of six years after high school, as compared with four years for the engineering degree. Moreover, there are annually tens of thousands of young men and young women who spend four years after high school merely obtaining a bachelor's degree. By comparison with that degree, an additional two years for the medical degree hardly seems excessive.

Finally it should be noted that the student of respectable means may on graduation be as much interested in an immediate livelihood as his less prosperous prototype of a generation ago. Even though he may have entered upon his medical course with much larger capital or more secure backing than did the student of an earlier day, his course has lasted so much longer and has been so much more costly that at its termination he is likely to be even more eager for the immediate return than was the other; and those who have had a first-hand contact with medical students extending over many years unite in the belief that to the typical graduate of today the chance for an immediate livelihood makes fully as strong an appeal as it did to the younger and less thoroughly trained graduate of a generation ago. Statements received by us from over two thousand representative graduates of 1916-20 (about one-seventh of all the graduates of those years) demonstrate that for all but a very small proportion of these graduates the desire for immediate income was a primary factor in determining their initial choice of a location or a position. The recent graduate's avoidance of the rural location, therefore, must be ascribed largely to the lessened opportunities for making a livelihood 
there as contrasted with the opportunities found in towns and cities.

Closely related to the question of the poor boy, yet presenting distinct aspects of its own, is the case of the country boy and his alleged more or less complete elimination from the medical student-body by the developments of the past two decades. Here, as in the case of the poor boy, there are available no statistics bearing on the proportion of country boys in the medical student-body nor has it been found practicable to develop any. The general impression prevails, however, among country practitioners that the country districts send far fewer students to medical schools than formerly. The chief reason assigned is that changes in medical education have borne more heavily on the country boy than on the city boy; for the country boy must usually leave home even to attend high school, and the expenses of living and of tuition are higher by comparison with rural than they are by comparison with urban standards of expenditure and are correspondingly harder to meet.

These considerations seem plausible enough, though they do not suggest that here, any more than in the case of the poor city boy, a reduction of two years in entrance requirements would greatly ameliorate matters. We venture to think, moreover, that we have here several factors other than the relatively greater poverty of the country boy.

The extent to which intending medical students, whether in the city or the country, have contact with physicians, has already been adverted to. As a result the economic conditions obtaining in any given part of the medical world are sooner or later reflected in the 
number of entrants to medical schools from that part. While, therefore, no proof is adducible, it is not unreasonable to assume that the low estate to which the rural practitioner has fallen in recent years, and the declining number of such practitioners, has had a discouraging effect on the potential medical students of the rural areas. So far, moreover, as the students might come from the immediate families of rural practitioners, this factor would have a more direct effect in actually making it more difficult for the rural practitioner to afford the cost of a medical education for his son or relative.

The drastic reduction in the number of medical schools, above referred to, with the presumable result of making medical schools less accessible than formerly to certain areas, has also been charged with a measure of responsibility for the diminished attendance of the country boy. In but few instances, however, were the schools abolished so located as to be more convenient to any considerable rural area than are the schools of today. Of the one hundred medical schools open in 1905 and now extinct, no less than seventy-seven were located in the larger centers which still have one or more medical schoolsAtlanta, Baltimore, Chicago, Cincinnati, Cleveland, Columbus, Dallas, Denver, Detroit, Indianapolis, Kansas City, Los Angeles, Louisville, Memphis, Milwaukee, Minneapolis, Nashville, New Orleans, New York, Oklahoma City, Omaha, Philadelphia, Pittsburg, Richmond, St. Louis, and San Francisco. Of the twenty cities which had a school in $1905^{1}$ and now have none, but few are

\footnotetext{
1Birmingham, Mobile, Alabama; Oakland, California; Des Moines, Keokuk. Sioux City, Iowa; Grand Rapids, Michigan; Meridian, Mississippi; Lincoln, St. Joseph, Mussouri; Charlotte, Raleigh, North Carolina; Toledo, Ohio; Salem, Oregon; Chattanooga, Knoxville, Sewanee, Tennessee; Fort Worth and Texarkana, Texas.
} 
located at any considerable distance from a city which has a medical school. So that mere physical accessibility to a medical school has probably been of small account in reducing the number of country boys who take up medicine. Indeed the reduction in the number of cities having medical schools probably has, if anything, worked in the contrary direction; for in every such city there is always a limited number of medical students resident in that city who, were.they compelled to live.away from home while studying medicine, would find the.burden too great.

Nor do the facts lend much apparent, support to the assertion, frequently encountered, that modern medical education spoils the country boy for rural practice in a way that the medical course of a generation ago did not, by accustoming him to the conveniences and diversions of urban existence. Implicit in this allegation is often found the belief that the older medical schools, which have. passed away, were located in small. towns, so close to the great open. spaces that the student from the farm would hardly forget. that God made the country but the devil.made the town; while.the.school of today, to which the country boy must repair, is located in the great city. The fact is that far the greater number of the "diploma mills" of the last generation, and particularly those which attained the greatest size, were located in the large centers-often in the largest, as in New York, Chicago, Baltimore and St. Louis. The total contribution to the roll of physicians made.by the schools, usually short-lived, which were established in the smaller towns is negligible by comparison. ${ }^{1}$

\footnotetext{
1Exceptions were the schools at Portland, Maine (Bowdoin) and at Hanover, New Hampshire (Dartmouth) which were during their life an important source of supply of physicians to New England, though the number needed and produced was never large.
} 
Nor would it seem that the fact that the medical course now necessitates the country boy's absence from home in the large city for six years instead of four would be likely to be a decisive factor in increasing his distaste for rural life. Four years of city life surely was enough to give the medical student from the country (who had often enough, of course, despite the lax admission requirements, previously passed through a high school course in a fair-sized town) a sufficiently accurate notion of the relative attractions of city and country to neutralize any purely sentimental attachment to bucolic ideals.

All the foregoing has been said without the intention of judging the inherent soundness of the present standards of entrance to and graduation from medical school. The purpose has been solely to consider whether the need of a future supply of practitioners for the rural areas warrants the relaxation of those standards. Into the educational question as such it is not the province of this report to enter.

THE CURRENT MEDICAL COURSE AS A PREPARATION FOR RURAL PRACTICE

Quite aside from the increase in the length of the medical course, it is at times urged that the content and method of instruction are responsible for the apparent aversion of the recent graduate to rural practice. The medical course as at present conducted-so it is alleged -emphasizes the importance of the more recently developed instruments of precision and laboratory technique, and of highly specialized skill, till the student feels lost when out of reach of the facilities of the school. Hence the graduate tends to avoid the rural location, 
which demands from him the very type of service and skill which his medical course had done least to develop.

The authors of this report are not in position to express an opinion on the validity of these contentions; but it is clear that if they prove to any degree valid, the remedy would lie in a change in medical teaching, and not in a reduction of the length of the medical course. ${ }^{1}$ Indeed, the opinion has been expressed to us by some members of the rural profession themselves, that the greater responsibilities necessarily assumed by the rural physician, due to the inaccessibility of hospitals and specialists, render even the present extended medical course inadequate for the proper training of a rural practitioner.

Moreover, there is no inherent validity in the view, implicit in most of these discussions, that the proportion of recent graduates settling in the rural locations is lower than the rural population has a right to expect. As pointed out in a preceding chapter, ${ }^{2}$ it is impossible to define any standard by which the adequacy of the proportion of recent graduates settling in rural areas may be measured. The standard of comparison used in that chapter-the proportion of all other physicians located in those areas -is one of convenience solely, used only for lack of anything better. Had the balance

\footnotetext{
IIf the tendency of recent graduates to avoid rural locations is due in whole or in part to the more recently developed characteristics of medical teaching, and to the contemporaneous elevation of standards, it might be expected that this tendency would show a progressive increase among the successive classes. With a view to ascertaining whether such an increase was actually shown, the proportion of the graduates of 1916-20 located in 1923 in places of less than 1,000 inhabitants was computed separately for the graduates of each of those five years. The results (given in the Appendix, p. 177) fail to disclose any clearly discernible tendency.
}

${ }^{2}$ See p. 59. 
between the urban and rural areas in respect to medical service been in a state of stable equilibrium during recent years, it might indeed have reasonably been expected that the graduates of these years should be found in the rural areas in at least as high a proportion as the remainder of the profession. Instead of stable equilibrium, however, there has been a wholesale and unremitting desertion of the countryside by physicians long established there. Manifestly, it was not to be expected that the graduate seeking his first location would look with as much favor as formerly upon a field which was so plainly on the decline. In every profession and business the newcomers are found chiefly, if not exclusively, in those branches and locations which hold promise for the future.

Finally, in charging the tendency to specialization with so large a share of the responsibility for the avoidance of the rural location by the recent graduate, there is usually implicit a misconception of the facts. Some of the assertions made in this connection would indeed appear to assume that the graduates of today no longer take any interest in general medicine, but that they usually enter on the practice of specialties immediately on graduation. ${ }^{1}$ How wide of the mark is such a notion may be seen in the figures of distribution of the graduates of 1916-20, no less than i8 per cent. of whom are found today in towns of less than 2,500 inhabitants, in which the practice of specialties is a rarity. Moreover, among specialists as a whole, in all the states selected for

\footnotetext{
1 Of course even to the extent that this is true, the explanation is rather to be found in the great demand for specialist service on the part of the public than in the influence of medical teaching.
} 
detailed study, the graduates of 1916-20 are found today in substantially fewer numbers, relatively, than are the older physicians, and in very much smaller numbers than are the graduates of I9II-I 5 and even those of I906-Io, ${ }^{1}$ which last may be regarded, with relatively few exceptions, as the product of the older order of medical education.

It is true that the graduates of those institutions which usually come to mind as the exemplars of the new order in medical education-Harvard, Johns Hopkins and Columbia, for example-are not found in the rural areas in equal proportions with those of schools less prominent, ${ }^{2}$ but the explanation for this is manifestly to be found in part in the character of the territory in which these schools are located-for despite their national fame their constituency is largely local-and in part in the fact that by virtue of their pre-eminence they attract a disproportionately large number of students who (often amply equipped with funds) have long aforetime fixed their eyes upon a career in research or in a specialty. Moreover, it must always be remembered that whether by express requirements - as in the case of Harvard, Cornell, Hopkins, Rush and others - or by means of selection from a great excess of applicants, or by both, these leading institutions in effect impose a standard of entrance requirement substantially higher than the standard fixed by the Council on Education of the American Medical Association or by the state licensing boards; and the required standard of performance in the course itself is substantially higher than in most schools. For all these

1For figures see Appendix, p. 195.

${ }^{2}$ For figures see Appendix, pp. 178-181. 
reasons the distribution of the graduates of these schools furnishes no valid basis for appraising the compatability of current standards of medical education with the willingness to do rural practice. ${ }^{1}$

In summary, to one taking a broad view of all factors, it seems reasonably clear that neither changes in the medical school constituency, nor changes in the mental attitude of the graduate induced by the current methods of instruction, have been more than a secondary influence in leading recent graduates to avoid rural locations, and that the primary factors have been substantially the same as in the case of the practitioners of longer standing - the increasingly superior financial, social and professional advantages of the larger places: factors which have appealed with equal force to all types of practitioners, including those who received their medical education under a régime far removed from that of today. ${ }^{2}$

It remains to notice the proposal which has been put forward from time to time in recent years that an attempt be made to educate a special class of medical practitioners of lower attainments than the rest of the profession, and

\footnotetext{
1The relations of the several medical schools to the diverse territories served by them, and the possession by many schools of a special constituency based largely on tradition and sentiment, together with the other factors affecting selection of student-body above referred to, render it virtually impossible to draw any valid conclusions, from figures showing distribution of graduates, as to the effect of one or another type of medical instruction or school organization or location in inclining its graduates to settle in the rural areas. Special studies made in this connection for earlier periods, when schools were, more numerous and divergencies of standard greater, fail, however, to support the general belief that the inferior schools always produce relatively a greater proportion of rural physicians than the better schools. These studies (for the states of North Carolina, Kentucky, Alabama, Missouri and Iowa) are on file and may be examined.

2That the medical graduate of today has no inherent aversion to practice under adverse social and professional conditions, provided a proper income is assured, is evidenced by the lack of difficulty experienced by lumber, mining and construction enterprises in recruiting camp physicians from among the more recent graduates.
} 
that these be limited in practice to specified rural areas. ${ }^{1}$ In this way it is hoped that the particular need for medical service would be met in the backward rural districts without lowering the standards for the profession as a whole. This suggestion usually runs on the premise, expressed or implied, that to the medical graduate of today the investment represented by the time and money expended in his education is so large that he cannot possibly secure an adequate return on it in rural practice and will not therefore take up a rural location. This implies that the medical graduate has computed the actual amount of his investment, has determined upon the minimum income which would represent an adequate return thereon, and has resolved to consider no location which does not hold assurance of a definite income. Manifestly nothing could be further from the realities of the case. Medical graduates, like other men, when confronted with the necessity of making a living, as a rule take the best thing they can get, wholly regardless of its relation to a theoretically just return. Were it not so, they would decline also to take up the average town location, and would promptly give up the practice of medicine. For if the investment in a medical education be computed on a theoretical basis, and a scale of interest and amortization payments extending over even twenty-five years of practice be projected, the annual requirement for this purpose, when added to current requirements, would be

\footnotetext{
1In North Carolina the State Board of Medical Examiners has granted a few licenses limited to various specified remote rural areas; but the licensees were men who had either been suffered for some time previously to practise without license or had for some reason failed to meet the requirements for regular license. In neither case, therefore, do they fall within the terms of the proposal under discussion.
} 
so large as to be well beyond the prospects of the average beginner in town or city practice for from five to ten years.

In only one instance that has come to our attention has the proposal for a sub-standard class of practitioners for the rural areas been formulated in concrete terms. As a counter-proposal to the effort made in Kentucky in I 922 to reduce the medical school entrance requirements, the state health department proposed that students who had completed three years of the regular medical course might be licensed to practise in specified rural districts under the supervision of the state health department. To one familiar with the way in which the subject-matter of the medical curriculum is commonly apportioned over the four-year course, the suggestion that the first three years can be regarded for any purpose as a complete course, qualifying the student to assume responsibility for healing the sick, is rather startling; and its inconsistency was doubtless fully appreciated by its proponents. That they were apparently unable to suggest any other practicable method is indicative of the extreme difficulty involved in setting up a special course for the proposed group of limited practitioners. Even were such a course established, the difficulty of drawing students who would know in advance that their field was limited to the most unattractive and unremunerative locations-so unattractive and so unremunerative indeed that no regularly trained physician can be induced to consider themwould seem insuperable. Nor is there any reason to believe that the rural population, except in the most remote and poverty-stricken areas, would take kindly to the idea of entrusting their lives to the ministrations of 
one without sufficient training to be permitted to practise in the towns. Finally, in so far as the places needing physicians do not offer a reasonable assurance of a living income, it is difficult to understand on what theory it is assumed that even a physician of sub-standard training will be content to locate in them or will remain in them when once located. In short, from whatever aspect approached, the suggestion of an inferior class of practitioners for the rural areas seems quite impracticable.

If the conclusions reached in the present chapter are sound, no reduction of medical school requirements, either for entrance or graduation, that is at all within the realm of possibility, would be likely to have a significant effect upon the future supply of physicians to the rural areas; and the creation of a sub-standard class of physicians for those areas is quite impracticable. Whatever may be thought, therefore, of the necessity for taking measures to meet the problem of rural medical service, it seems clear that the situation does not call for any present action in the field of medical education in the direction of a reduction in requirements or a lowering of standards. 
STATISTICAL APPENDIX 



\section{STATISTICAL APPENDIX}

I. The Country as A Whole. . . . . I57

II. Selected States or Portions of States. 185 
Unless otherwise indicated, the figures given were obtained by a name-by-name count and classification of the list of physicians appearing in the American Medical Directory of the year indicated, such list containing in each case the school and year of graduation of each physician listed, as well as his name and address. 


\section{THE COUNTRY AS A WHOLE}

\section{List of TABLES AND Chakts ${ }^{1}$}

TABLE FIG. PAGE

I. Number of Physicians, Graduates and StuDENTS.

I. Number of physicians and population per physician.

I. 1850-r920 (U. S. Census)

2. I906, I909, I912, I916, I921, 1923 (American Medical Directory)

2. Medical graduates and deaths of physicians, 1906-25.

3. Medical schools, attendance, graduates and residence of students, by sections, rgo0-25.

4. Population, physicians and medical students, 1880-1925; showing also new matriculants since IgI 2 (Graph)

2. Distribution of Population

I. Counties decreasing in population, rgro to r920 (Map)

2. Population in and about places having physicians: 1906 and 1923

3. Distribution of Physicians

I. Physicians in places of various sizes: 1906 and 1923

'For compactness and convenience of reference condensed titles are given for certain of the tables in lieu of the complete and explicit titles appearing at the head of the tables themselves. 
2. Population per physician in and about places of various sizes: 1906 and 1923

I. Absolute

2. Relative to population per physician in and about places of less than $I, \infty 00$ inhabitants

4. Distribution of Recent Graduates

r. Proportion of all physicians and of recent graduates in places of various sizes: r906 and r923

I. Absolute

2. Comparative

Io

2. Difference between actual and proportion ate number of graduates of $1916-20$ in places of less than 1,000 inhabitants, r923

3. Proportion of graduates of 1917,1918 , r9r9 and 1920 in places of various sizes compared with the proportion of graduates of r 9 r6 in such places: 1923

4. Graduates (of rgr6-20) of the several medical schools in places of various sizes: 1923

5. Places Having Physicians

I. Number of places of various sizes: 1906 and 1923

2. Average distance between places: 1906 and 1923 


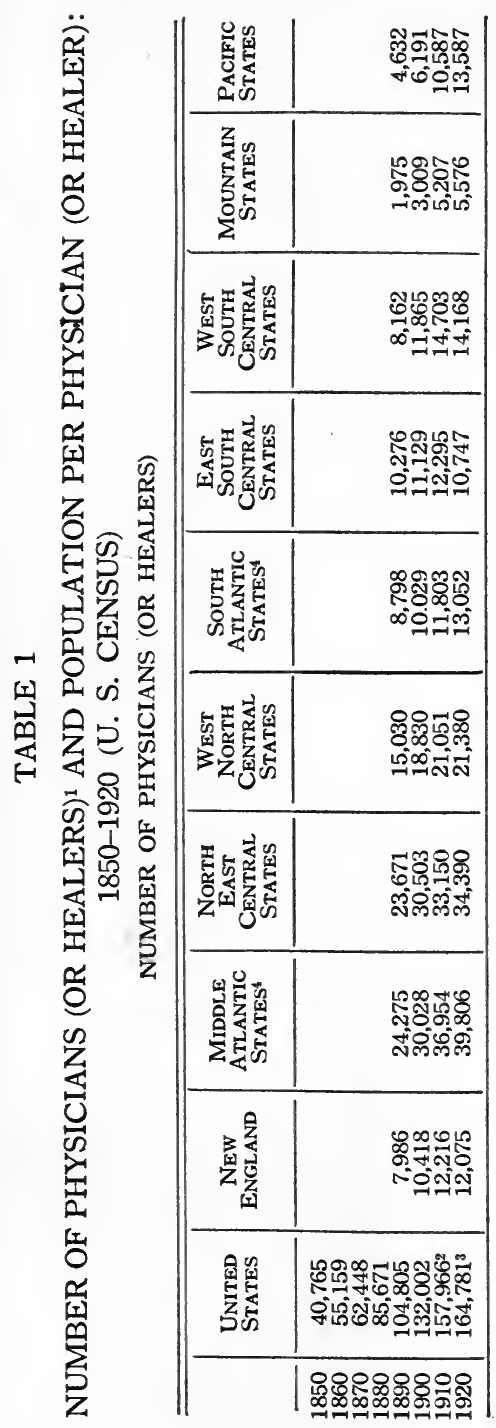

\begin{tabular}{|c|c|}
\hline 造罢 & 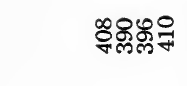 \\
\hline 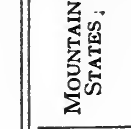 & 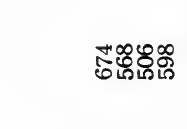 \\
\hline 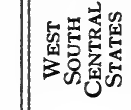 & 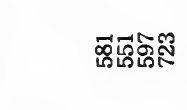 \\
\hline 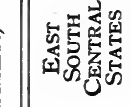 & : \\
\hline | & 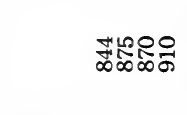 \\
\hline | & 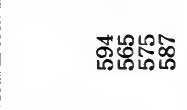 \\
\hline 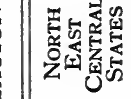 & 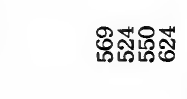 \\
\hline 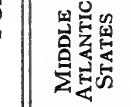 & ณำำกี \\
\hline 美量 & : \\
\hline 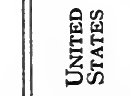 & 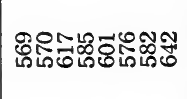 \\
\hline & 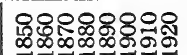 \\
\hline
\end{tabular}

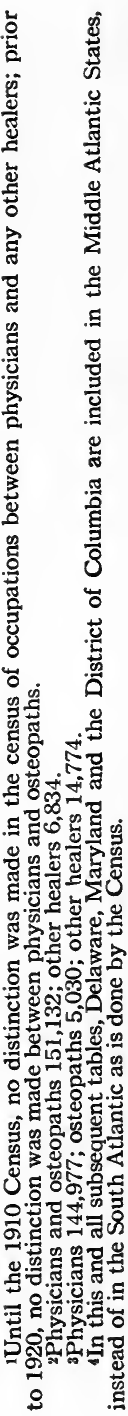




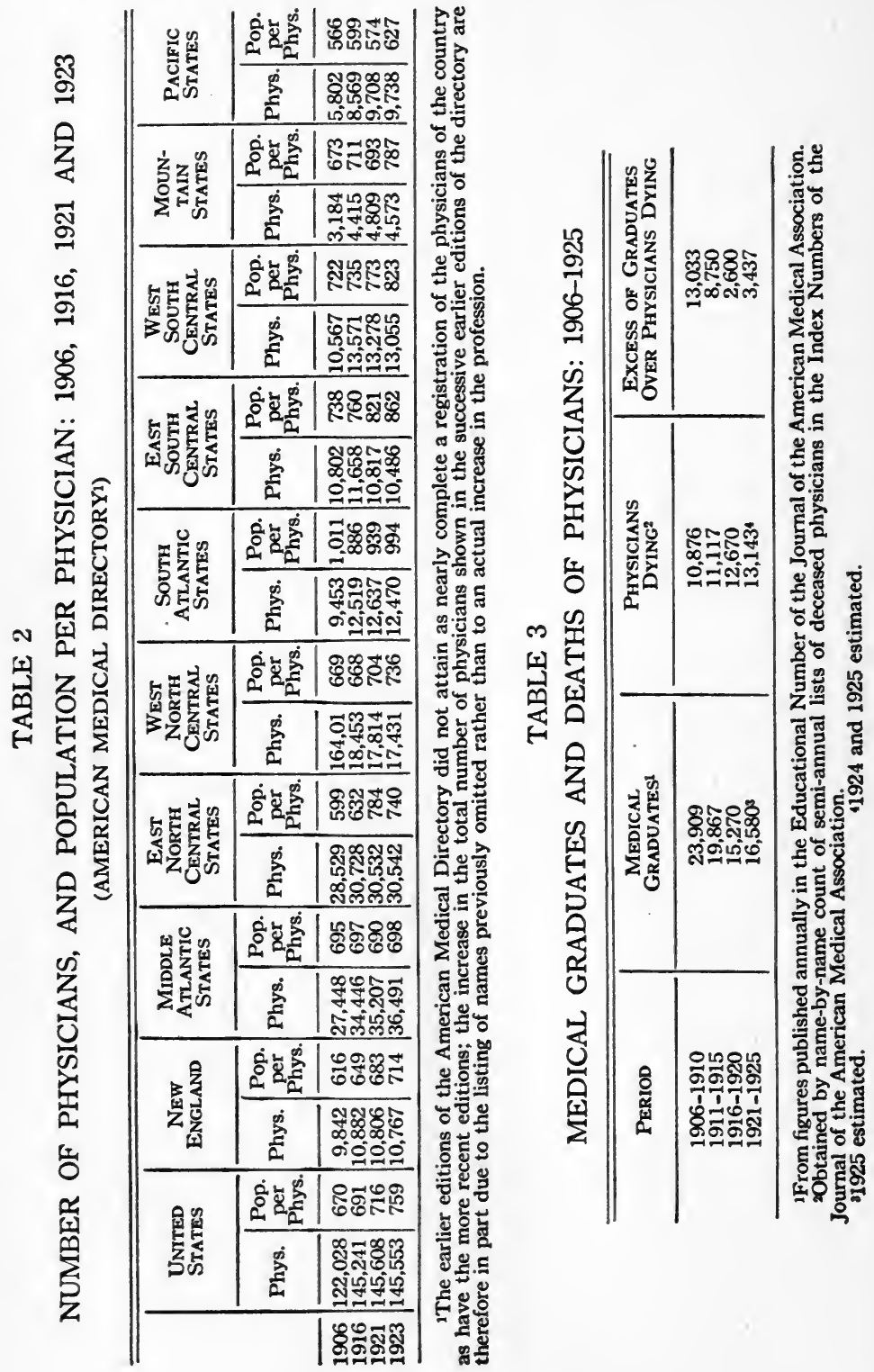


APPENDIX

\begin{tabular}{|c|c|c|c|c|c|}
\hline \multirow{11}{*}{ 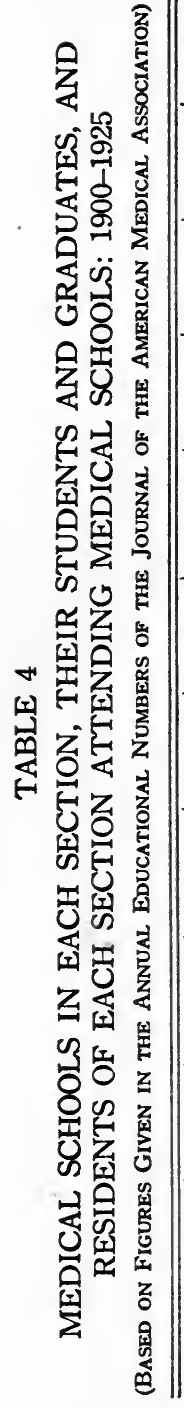 } & 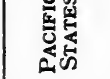 & 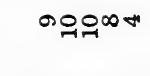 & 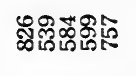 & 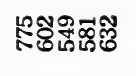 & స్తిరి: \\
\hline & 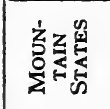 & mరాNNN & 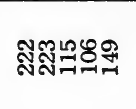 & : & 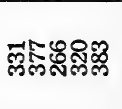 \\
\hline & 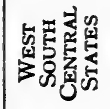 & $\theta=\pi$ an & 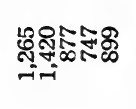 & 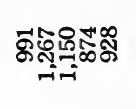 & 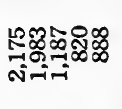 \\
\hline & 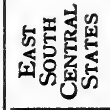 & 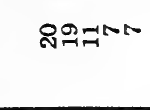 & 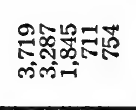 & 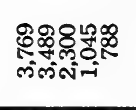 & 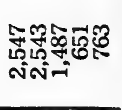 \\
\hline & 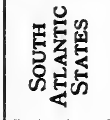 & $\exists \pm \pm \infty \infty \infty$ & 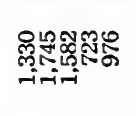 & 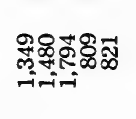 & 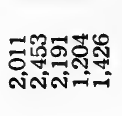 \\
\hline & 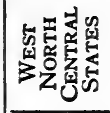 & ละลュュッ & 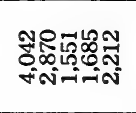 & 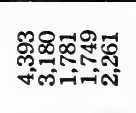 & 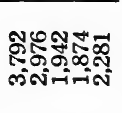 \\
\hline & 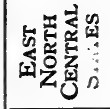 & หణ్లสసก & 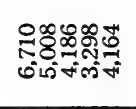 & 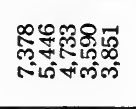 & 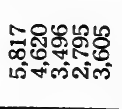 \\
\hline & 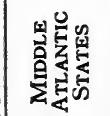 & ลิลిลสกา & 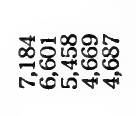 & 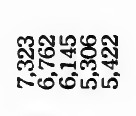 & 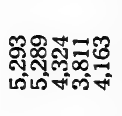 \\
\hline & 美昜 & $\infty \infty \infty \infty \infty \infty$ & 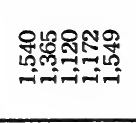 & 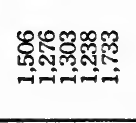 & 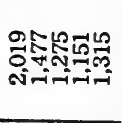 \\
\hline & 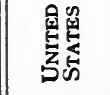 & 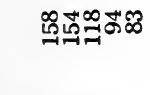 & 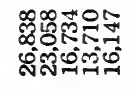 & 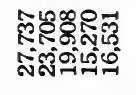 & 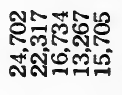 \\
\hline & & 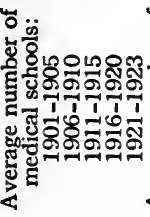 & nonom & 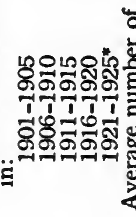 & 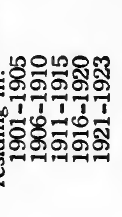 \\
\hline
\end{tabular}



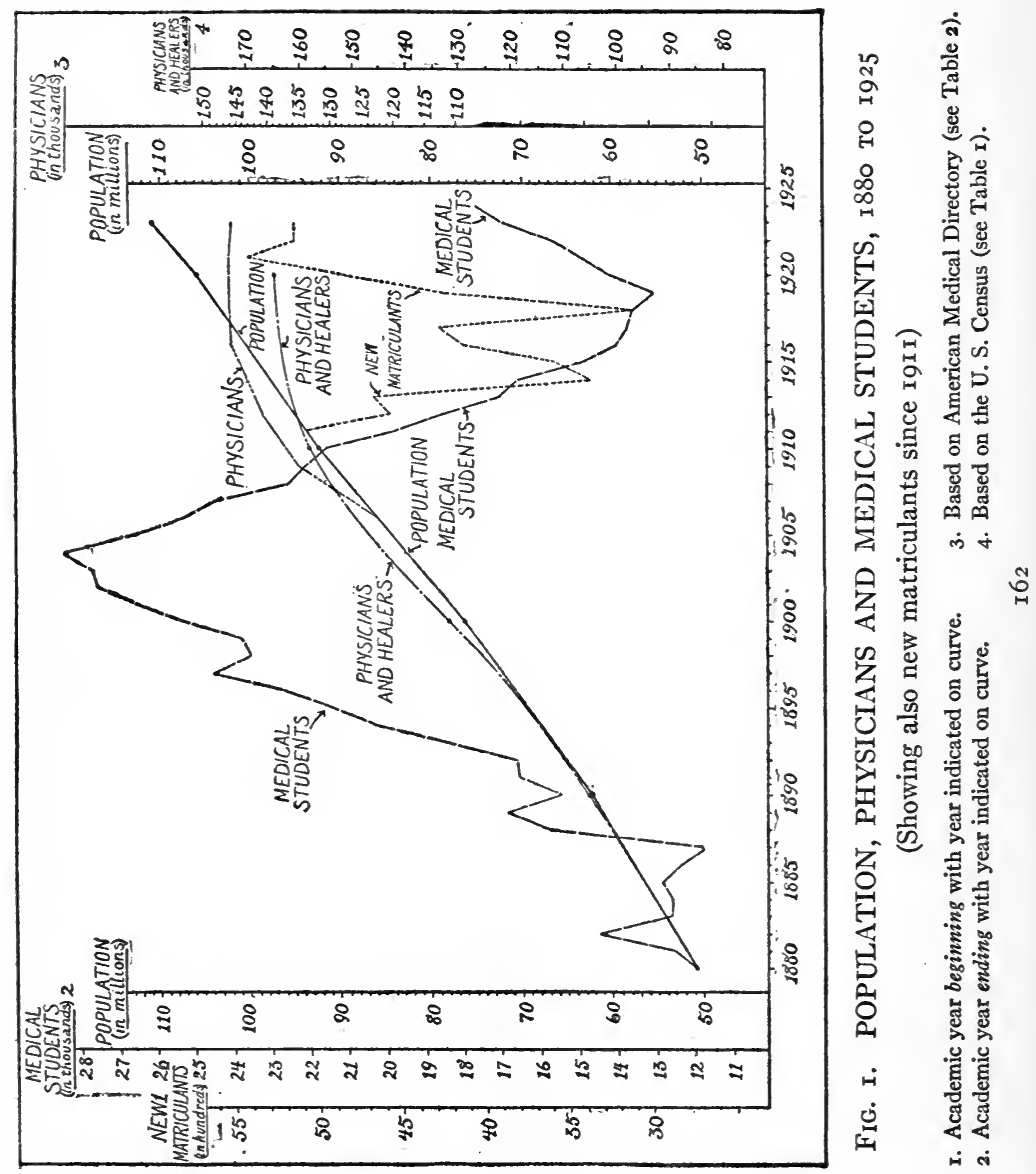


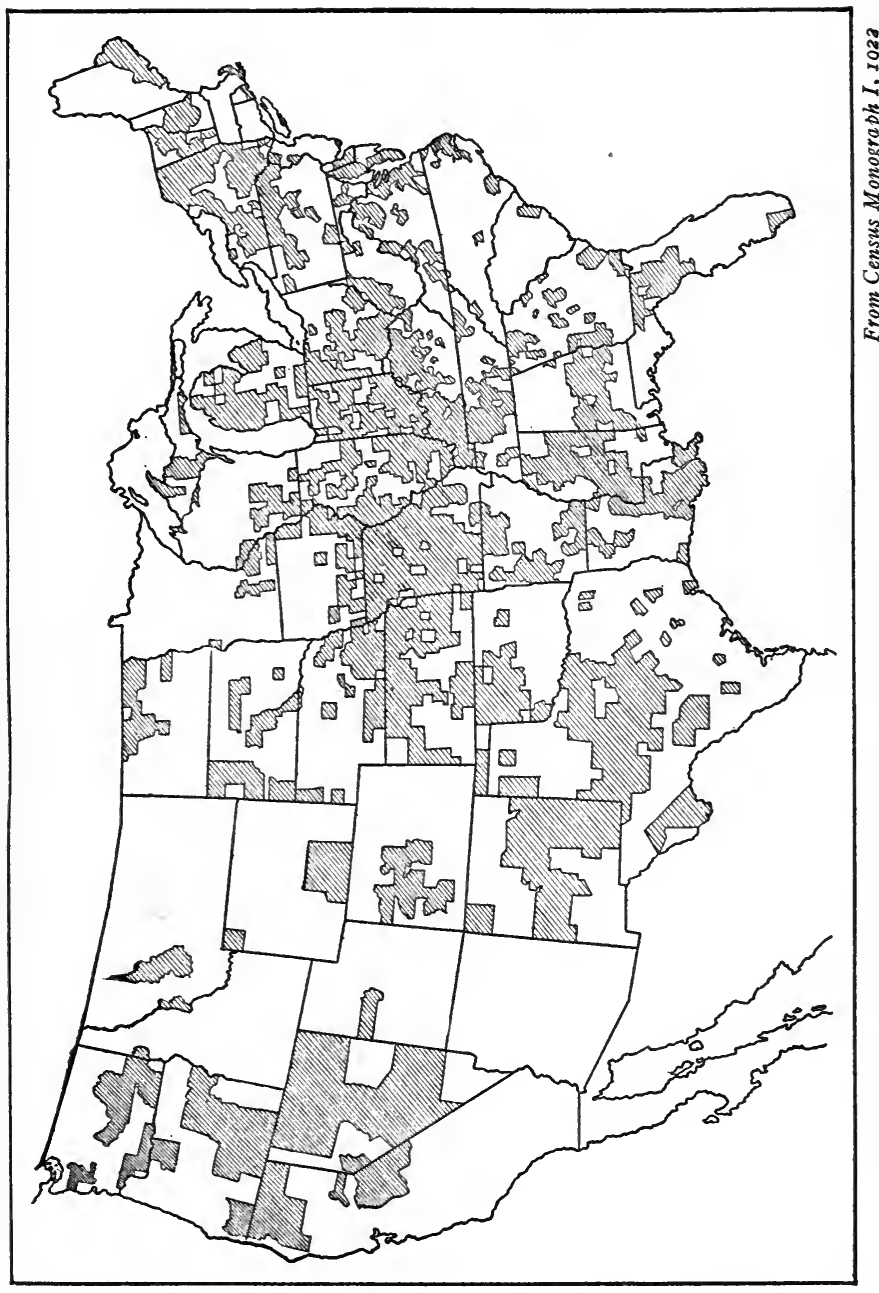

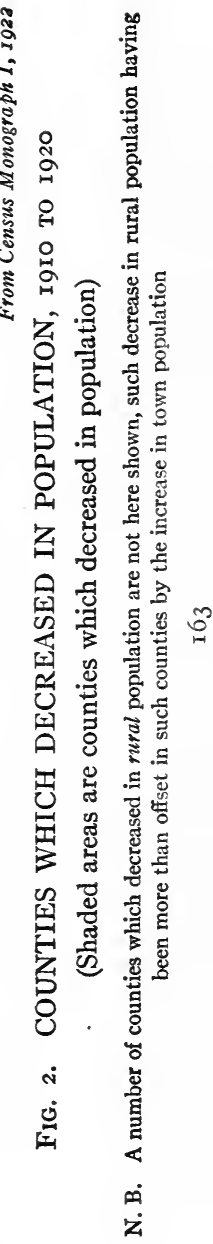


TAB

PER CENT. OF POPULATION LIVING IN AND ABOUT THE

\begin{tabular}{|c|c|c|c|c|c|c|c|c|c|c|}
\hline \multirow{2}{*}{$\begin{array}{l}\text { Places having } \\
\text { (in } 1906 \text { and } \\
1923 \text { respec- } \\
\text { tively) one or } \\
\text { more physi- } \\
\text { ciansand hav- } \\
\text { ing (in } 1910 \\
\text { and } 1920 \text { re- } \\
\text { spectively) a } \\
\text { population of: }\end{array}$} & \multicolumn{2}{|c|}{$\begin{array}{l}\text { UNITED } \\
\text { STATES }\end{array}$} & \multicolumn{2}{|c|}{$\begin{array}{l}\text { NEW } \\
\text { ENGLAND1 }\end{array}$} & \multicolumn{2}{|c|}{$\begin{array}{l}\text { U. S. } \\
\text { EXCLUDING } \\
\text { NEW } \\
\text { ENGLAND }\end{array}$} & \multicolumn{2}{|c|}{$\begin{array}{l}\text { MIDDLE } \\
\text { ATLANTIC } \\
\text { STATES }\end{array}$} & \multicolumn{2}{|c|}{$\begin{array}{c}\text { EAst } \\
\text { NoRTH } \\
\text { CENTRAL } \\
\text { States }\end{array}$} \\
\hline & 1906 & 1923 & 1906 & 1923 & 1906 & 1923 & 1906 & 1923 & 1906 & 1923 \\
\hline $\begin{array}{l}\text { Less than } 1,000 \\
1,000-2,500 \\
2,500-5,000 \\
5,000-10,000 \\
10,000-25,000 \\
25,000-50,000 \\
50,000-100,000 \\
\text { Over } 100,000\end{array}$ & $\begin{array}{r}4.5 \\
4.4 \\
22.0\end{array}$ & $\begin{array}{r}5.2 \\
5.3 \\
26.9\end{array}$ & $\begin{array}{l}11.4 \\
13.5 \\
24.4\end{array}$ & $\begin{array}{l}12.7 \\
11.6 \\
30.3\end{array}$ & $\begin{array}{r}43.6 \\
9.9 \\
6.0 \\
5.3 \\
5.9 \\
3.9 \\
3.6 \\
21.8\end{array}$ & $\begin{array}{r}32.5 \\
11.2 \\
6.7 \\
5.7 \\
7.8 \\
4.6 \\
4.9 \\
26.6\end{array}$ & $\begin{array}{r}20.1 \\
7.3 \\
5.3 \\
5.0 \\
6.9 \\
4.1 \\
5.6 \\
45.7\end{array}$ & $\begin{array}{r}16.0 \\
6.0 \\
5.3 \\
5.2 \\
7.3 \\
4.1 \\
6.1 \\
50.0\end{array}$ & $\begin{array}{r}36.7 \\
10.1 \\
6.1 \\
6.8 \\
7.8 \\
4.7 \\
3.4 \\
24.4\end{array}$ & $\begin{array}{r}20.3 \\
9.3 \\
5.6 \\
6.5 \\
12.5 \\
8.4 \\
5.2 \\
32.2\end{array}$ \\
\hline TotAL & 100.0 & 100.0 & 100.0 & 100.0 & 100.0 & 100.0 & 100.0 & 100.0 & 100.0 & 100.0 \\
\hline
\end{tabular}

\section{NOTE ON METHOD OF DERIVING THE ABOVE FIGURES}

The figure for population in and about each class of towns was obtained as follows:

1. The population of the United States was estimated for 1906 and 1923 (the census estimate being used for 1923).

2. The number of persons living in each class of towns was estimated for 1906 and 1923: a. For towns of over 10,000 inhabitants, for 1906, the actual population in 1900 was increased by .4887 of the increase between 1900 and 1910; for 1923 the census estimates of population as of July 1,1923 , were used. b. For the towns of 2,500 to 10,000 , the actual population in 1900 and 1920 was increased by the appropriate proportion of the increase between 1900-10 and 1910-20 respectively. c. For towns having 1,000-2,500 and less than 1,000, an arbitrary figure was necessarily assumed (most of these towns being unincorporated and therefore not separately enumerated by the census). Towns having 1,000 2,500 and estimated to have an average population of 1,500 at the census year were assigned

1For reasons for merging, in New England, the figures for all places of less than 25,000 inhabitants (in some of the following tables for all places of less than 10,000 inhabitants) see page 41 . 
LE 5

PLACES OF VARIOUS SIZES HAVING PHYSICIANS: 1906 AND 1923

\begin{tabular}{|c|c|c|c|c|c|c|c|c|c|c|c|}
\hline \multicolumn{2}{|c|}{$\begin{array}{c}\text { WEST } \\
\text { NoRTH } \\
\text { CENTRAL } \\
\text { STATES }\end{array}$} & \multicolumn{2}{|c|}{$\begin{array}{l}\text { SoUTH } \\
\text { ATLANTIC } \\
\text { StATES }\end{array}$} & \multicolumn{2}{|c|}{$\begin{array}{c}\text { EAST } \\
\text { SOUTH } \\
\text { CENTRAL } \\
\text { STATES }\end{array}$} & \multicolumn{2}{|c|}{$\begin{array}{c}\text { WEST } \\
\text { SOUTH } \\
\text { CENTRAL } \\
\text { STATES }\end{array}$} & \multicolumn{2}{|c|}{$\begin{array}{l}\text { Mountain } \\
\text { States }\end{array}$} & \multicolumn{2}{|c|}{$\begin{array}{l}\text { Pacific } \\
\text { States }\end{array}$} \\
\hline 1906 & 1923 & 1906 & 1923 & 1906 & 1923 & 1906 & 1923 & 1906 & 1923 & 1906 & 1923 \\
\hline $\begin{array}{r}52.0 \\
12.8 \\
6.5 \\
5.1 \\
4.2 \\
3.6 \\
3.1 \\
12.7\end{array}$ & $\begin{array}{r}41.4 \\
15.3 \\
7.3 \\
5.4 \\
6.5 \\
2.2 \\
4.1 \\
17.8\end{array}$ & $\begin{array}{r}67.6 \\
10.8 \\
5.0 \\
4.4 \\
4.0 \\
3.5 \\
2.2 \\
2.5\end{array}$ & $\begin{array}{r}55.2 \\
13.6 \\
6.5 \\
4.9 \\
5.4 \\
4.3 \\
5.5 \\
4.6\end{array}$ & $\begin{array}{r}72.0 \\
7.9 \\
4.0 \\
3.3 \\
2.8 \\
2.2 \\
1.2 \\
6.6\end{array}$ & $\begin{array}{r}61.0 \\
11.2 \\
6.4 \\
3.8 \\
4.8 \\
1.4 \\
3.1 \\
8.3\end{array}$ & $\begin{array}{r}64.0 \\
10.7 \\
6.6 \\
3.1 \\
4.4 \\
2.7 \\
4.4 \\
4.1\end{array}$ & $\begin{array}{r}49.2 \\
14.6 \\
8.2 \\
5.3 \\
5.9 \\
3.3 \\
3.5 \\
10.0\end{array}$ & $\begin{array}{r}43.1 \\
12.9 \\
11.2 \\
8.6 \\
6.6 \\
5.7 \\
3.6 \\
8.3\end{array}$ & $\begin{array}{r}37.9 \\
19.9 \\
9.7 \\
8.1 \\
7.8 \\
5.5 \\
11.1\end{array}$ & $\begin{array}{r}28.7 \\
12.4 \\
8.1 \\
3.8 \\
7.7 \\
4.4 \\
1.9 \\
33.0\end{array}$ & $\begin{array}{r}22.9 \\
9.5 \\
8.1 \\
6.1 \\
6.4 \\
4.8 \\
6.6 \\
35.6\end{array}$ \\
\hline 100.0 & 100.0 & 100.0 & 100.0 & 100.0 & 100.0 & 100.0 & 100.0 & 100.0 & 100.0 & 100.0 & 100.0 \\
\hline
\end{tabular}

a population of 1,250 and 1,750 in 1906 and 1923 respectively. Towns having a population of less than 1,000 and estimated to have an average population of 200 at the census year were assigned a population of 150 and 250 in 1906 and 1923 respectively.

3. The difference between the total population and the population living within the towns having physicians was divided by the number of places having physicians, and the quotient was regarded as the average number of persons round about, but not within, each place having a physician. (It was deemed impracticable and unnecessary, after much experimentation, to weigh or qualify this average to obtain a varying figure for each class of towns.)

4. The average number of persons round about each place having a physician, as thus obtained, was multiplied by the number of places of each class, and the resultant product added to the estimated number of persons within those places to obtain the total number in and about those places. 


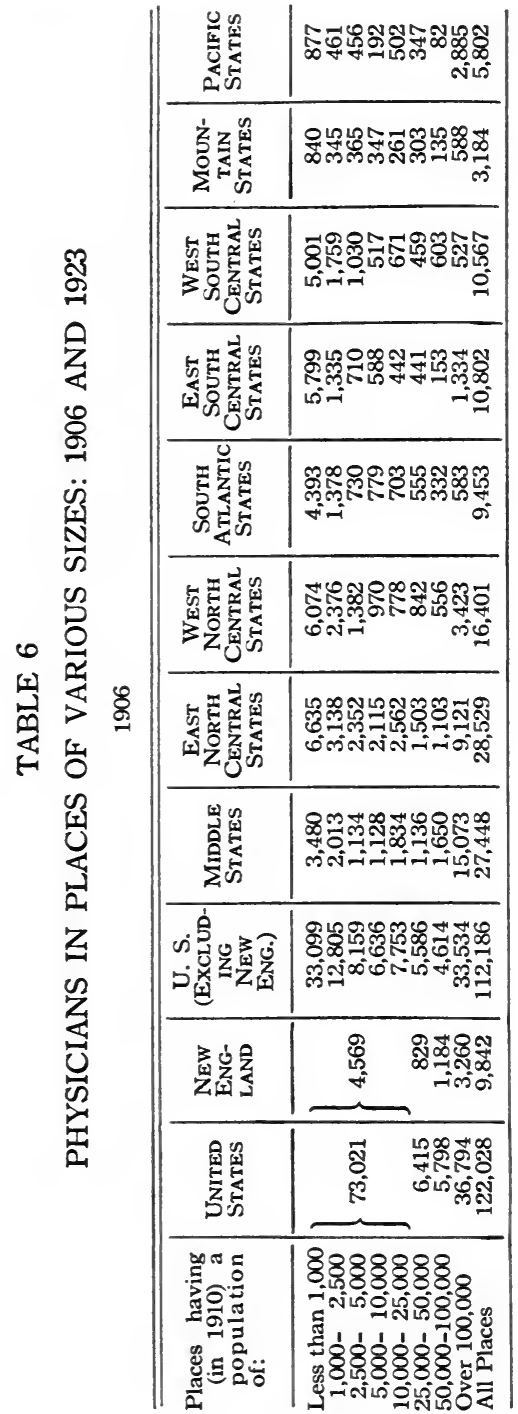

\begin{tabular}{|c|c|}
\hline 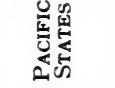 & 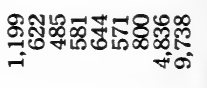 \\
\hline 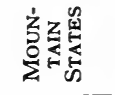 & 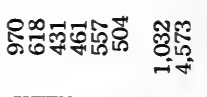 \\
\hline 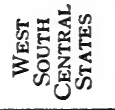 & 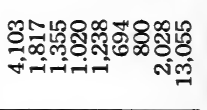 \\
\hline 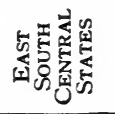 & 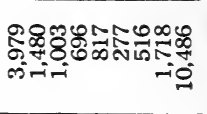 \\
\hline 总是 & 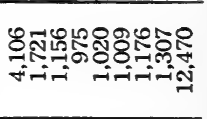 \\
\hline 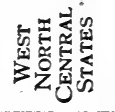 & 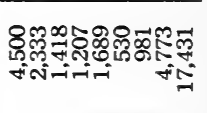 \\
\hline 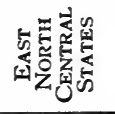 & 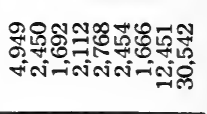 \\
\hline 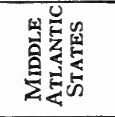 & 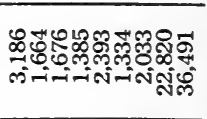 \\
\hline 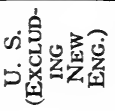 & 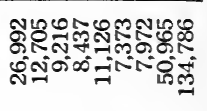 \\
\hline 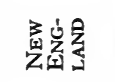 & 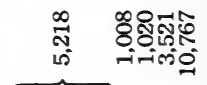 \\
\hline 量㟟 & 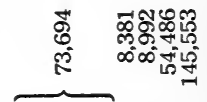 \\
\hline 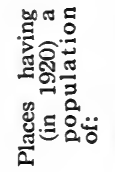 & 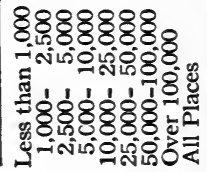 \\
\hline
\end{tabular}




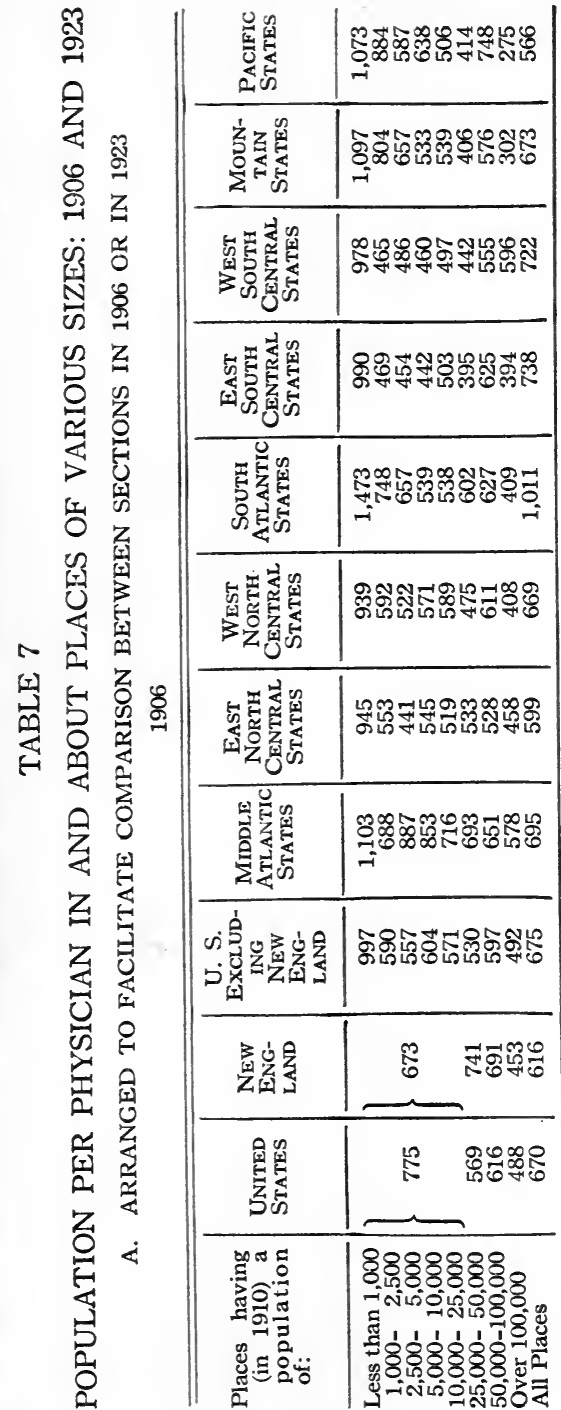

\begin{tabular}{|c|c|}
\hline 氛 & 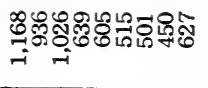 \\
\hline 竞留 & 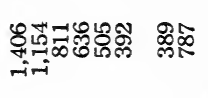 \\
\hline 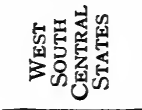 & 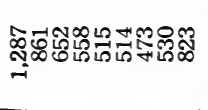 \\
\hline 点写罟罟 & 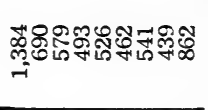 \\
\hline 总曾 & 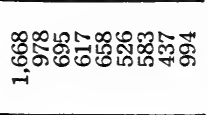 \\
\hline 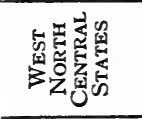 & 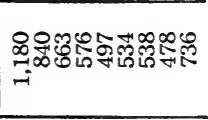 \\
\hline 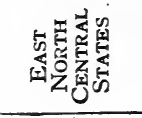 & 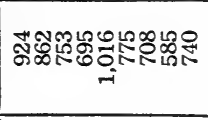 \\
\hline 里是罢 & 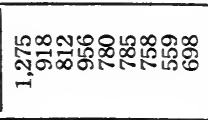 \\
\hline 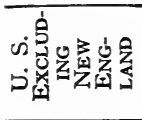 & 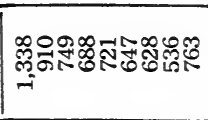 \\
\hline 童总量 & 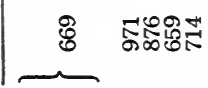 \\
\hline 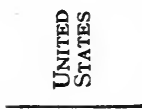 & 网 : \\
\hline 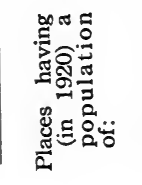 & 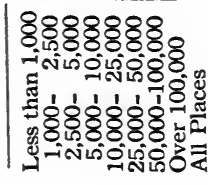 \\
\hline
\end{tabular}




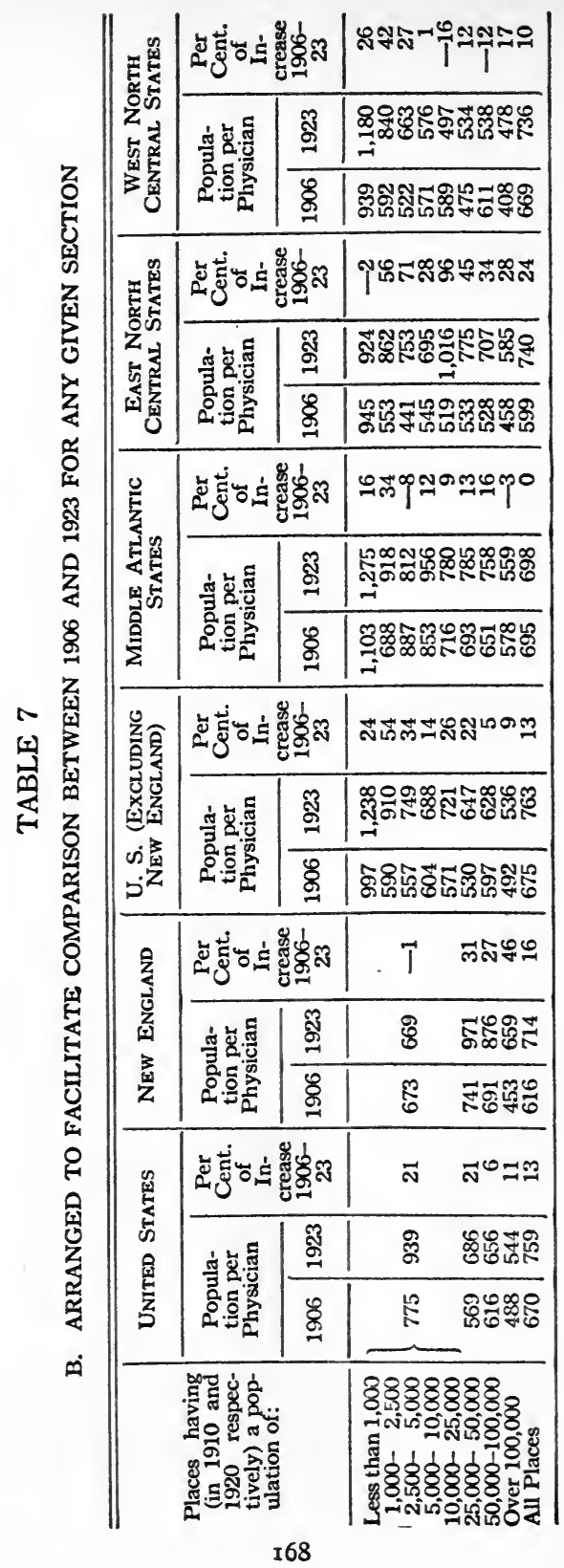




\begin{tabular}{|c|c|c|c|}
\hline \multirow{3}{*}{ 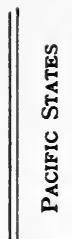 } & \multicolumn{2}{|c|}{ | } & 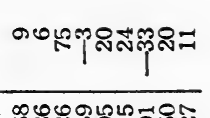 \\
\hline & \multirow{2}{*}{ 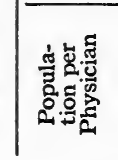 } & ֻू & 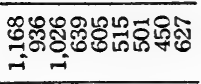 \\
\hline & & 8 & 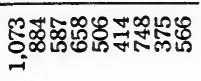 \\
\hline \multirow{3}{*}{ 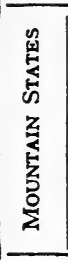 } & \multicolumn{2}{|c|}{ 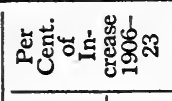 } & 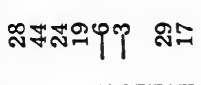 \\
\hline & \multirow{2}{*}{ 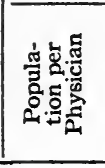 } & 兽| & 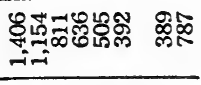 \\
\hline & & 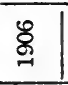 & - \\
\hline \multirow{3}{*}{ 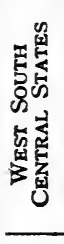 } & \multicolumn{2}{|c|}{ 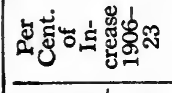 } & 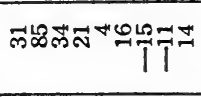 \\
\hline & \multirow{2}{*}{ 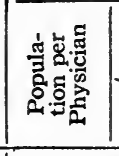 } & 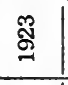 & 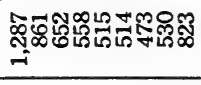 \\
\hline & & 8 & 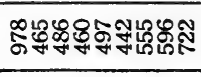 \\
\hline \multirow{3}{*}{ 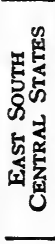 } & \multicolumn{2}{|c|}{ 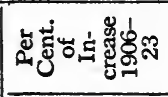 } & 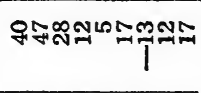 \\
\hline & \multirow{2}{*}{ 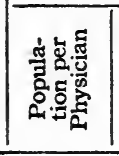 } & סू & 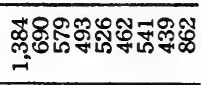 \\
\hline & & 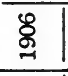 & 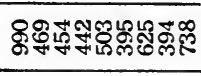 \\
\hline \multirow{3}{*}{ 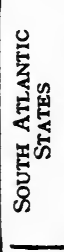 } & \multicolumn{2}{|c|}{ 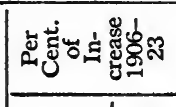 } & 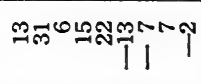 \\
\hline & \multirow{2}{*}{ 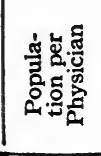 } & 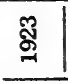 & 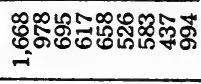 \\
\hline & & 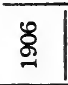 & man \\
\hline & 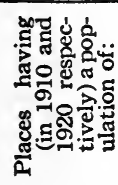 & & 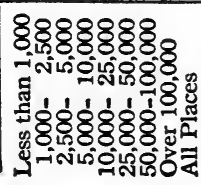 \\
\hline
\end{tabular}




\section{APPENDIX}

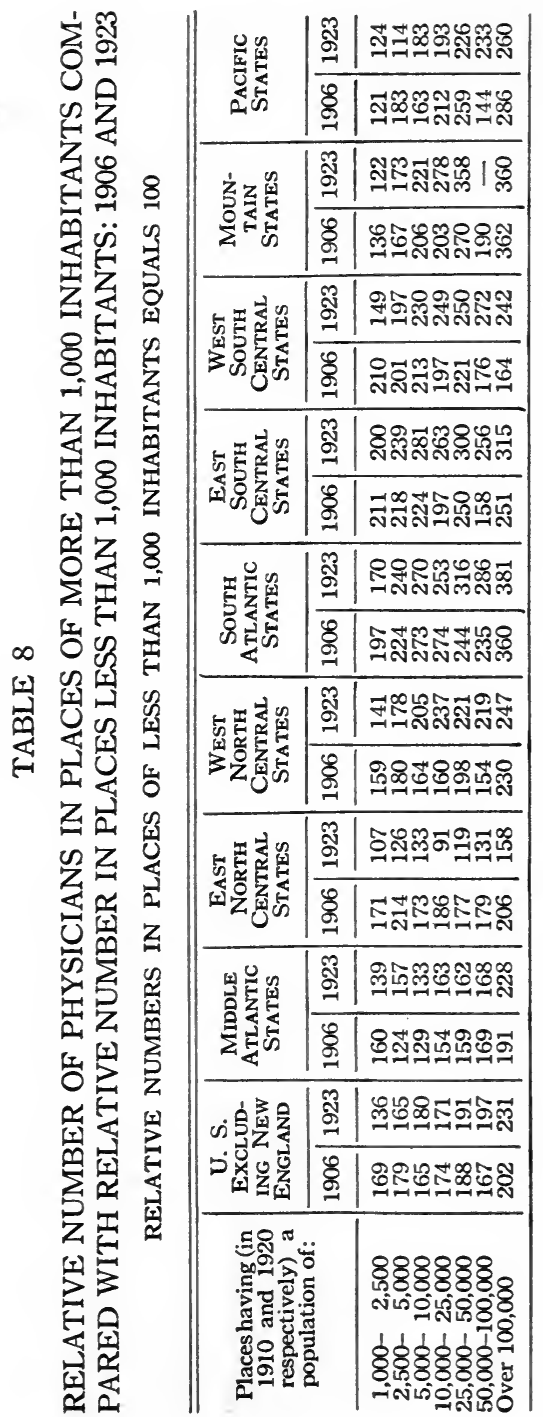




\begin{tabular}{|c|c|c|c|c|c|c|c|c|c|c|c|c|c|}
\hline 告 & & 总临 & ฒู & ตี่ & $\begin{array}{l}\forall \rightarrow \infty \\
\dot{\infty} \infty\end{array}$ & 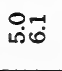 & ஸ் & $\stackrel{\varphi}{6}$ & कृ & ஸุঙ̆ & 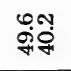 & ஜ̊요 & \\
\hline 幽 & 을 & 2⿺𠃊5 & \&. & मृं & જ઼ำ & $\stackrel{\mathscr{r}}{\sim}$ & जิ & חึ & ตุ่ & 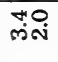 & ஸ்요 & 80. & \\
\hline 兵 & $\begin{array}{l}\frac{a}{2} \\
Z\end{array}$ & 家z员 & สิ & $\begin{array}{l}\text { พุe } \\
\text { ลี่ง }\end{array}$ & 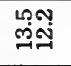 & जi० & 푸융유 & ஸูย̆ & $\stackrel{0}{=}$ & 11 & $\begin{array}{l}\text { แก } \\
\text { ลี่ }\end{array}$ & 웅요 & \\
\hline ర్ & $\sum_{0}^{\sqrt[1]{2}}$ & 究出 & \&్ & ثึં & $\stackrel{\infty}{0} 0$ & $\stackrel{109}{=}$ & 웅유 & ஸุ & कृष & $\underset{\text { mem }}{m}$ & +ீ. & 우요 & \\
\hline$\stackrel{5}{S}$ & z & 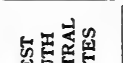 & హ్స & 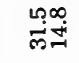 & कृष & $\stackrel{\infty}{\infty}^{+\infty}$ & جִ & 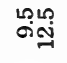 & $\begin{array}{l}\text { मீं } \\
\text { ம் }\end{array}$ & ஸิตั & $\begin{array}{l}\text { mo } \\
\text { [ొ⿻ }\end{array}$ & 웅ㅇ & \\
\hline$\underset{B}{Z}$ & 号 & 陉䍐 & $\mathscr{E}$ & พั่ & 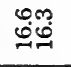 & कृ: & भुष & $\begin{array}{l}\text { mo } \\
010\end{array}$ & m & ம் & 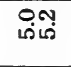 & 80 & \\
\hline 6 & ઝิ & 占要这员 & హ్త & 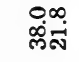 & تี & ตேష & $\mathscr{0}$ & $\stackrel{\infty}{\sim}$ & $\stackrel{\bullet}{\dot{N}}=$ & $\begin{array}{l}9 \infty \\
+0\end{array}$ & ํำ & 웅요 & \\
\hline 2 & 案 & 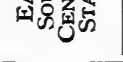 & $\mathscr{8}$ & 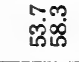 & $\begin{array}{l}\text { ஸ் } \\
\text { ஸें }\end{array}$ & $\ddot{0}+\underset{+}{0}$ & เึ่ & नुं & تُ & تִ & 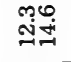 & சீ요 & \\
\hline 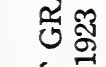 & 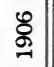 & 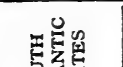 & พิ & 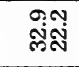 & $\begin{array}{l}\infty 0 \\
\text { miฺ }\end{array}$ & min & $\stackrel{\infty}{\sim}$ & พ్ุ๊ & 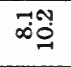 & హัNָ & L & ஜ용 & \\
\hline$Z \frac{1}{Z}$ & Z & 象造 & ஜू & 乐-1 & $\stackrel{\varphi}{+}$ & $\stackrel{+\infty}{\infty}$ & พูo & 芯 & 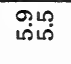 & ผุต & พ゙્ָุ & 웅요 & \\
\hline 똬 & $\underset{B}{m}$ & 旨: & ๙્ఝ & 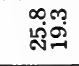 & ஸ் & $\begin{array}{l}-\infty \\
\infty \\
\infty\end{array}$ & ชุเ & $\ddot{\sigma}$ & $\overrightarrow{\text { mंते }}$ & ตั & సั่ & 웅요 & \\
\hline 至: & ž & 吼思 & \&્ & 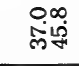 & & $\begin{array}{l}\forall \rightarrow \infty \\
\infty i 0\end{array}$ & 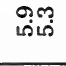 & $\stackrel{\infty}{+\infty}$ & ஸุษ & भĩ & 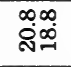 & 웅요 & \\
\hline$\angle 5$ & ֻ & 战焉是 & హ్ & ஸैพ & $\underset{\infty}{\infty}$ & $\begin{array}{l}\operatorname{L} \infty \infty \\
\text { Lัง }\end{array}$ & 9ृ. & कฺָ̈ & क्ष & 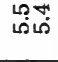 & ำฺ & ஜ요 & \\
\hline Z & O & 红吕䍐占 & \&్- & miّ" & $\begin{array}{l}0 \infty \\
=\infty\end{array}$ & ஸุฒ & సோ & $\stackrel{\circ}{\circ \infty}$ & 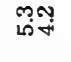 & $\begin{array}{l}\sigma 0 \\
\text { लें }\end{array}$ & $\begin{array}{l}\text { कं० } \\
\text { लंట్ं }\end{array}$ & 8용 & \\
\hline$\tilde{U}$ & $\stackrel{\text { 된 }}{\stackrel{E}{\leftrightarrow}}$ & 果是包 & హ్. & $\stackrel{\infty}{\infty} \stackrel{0}{+}$ & $\begin{array}{l}\varphi \infty \\
\dot{\forall}+\dot{N}\end{array}$ & $\stackrel{\varphi}{\forall} \stackrel{9}{*}$ & $\begin{array}{l}\infty \pi \\
\dot{n} \tilde{N}\end{array}$ & $\begin{array}{l}\ddot{\infty} \infty \\
\dot{0} \sim{ }^{\circ}\end{array}$ & $\begin{array}{l}\infty \infty \\
\dot{m i n}\end{array}$ & $\begin{array}{l}\varphi \infty \\
\dot{10}+\end{array}$ & ชิ่ & 웅ㅇ & ? \\
\hline 空 & 点 & 它完 & \&్ & $\begin{array}{l}\text { ஸे } \\
\text { जૈఱ్త }\end{array}$ & $\stackrel{\varphi}{\varphi}$ & 年 & Fi & نั & تีஷ & ำ & 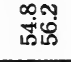 & 우요 & \\
\hline 点 & \& & 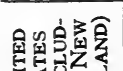 & హิ & 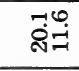 & कें & 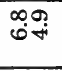 & พื่ & ஸุก & 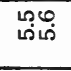 & $\begin{array}{l}\text { कृन } \\
\text { ம் }\end{array}$ & क़ं & 웅유 & \\
\hline$\frac{5}{6}$ & 匀 & 孞我势 & \& & 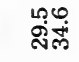 & ఝீ: & พฺָ & 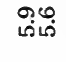 & जo & 윰 & พૈ心 & कి. & 8. & \\
\hline 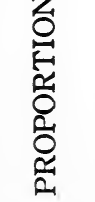 & 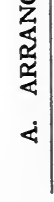 & 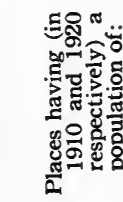 & & 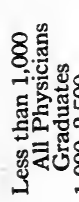 & 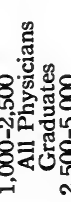 & 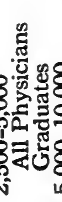 & 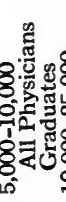 & 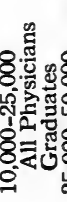 & 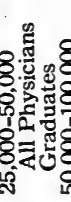 & 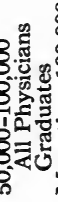 & 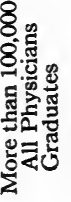 & 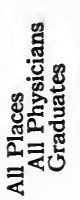 & s \\
\hline
\end{tabular}




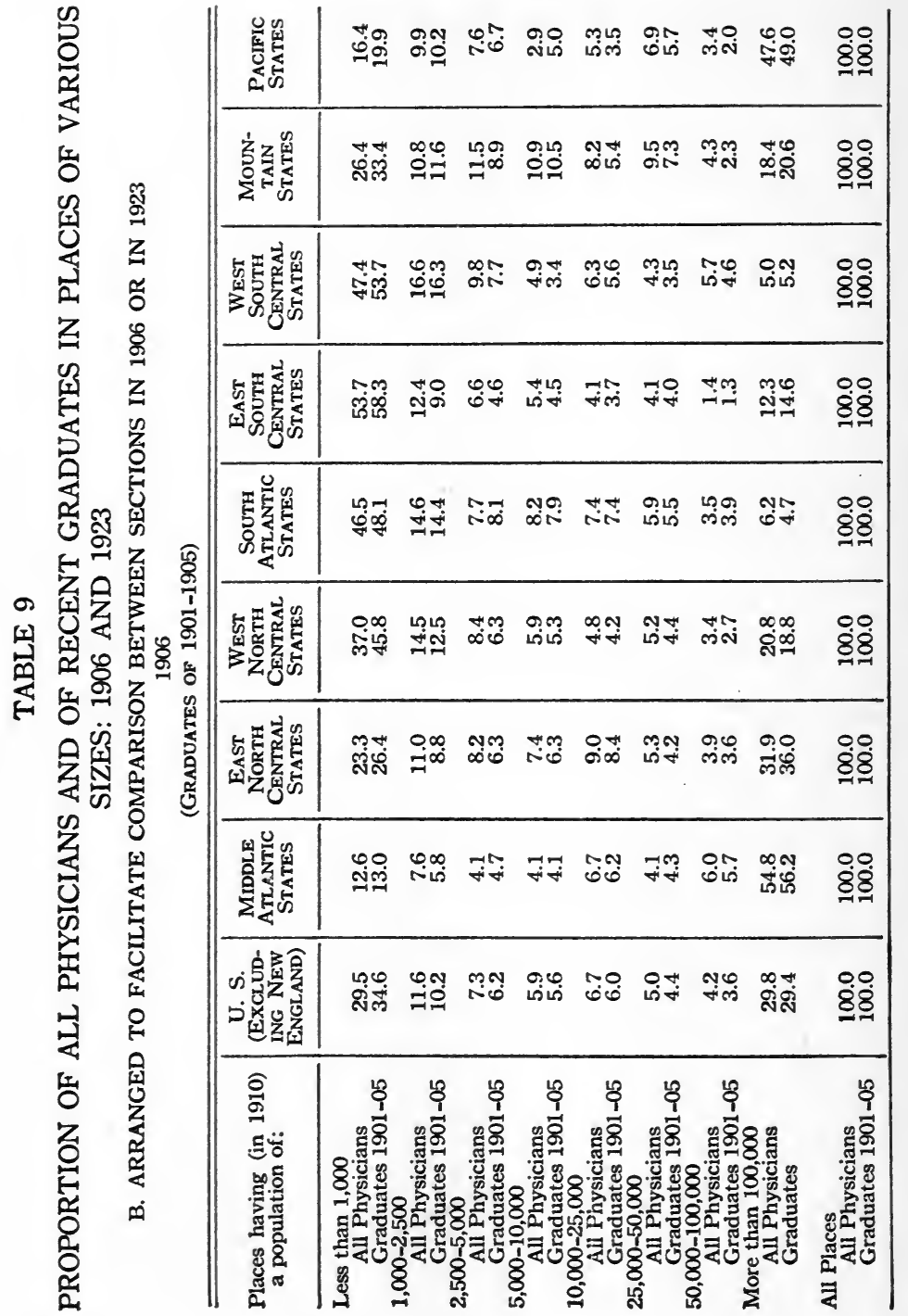




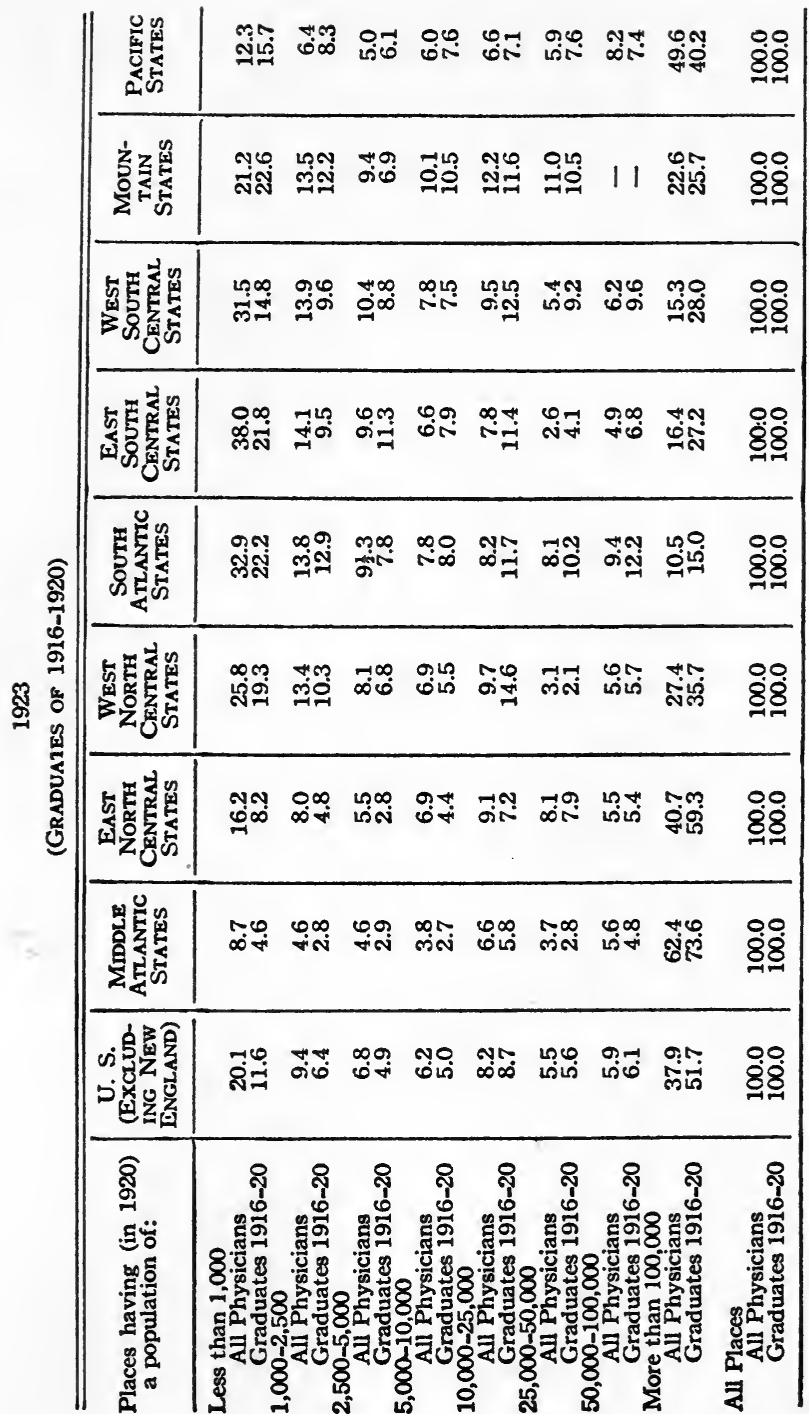




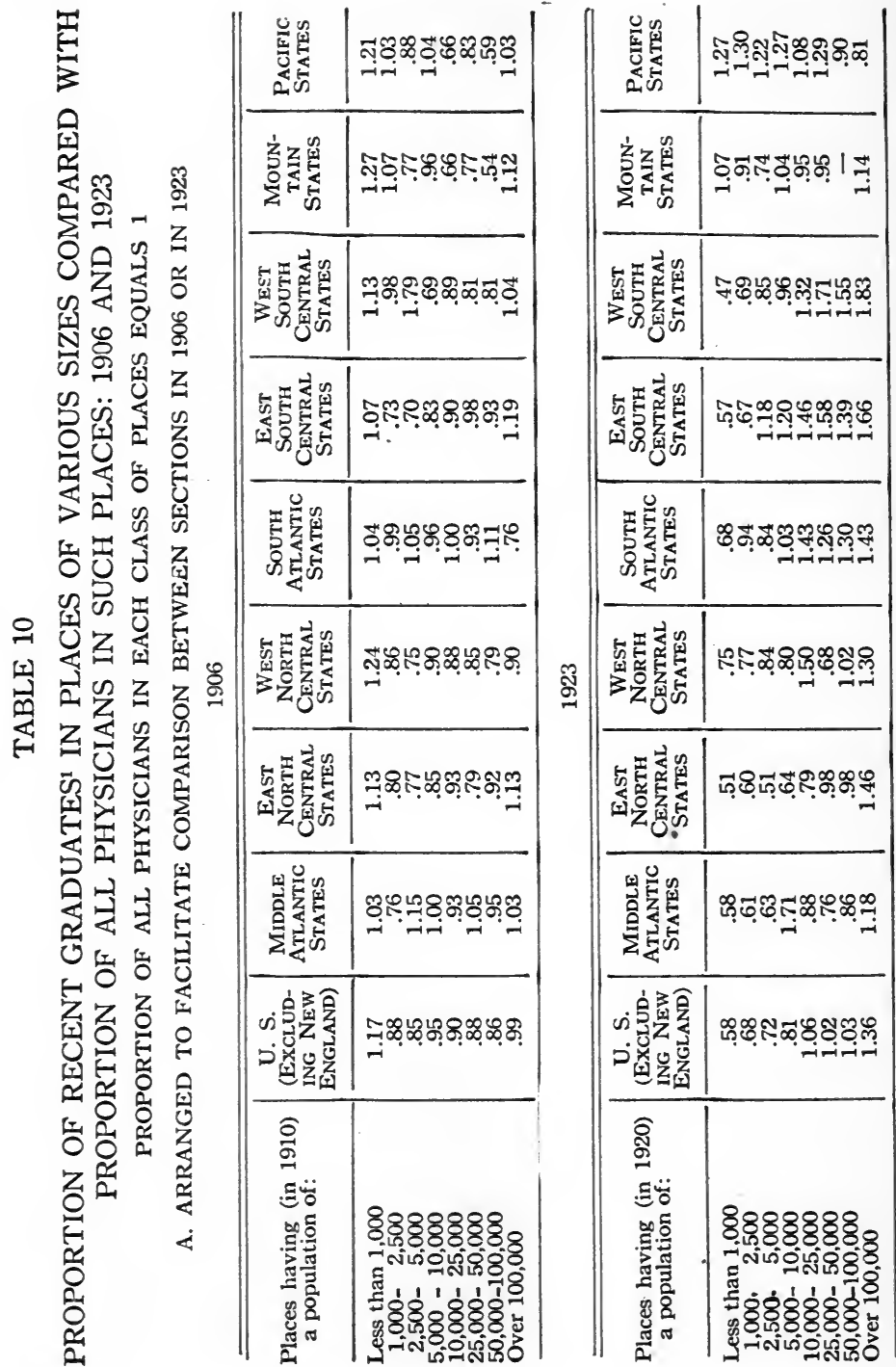




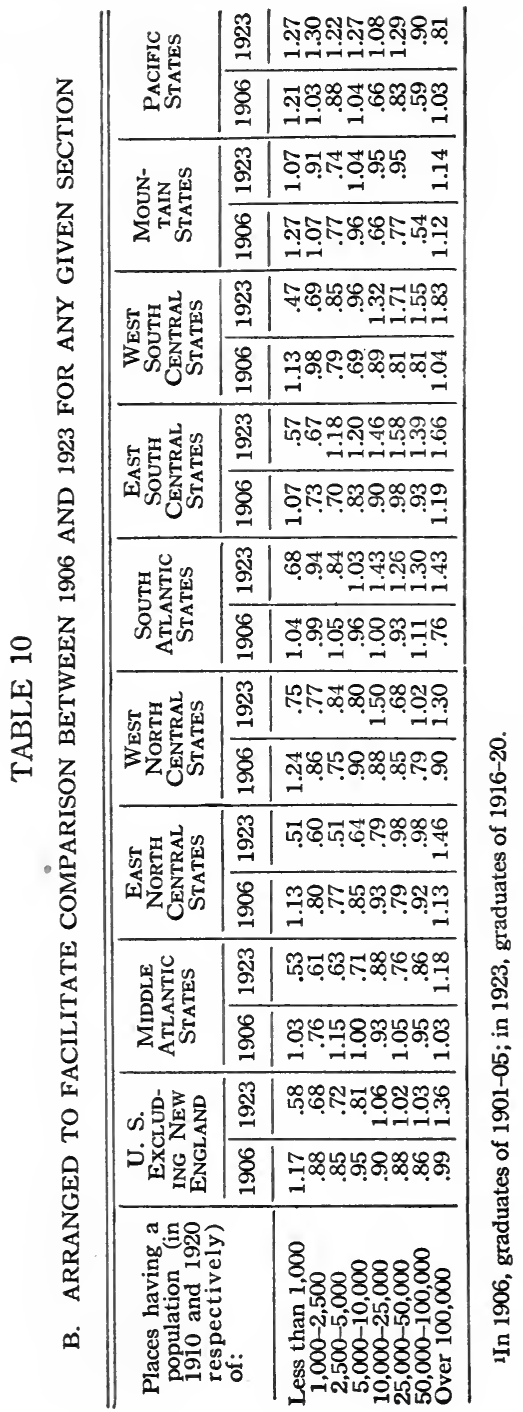




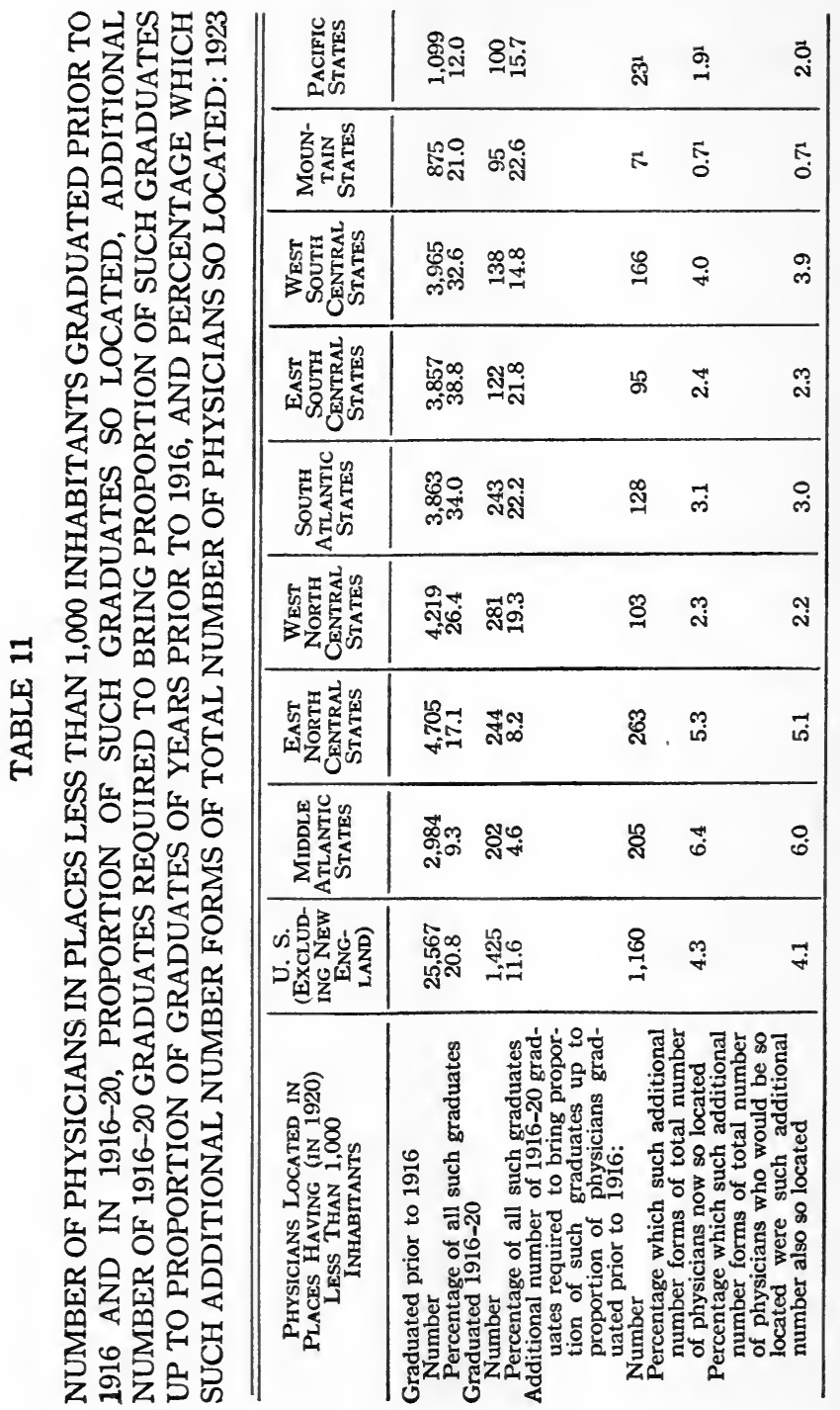


TABLE 12

PROPORTION OF THE GRADUATES OF 1917, 1918, 1919, AND 1920 IN PLACES OF VARIOUS SIZES COMPARED WITH THE PROPORTION OF THE GRADUATES OF 1916 IN SUCH PLACES: 1923

\begin{tabular}{|c|c|c|c|c|c|c|c|c|c|c|c|c|}
\hline \multirow[b]{2}{*}{ Graduates of } & \multicolumn{4}{|c|}{$\begin{array}{c}\text { U. S. } \\
\text { (EXCLUDING } \\
\text { NEW ENGLAND) }\end{array}$} & \multicolumn{4}{|c|}{$\begin{array}{l}\text { MIDDLE } \\
\text { ATLANTIC } \\
\text { STATES }\end{array}$} & \multicolumn{4}{|c|}{$\begin{array}{l}\text { EAST NoRTH } \\
\text { CENTRAL } \\
\text { STATES }\end{array}$} \\
\hline & 1917 & 1918 & 1919 & 1920 & 1917 & 1918 & 1919 & 1920 & 1917 & 1918 & $|1919|$ & 1920 \\
\hline $\begin{array}{l}\text { Places having } \\
\text { (in 1920) a } \\
\text { population of: }\end{array}$ & & & & & & & & & & & & \\
\hline Less than 1,000 & .92 & .83 & .79 & .81 & .80 & .74 & 1.04 & 1.04 & 1.10 & .84 & .71 & .79 \\
\hline & 10 & .83 & .88 & & & .68 & & & .00 & .52 & 1.24 & .92 \\
\hline - 10,000 & 1.02 & .92 & .76 & .92 & 1.1 & .77 & .52 & .8 & .88 & 1.00 & .81 & .8 \\
\hline$-25,00$ & .92 & 1.04 & .94 & 1.11 & 1. & .68 & .9 & & .89 & 1.35 & 1.04 & 1.3 \\
\hline & & .84 & .82 & .92 & .9 & .81 & 1.1 & & .93 & .87 & & 1.0 \\
\hline & .9 & .85 & .96 & .76 & 1.16 & .84 & .6 & .6 & .69 & .96 & 1,37 & 1.07 \\
\hline & 1.0 & 1.14 & 1.15 & 1.13 & 1.00 & 1.12 & 1.08 & 1.04 & 1.09 & 1.05 & 1.07 & 1.01 \\
\hline
\end{tabular}

\begin{tabular}{|c|c|c|c|c|c|c|c|c|c|c|c|c|}
\hline \multirow[b]{2}{*}{ GRADUATES OF } & \multicolumn{4}{|c|}{$\begin{array}{c}\text { WEST NORTH } \\
\text { CENTRAL } \\
\text { STATES }\end{array}$} & \multicolumn{4}{|c|}{$\begin{array}{l}\text { SouTH } \\
\text { ATLANTIC } \\
\text { StATES }\end{array}$} & \multicolumn{4}{|c|}{$\begin{array}{c}\text { EAST SOUTH } \\
\text { CENTRAL } \\
\text { StATES }\end{array}$} \\
\hline & 1917 & 1918 & |1919| & 1920 & 1917 & 1918 & 1919 & 1920 & 1917 & 7) 1918 & 1919 & 1920 \\
\hline $\begin{array}{l}\text { Places having } \\
\text { (in 1920) a } \\
\text { population of: }\end{array}$ & & & & & & & & & & & & \\
\hline Less than 1,000 & .84 & .88 & .87 & .89 & .76 & 1.02 & .79 & .89 & .95 & .57 & .94 & .68 \\
\hline $1,000-2,500$ & .90 & .79 & .70 & .78 & .88 & .65 & 1.01 & 1.17 & 1.03 & 1.23 & .51 & .39 \\
\hline $2,500-5,000$ & 1.01 & .79 & .93 & .58 & 1.16 & .91 & 1.38 & .78 & 1.30 & .80 & 1.02 & .77 \\
\hline $5,000-10,000$ & .73 & .62 & .49 & .84 & 1.17 & 1.25 & 1.08 & 1.18 & 2.29 & 2.44 & .68 & 3.14 \\
\hline $10,000-25,000$ & 1.21 & 1.42 & 1.16 & 1.71 & .74 & 1.23 & .89 & 1.06 & $\mid .50$ & .64 & .92 & 1.24 \\
\hline $25,000-50,000$ & 1.05 & 1.58 & 1.52 & .32 & 1.31 & 1.39 & 1.06 & 1.39 & .35 & .60 & 1.27 & .78 \\
\hline חרת & & 1.12 & 1.33 & 1.02 & .82 & .76 & 1.07 & 1.04 & .54 & .48 & 2.04 & 1.40 \\
\hline Over 100,000 & & & 1.19 & & 1.63 & 1.02 & 1.11 & . .69 & 1.27 & 1.76 & 1.02 & 1.17 \\
\hline
\end{tabular}

\begin{tabular}{|c|c|c|c|c|c|c|c|c|c|c|c|c|}
\hline \multirow[b]{2}{*}{ GRADUATES OF } & \multicolumn{4}{|c|}{$\mid \begin{array}{c}\text { WEST South } \\
\text { CENTRAL } \\
\text { STATES }\end{array}$} & \multicolumn{4}{|c|}{$\begin{array}{l}\text { MOUNTAIN } \\
\text { States }\end{array}$} & \multicolumn{4}{|c|}{$\begin{array}{l}\text { PACIFIC } \\
\text { States }\end{array}$} \\
\hline & 1917 & 1918 & 1919 & 1920 & 1917 & 1918 & 1919 & 1920 & 1917 & 1918 & $8 \mid 1919$ & 1920 \\
\hline $\begin{array}{l}\text { Places having } \\
\text { (in 1920) a } \\
\text { population of: }\end{array}$ & & & & & & & & & & & & \\
\hline $\begin{array}{c}\text { Less than } 1,000 \\
1,000-2,500\end{array}$ & $\begin{array}{l}.77 \\
.75\end{array}$ & $\begin{array}{r}.67 \\
1.01\end{array}$ & $\begin{array}{r}.58 \\
122\end{array}$ & .88 & 1.01 & $\begin{array}{l}1.42 \\
1.91\end{array}$ & 1.13 & $\begin{array}{l}.87 \\
93\end{array}$ & 1.65 & 1.05 & $\begin{array}{l}7.0 \\
188\end{array}$ & 1.03 \\
\hline $1,500-5,000$ & 1.15 & $\begin{array}{l}1.01 \\
1.19\end{array}$ & 1.64 & $\begin{array}{l}.90 \\
.92\end{array}$ & $\begin{array}{l}1.10 \\
4.91\end{array}$ & 3.23 & 5.42 & 2.09 & $\begin{array}{l}1.01 \\
1.38\end{array}$ & 1.25 & $\mid \begin{array}{l}1.00 \\
1.82\end{array}$ & \\
\hline $5,000-10,000$ & .97 & 1.29 & 1.96 & 1.10 & .55 & .40 & .45 & .58 & 1.57 & 1.43 & .91 & \\
\hline $10,000-25,000$ & 1.01 & 1.16 & .76 & .79 & .73 & .92 & 1.09 & .86 & .54 & .73 & .70 & 1.1 \\
\hline & & & 1.01 & & 1.16 & .64 & .95 & 1.04 & & & & \\
\hline 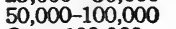 & 1.2 & .85 & .99 & .52 & & & & & & 07 & & \\
\hline & & & 1.28 & 1.52 & .97 & .67 & .89 & 1.37 & .79 & & 1.21 & 1.12 \\
\hline
\end{tabular}




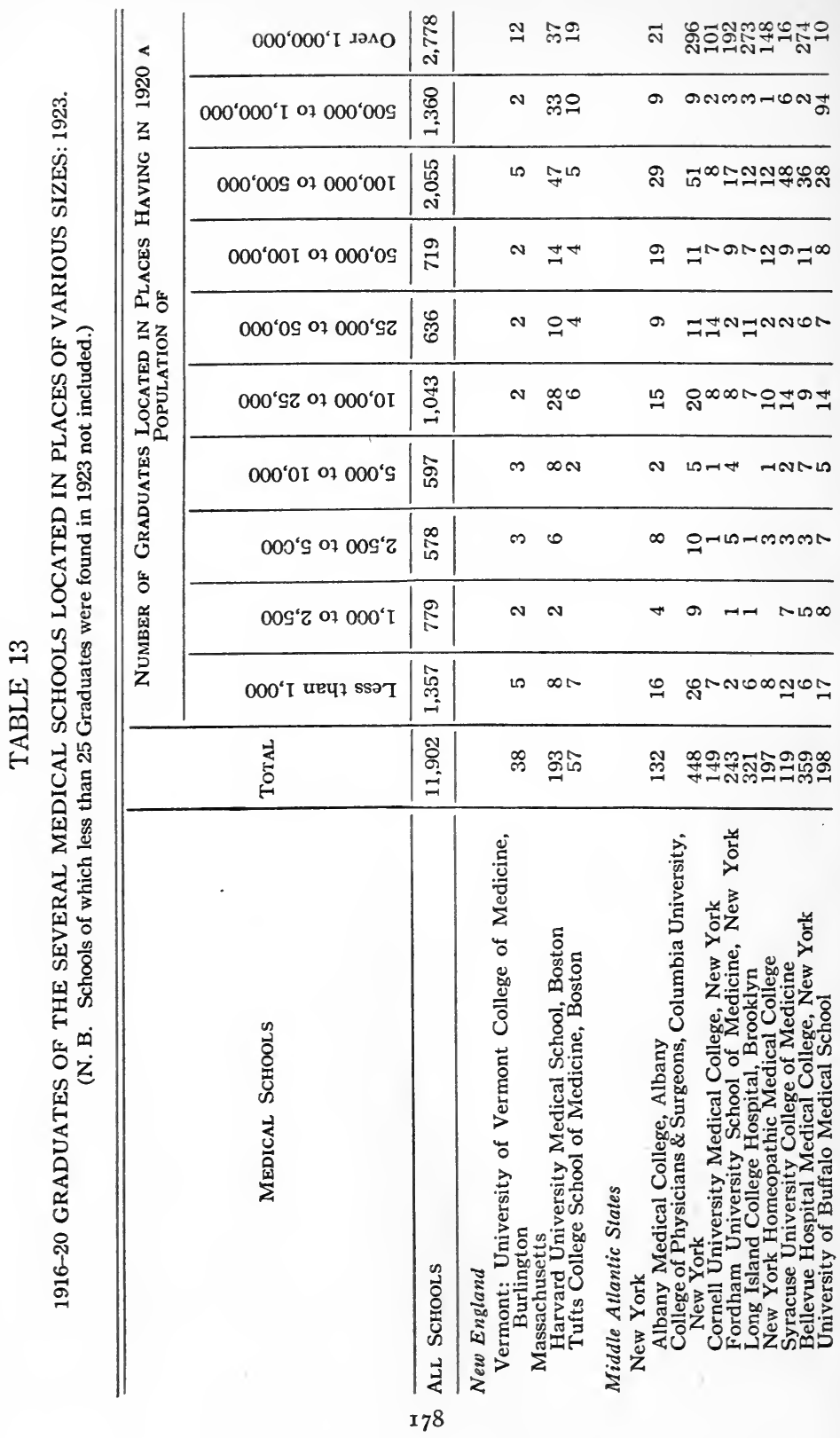




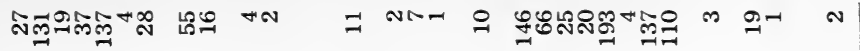
の

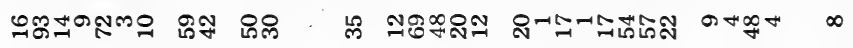

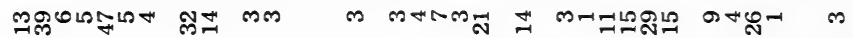

-

サ

\begin{tabular}{|c|c|c|c|c|c|c|c|}
\hline OR⿴囗⿰丿㇄口⿴囗十⿻ & ஸैल & $\cos$ & حما & N@্ $N$ & అ & 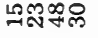 & NON \\
\hline
\end{tabular}

Nint

ம

\begin{tabular}{|c|c|c|c|c|c|c|c|}
\hline com & $\infty \underset{-1}{\infty}$ & 0 & $N$ & 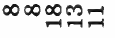 & 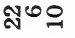 & 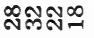 & $\infty 0 N O$ \\
\hline
\end{tabular}

\begin{tabular}{|c|c|c|c|c|c|c|}
\hline 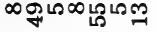 & चய & $D-1$ & $\stackrel{+1}{ \pm 1}$ & 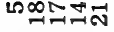 & 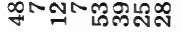 & $\ddot{n} \nabla^{n}$ \\
\hline
\end{tabular}

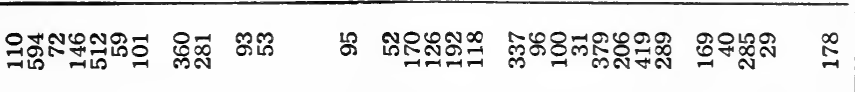

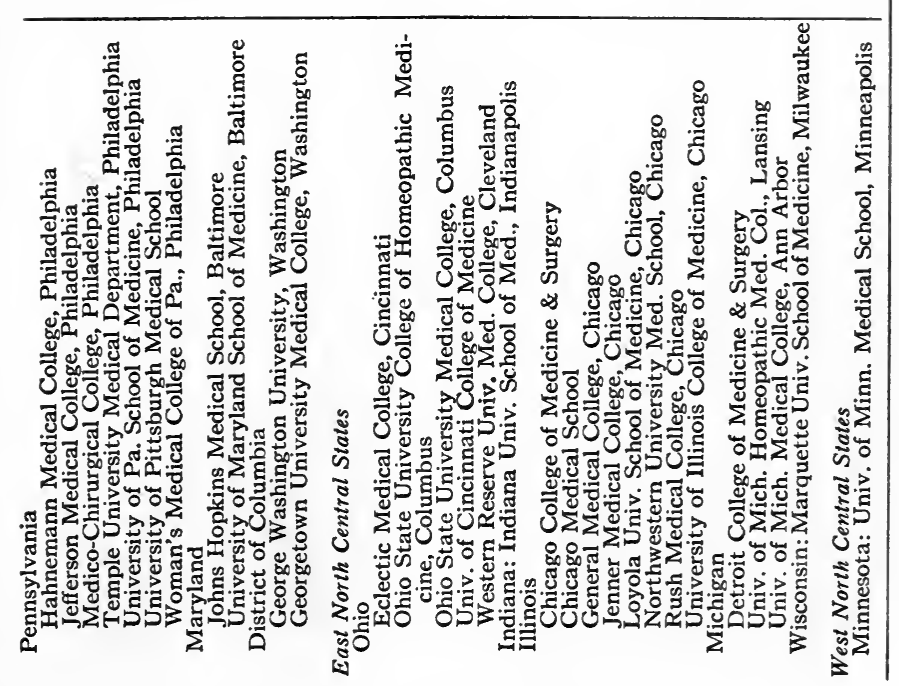




\begin{tabular}{|c|c|c|c|c|}
\hline \multirow{10}{*}{ 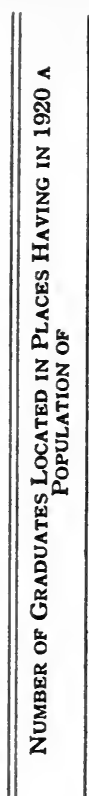 } & $000^{\prime} 000^{\prime} \mathrm{T}$ دәАO & $n \neg-\infty \omega \pi-6$ & $n-$ & $\Xi \Xi$ \\
\hline & $000^{\circ} 000^{\prime} \mathrm{I}$ O $07000^{\circ} 00 \mathrm{~s}$ & 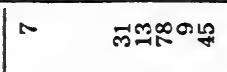 & Lеल -1 & $n+a$ \\
\hline & $000^{\prime} 00 \mathrm{~s}$ or $000^{\prime} 00 \mathrm{I}$ & | & ザ゙ ה゙ & ใลก 0 \\
\hline & $000^{\prime} 00$ โ $07000^{\prime} 0 \mathrm{~s}$ & ๓ & NoL & $=0 \cong$ \\
\hline & $000^{\prime} 0 \mathrm{~S}$ of $000^{\prime} \mathrm{sz}$ & a $\forall-N$ - & 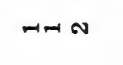 & $=0$ \\
\hline & $000^{\circ} \mathrm{sz} 07000^{\prime} 0 \mathrm{I}$ & Lூ & UN & $\tilde{N} \approx \sigma$ \\
\hline & $000^{\circ} 0107000$ 's & $\therefore \quad$ mon $=m o$ & $-\infty i$ & No \\
\hline & 000 's $0700{ }^{\prime}$ & $\cong$ மmO & เos $\sigma$ & OQ N \\
\hline & $009^{\prime} Z 07000^{\circ} \mathrm{I}$ & $\infty$ LNZ్తNHON & กำ & 워요 \\
\hline & $000^{\prime} \mathrm{I}$ ueq7 & ల్ & 禺品 & 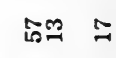 \\
\hline & $\underset{H}{\stackrel{L}{L}}$ & 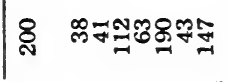 & $\stackrel{m}{a}=\bar{\infty}$ & $\stackrel{\infty}{*} \stackrel{2}{\circ}$ \\
\hline & 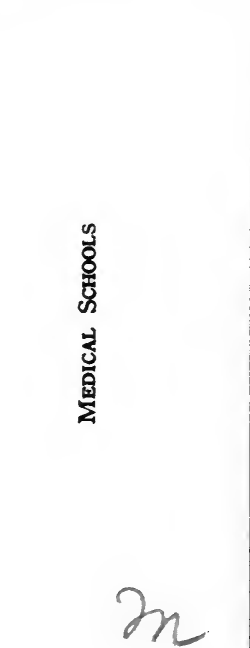 & 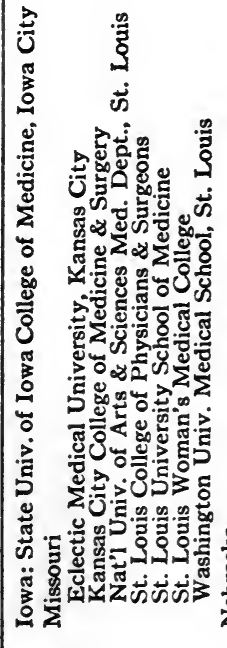 & 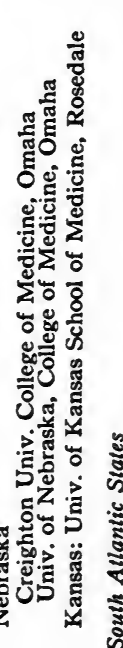 & 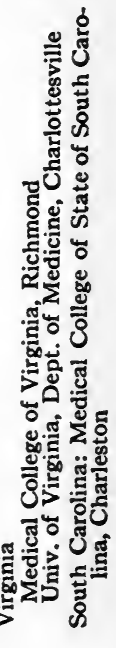 \\
\hline
\end{tabular}




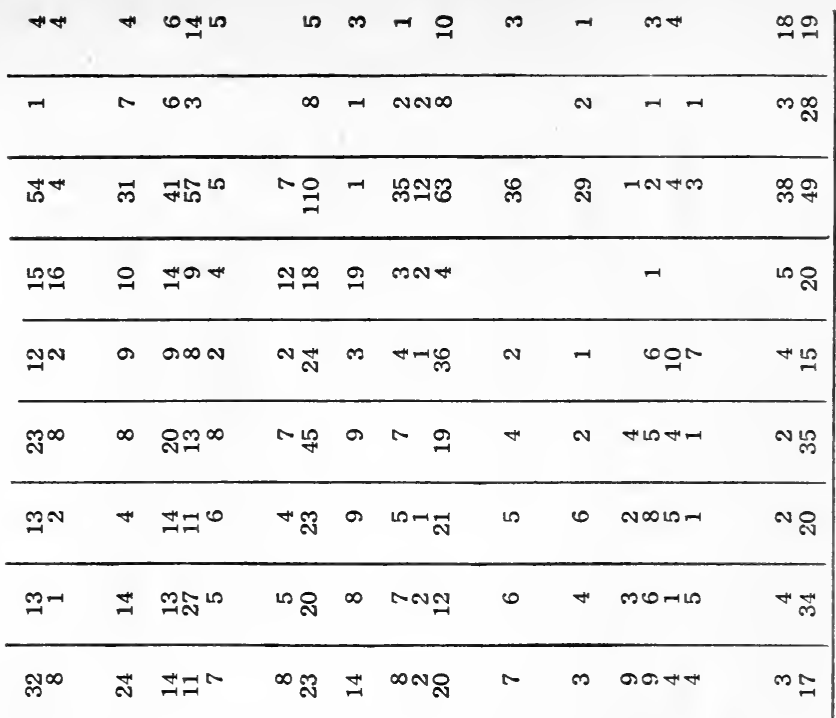

\begin{tabular}{|c|c|c|c|c|c|c|c|c|c|}
\hline लెం & \& & ભస్త & $=0$ & $=$ & 이요 & $\stackrel{0}{-1}$ & 0 & $\mathscr{\sim} \underset{-1}{\mathbb{N}}$ & $\sim \infty$ \\
\hline
\end{tabular}

\begin{tabular}{|c|c|c|c|c|c|c|c|c|c|}
\hline ל్లి & 8 & 导志 & เัน & $\rightleftarrows$ & ஸ心: & $\Re$ & เั & ผึก็กิก & $\infty$ ㄴ? \\
\hline
\end{tabular}

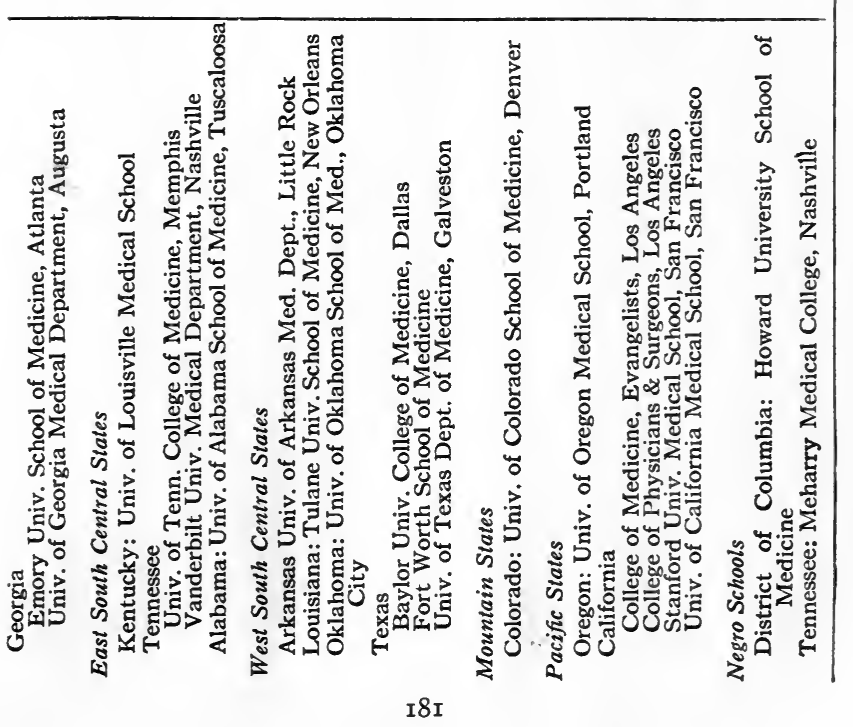




\begin{tabular}{|c|c|c|c|}
\hline & & 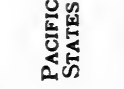 & : \\
\hline & శ్ & 蜜憵 & 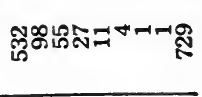 \\
\hline హิ & $\begin{array}{l}z \\
\tilde{z} \\
0 \\
q\end{array}$ & 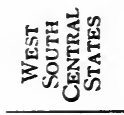 & 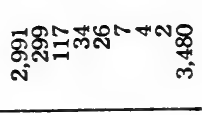 \\
\hline $\begin{array}{l}2 \\
2 \\
8 \\
8\end{array}$ & 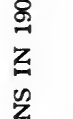 & 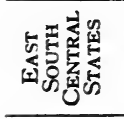 & 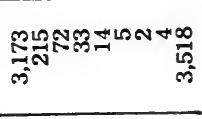 \\
\hline$\ddot{\ddot{n}}$ & 을 & 总最 & 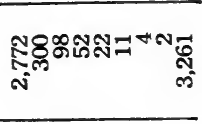 \\
\hline 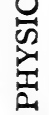 & $\sum_{\substack{1 \\
0}}^{5}$ & 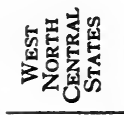 & 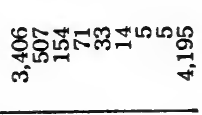 \\
\hline$\underset{⿱ 乛 龰}{Z}$ & zo & 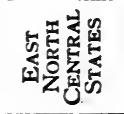 & 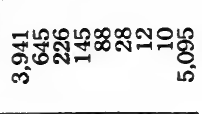 \\
\hline 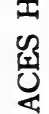 & $\sum_{0}^{0}$ & 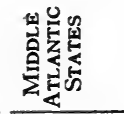 & 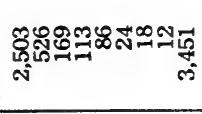 \\
\hline$\frac{1}{0}$ & 岕 & 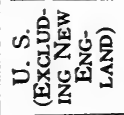 & 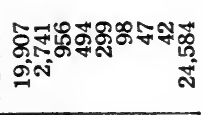 \\
\hline$\sum^{\frac{9}{5}}$ & $\stackrel{0}{\circ}$ & 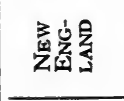 & 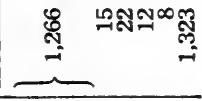 \\
\hline Z & 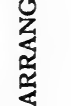 & 量昌 & 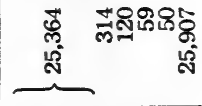 \\
\hline & $\dot{4}$ & 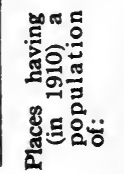 & 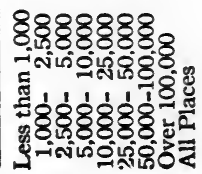 \\
\hline
\end{tabular}

\begin{tabular}{|c|c|}
\hline 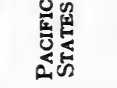 & 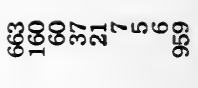 \\
\hline 方色 & 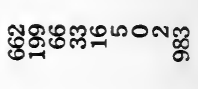 \\
\hline 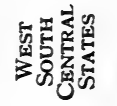 & 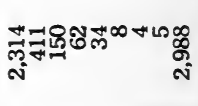 \\
\hline 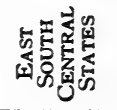 & 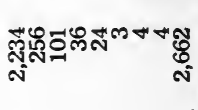 \\
\hline 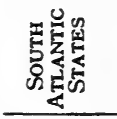 & 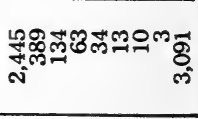 \\
\hline 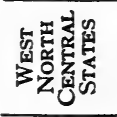 & 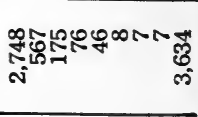 \\
\hline 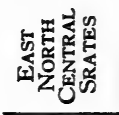 & 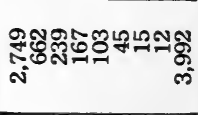 \\
\hline 电麓照 & 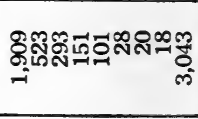 \\
\hline 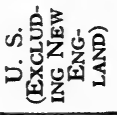 & 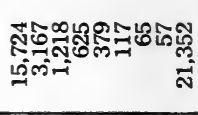 \\
\hline 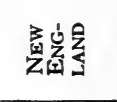 & 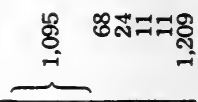 \\
\hline 䱛 & 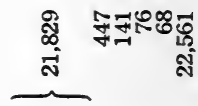 \\
\hline 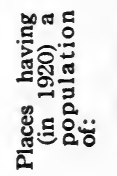 & 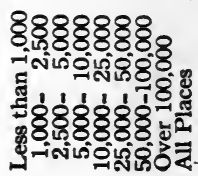 \\
\hline
\end{tabular}




\section{TABLE 14}

B. ARRANGED TO FACILITATE COMPARISON BETWEEN 1906 AND 1923 FOR ANY GIVEN SECTION

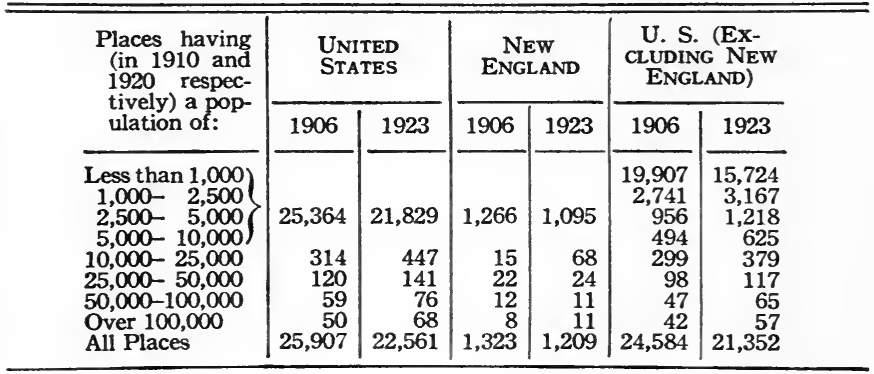

\begin{tabular}{|c|c|c|c|c|c|c|c|c|}
\hline \multirow{2}{*}{$\begin{array}{l}\text { Places having } \\
\text { (in } 1910 \text { and } \\
1920 \text { respec- } \\
\text { tively) a pop- } \\
\text { ulation of: }\end{array}$} & \multicolumn{2}{|c|}{$\begin{array}{l}\text { MIDDLE } \\
\text { ATLANTIC } \\
\text { StaTES }\end{array}$} & \multicolumn{2}{|c|}{$\begin{array}{c}\text { EAST North } \\
\text { CENTRAL } \\
\text { States }\end{array}$} & \multicolumn{2}{|c|}{$\begin{array}{c}\text { WEST NoRTH } \\
\text { CENTRAL } \\
\text { StATES }\end{array}$} & \multicolumn{2}{|c|}{$\begin{array}{l}\text { SOUTH } \\
\text { ATLANTIC } \\
\text { STATES }\end{array}$} \\
\hline & 1906 & 1923 & 1906 & 1923 & 1906 & 1923 & 1906 & 1923 \\
\hline $\begin{array}{l}\text { Less than } 1,000 \\
1,000-2,500 \\
2,500-5,000 \\
5,000-10,000 \\
10,000-25,000 \\
25,000-50,000 \\
50,000-100,000 \\
\text { Over } 100,000 \\
\text { All Places }\end{array}$ & $\begin{array}{r}2,503 \\
526 \\
169 \\
113 \\
86 \\
24 \\
18 \\
12 \\
3,451\end{array}$ & $\begin{array}{r}1,909 \\
523 \\
293 \\
151 \\
101 \\
28 \\
20 \\
18 \\
3,043\end{array}$ & $\begin{array}{r}3,941 \\
645 \\
226 \\
145 \\
88 \\
28 \\
12 \\
10 \\
5,095\end{array}$ & $\begin{array}{r}2,749 \\
662 \\
239 \\
167 \\
103 \\
45 \\
15 \\
12 \\
3,992\end{array}$ & $\begin{array}{r}3,406 \\
507 \\
154 \\
71 \\
33 \\
14 \\
5 \\
5 \\
5 \\
4,195\end{array}$ & $\begin{array}{r}2,748 \\
567 \\
175 \\
76 \\
46 \\
8 \\
7 \\
7 \\
3,634\end{array}$ & $\begin{array}{r}2,772 \\
300 \\
98 \\
52 \\
22 \\
11 \\
4 \\
2 \\
3,261\end{array}$ & $\begin{array}{r}2,445 \\
389 \\
134 \\
63 \\
34 \\
13 \\
10 \\
3 \\
3,091\end{array}$ \\
\hline
\end{tabular}

\begin{tabular}{|c|c|c|c|c|c|c|c|c|}
\hline \multirow{2}{*}{$\begin{array}{l}\text { Places having } \\
\text { (in } 1910 \text { and } \\
1920 \text { respec- } \\
\text { tively) a pop- } \\
\text { ulation of: }\end{array}$} & \multicolumn{2}{|c|}{$\begin{array}{c}\text { EAST SOUTH } \\
\text { CENTRAL } \\
\text { STATES }\end{array}$} & \multicolumn{2}{|c|}{$\begin{array}{c}\text { West South } \\
\text { CENTRAL } \\
\text { States }\end{array}$} & \multicolumn{2}{|c|}{$\begin{array}{l}\text { MOUN- } \\
\text { TAIN } \\
\text { STATES }\end{array}$} & \multicolumn{2}{|c|}{$\begin{array}{l}\text { Pacific } \\
\text { States }\end{array}$} \\
\hline & 1906 & 1923 & 1906 & 1923 & 1906 & 1923 & 1906 & 1923 \\
\hline $\begin{array}{l}\text { Less than } 1,060 \\
1,000-2,500 \\
2,500-5,000 \\
5,000-10,000 \\
10,000-25,000 \\
25,000-50,000 \\
50,000-100,000 \\
\text { Over } 100,000 \\
\text { All Places }\end{array}$ & $\begin{array}{r}3,173 \\
215 \\
72 \\
33 \\
14 \\
5 \\
2 \\
4 \\
3,518\end{array}$ & $\begin{array}{r}2,234 \\
256 \\
101 \\
36 \\
24 \\
3 \\
4 \\
4 \\
2,662\end{array}$ & \begin{tabular}{|r}
2,991 \\
299 \\
117 \\
34 \\
26 \\
7 \\
4 \\
2 \\
3,480
\end{tabular} & $\begin{array}{r}2,314 \\
411 \\
150 \\
62 \\
34 \\
8 \\
4 \\
5 \\
2,988\end{array}$ & $\begin{array}{r}532 \\
98 \\
55 \\
27 \\
11 \\
4 \\
1 \\
1 \\
729\end{array}$ & $\begin{array}{r}662 \\
199 \\
66 \\
33 \\
16 \\
5 \\
0 \\
0 \\
2 \\
983\end{array}$ & $\begin{array}{r}589 \\
151 \\
65 \\
19 \\
19 \\
5 \\
1 \\
6 \\
855\end{array}$ & $\begin{array}{r}663 \\
160 \\
60 \\
37 \\
21 \\
7 \\
5 \\
6 \\
959\end{array}$ \\
\hline
\end{tabular}


TABLE 15

\section{AVERAGE DISTANCE BETWEEN PLACES HAVING PHYSICIANS: 1906 AND 1923}

\begin{tabular}{|c|c|c|c|c|c|c|c|c|c|c|}
\hline & U. S. & $\begin{array}{c}\text { NEW } \\
\text { ENG. } \\
\text { STS. }\end{array}$ & $\begin{array}{l}\text { MID. } \\
\text { ATL. } \\
\text { STS. }\end{array}$ & $\begin{array}{l}\text { E. N. } \\
\text { CEN. } \\
\text { STS. }\end{array}$ & $\begin{array}{l}\text { W. N. } \\
\text { CEN. } \\
\text { STS. }\end{array}$ & $\begin{array}{l}\text { So. } \\
\text { ATL. } \\
\text { STS. }\end{array}$ & $\begin{array}{l}\text { E. S. } \\
\text { CEN. } \\
\text { STS. }\end{array}$ & $\begin{array}{l}\text { W. S. } \\
\text { CEN. } \\
\text { STS. }\end{array}$ & $\begin{array}{l}\text { MT. } \\
\text { STS. }\end{array}$ & $\begin{array}{l}\text { PAC. } \\
\text { StS. }\end{array}$ \\
\hline $\begin{array}{l}1906 \\
1923\end{array}$ & $\begin{array}{l}12.04 \\
12.90\end{array}$ & $\begin{array}{l}6.88 \\
7.18\end{array}$ & $\begin{array}{l}6.36 \\
6.76\end{array}$ & $\begin{array}{l}7.82 \\
8.82\end{array}$ & $\begin{array}{l}12.44 \\
13.36\end{array}$ & $\begin{array}{l}10.02 \\
10.26\end{array}$ & $\begin{array}{l}8.06 \\
9.24\end{array}$ & $\begin{array}{l}12.52 \\
13.50\end{array}$ & $\begin{array}{l}38.74 \\
33.36\end{array}$ & $\begin{array}{l}21.76 \\
20.54\end{array}$ \\
\hline
\end{tabular}

1Excluding uninhabited forest areas in Maine (except areas within 10 miles of a town having a physician) totalling $12,797 \mathrm{sq}$. $\mathrm{mi}$.

${ }^{2}$ Excluding the uninhabited areas in the Catskill and Adirondack regions (except areas within 10 miles of a town having a physician) totalling $1,881 \mathrm{sq}$. mi. 
II. Selected States or Portions of States:

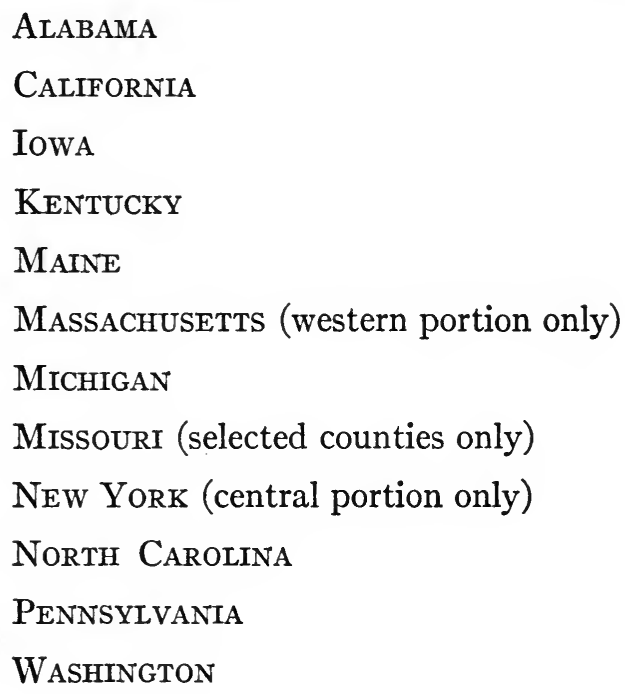


N. B. The areas covered in the states of Massachusetts, Missouri, and New York are as follows:

\section{Massachusetrs (western portion)}

The counties of Berkshire, Franklin, Hampden, and Hampshire.

NEW YoRK (central portion)

The counties of Broome, Cayuga, Chemung, Chenango, Cortland, Delaware, Fulton, Hamilton, Herkimer, Jefferson, Lewis, Madison, Montgomery, Oneida, Onondaga, Orange, Oswego, St. Lawrence, Schoharie, Schuyler, Seneca, Tioga, and Tompkins.

Missouri (selected counties)

Northwestern group: Counties of Andrew, Atchison, Daviess, Dekalb, Gentry, Harrison, Holt, Nodaway, Worth.

Northeastern group: Counties of Clark, Knox, Lewis, Marion, Monroe, Ralls, Scotland, Shelby.

West Central group: Counties of Carroll, Cooper, Johnson, Lafayette, Pettis, Ray, Saline.

Southwestern group: Counties of Cedar, Dade, Dallas, Hickory, Polk, St. Clair.

Southeastern group: Counties of Bollinger, Cape Girardeau, Madison, Perry, St. Francois, Ste. Genevieve, and Wayne. 


\section{LIST OF TABIES}

I. Distrubution of Physicjans between Town and

COUNTRY: 1906-23

TABLE PAGE

I. Population per physician for the entire state, for places of over 1,000 inhabitants and for the remaining area

$16 \quad 189$

2. Migration as a factor in distribution.

a. Physicians removing from places of less than 500 and less than 1,000 inhabitants

I. Compared with total number in such places.

$17 \quad 190$

2. Compared with total decrease in physicians in such places.

b. Physicians removing from places of less than $\mathrm{r}, \infty 00$ inhabitants compared with total number removing from and dying in such places

I9 $\quad$ I92

2. Age as a Factor in Distrubutjon: igo6-23

I. Proportion of graduates of preceding five-year period to all physicians.

2. Distribution of all physicians, and of physicians in places of less than 1,000 inhabitants, among the several age-groups.

3. Percentage of all physicians compared with percentage of graduates of preceding five-year period located in places of less than $1, \infty 00$ inhabitants and places of more than 25,000 inhabitants 
4. Percentage of graduates of various periods removing from places of less than 1,000 inhabitants to larger places

3. Age as a Factor in Specialuzation.

Percentage of graduates of each period practising as specialists.

4. Places Having Physicians.

I. Percentage of decrease in numbers of places of less than 500 inhabitants having physicians

2. Specimen map showing places more than ro miles from a physician 


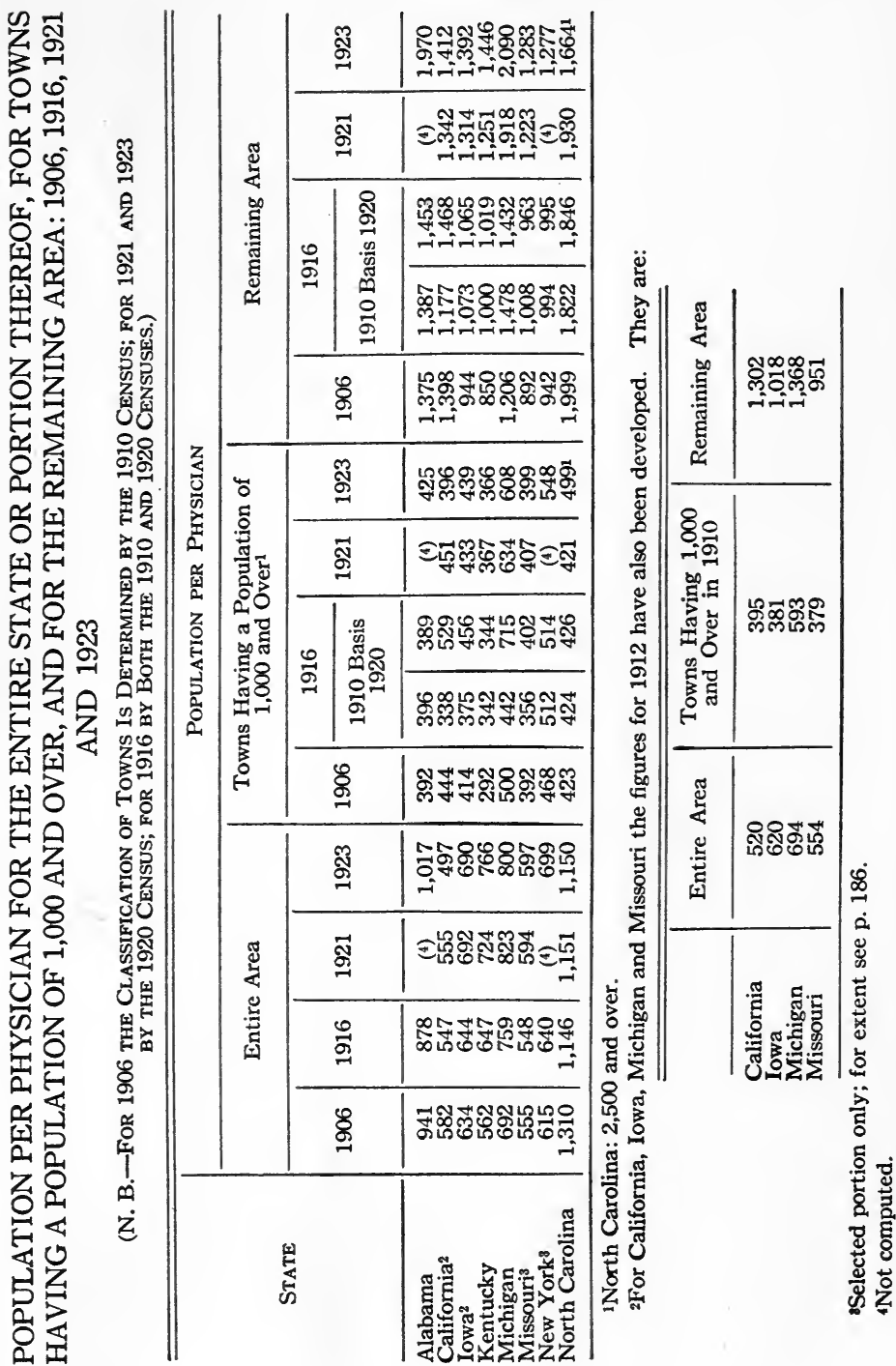




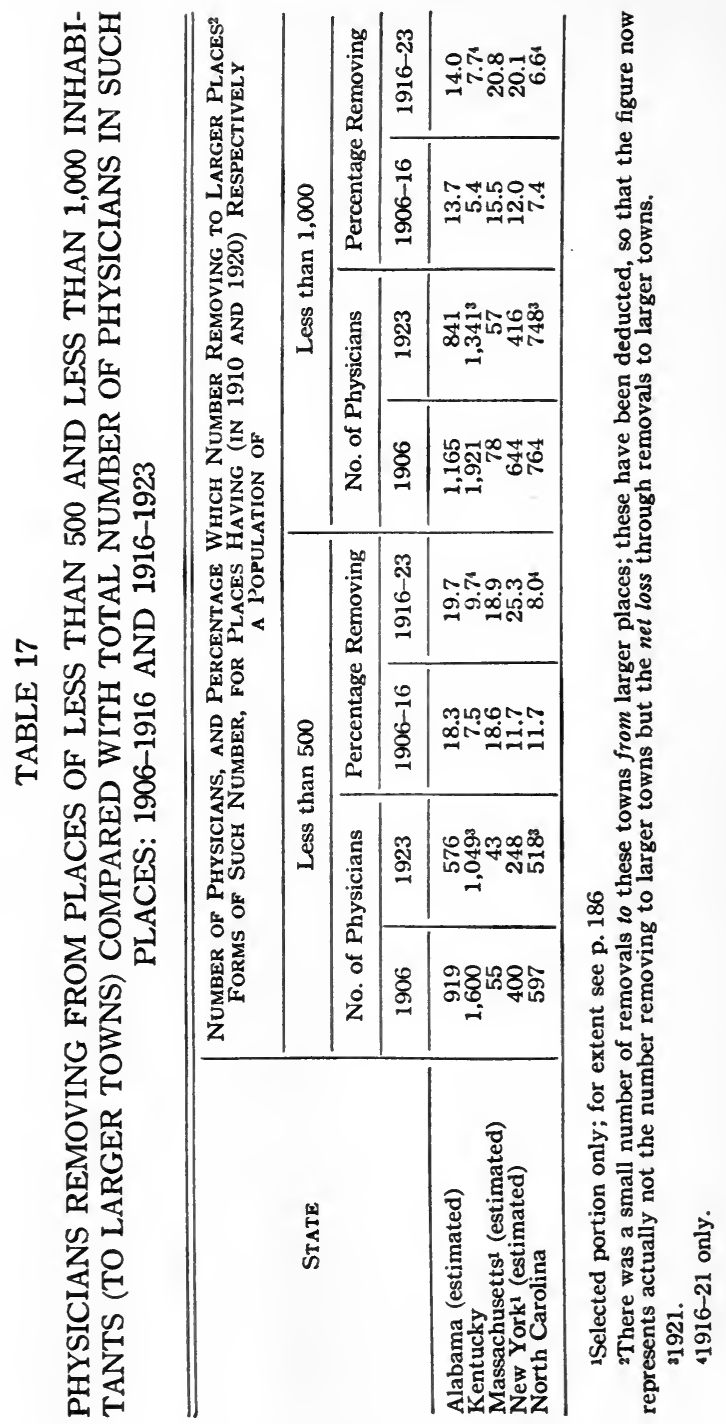


TABLE 18

PHYSICIANS REMOVING FROM PLACES OF LESS THAN 500 AND LESS THAN 1,000 INHABITANTS (TO LARGER TOWNS) COMPARED WITH TOTAL DECREASE IN PHYSICIANS IN SUCH PLACES: 1906-16 AND 1916-23

\begin{tabular}{|c|c|c|c|c|}
\hline \multirow{3}{*}{ State } & \multicolumn{4}{|c|}{$\begin{array}{l}\text { PERCENTAGE WHICH NUMBER OF PHYSICIANS } \\
\text { REMOVING TO LARGER PLACES }{ }^{2} \text { FORMS OF } \\
\text { TOTAL DECREASE IN NUMBER OF PHYSICIANS } \\
\text { IN PLACES HAVING (IN } 1910 \text { AND } 1920 \text { RE- } \\
\text { SPECTIVELY) A POPULATION OF }\end{array}$} \\
\hline & \multicolumn{2}{|c|}{ Less than 500} & \multicolumn{2}{|c|}{ Less than 1,000} \\
\hline & $1906-16$ & $1916-23$ & $1906-16$ & 1916-23 \\
\hline $\begin{array}{l}\text { Alabama } \\
\text { Kentucky } \\
\text { Massachusetts } 1 \\
\text { New York } 1 \\
\text { North Carolina }\end{array}$ & $\begin{array}{l}28.0^{3} \\
55.5 \\
91.6 \\
77.2 \\
5\end{array}$ & $\begin{array}{l}65.1 \\
49.7 \\
76.9 \\
75.0 \\
71.6\end{array}$ & $\begin{array}{r}4 \\
43.1 \\
101.8 \\
72.2 \\
6\end{array}$ & $\begin{array}{l}57.4 \\
43.2^{7} \\
78.9 \\
74.0 \\
74.0^{7}\end{array}$ \\
\hline
\end{tabular}

1Selected portion only; for extent, see p. 186

2There was a small number of removals to these towns from larger places; these have been deducted, so that the figure used represents actually not the number removing to larger towns, but the net loss through removals to larger towns.

31912-16 only; for 1906-12 there was a net increase of 12, despite 112 removals.

4There was a net increase of 42 , despite 159 removals.

${ }^{5}$ There was a net increase of 77 , despite 70 removals.

'There was a net increase of 129 , despite 61 removals.

71916-21 only. 
TABLE 19

PHYSICIANS REMOVING (TO LARGER TOWNS) FROM PLACES OF LESS THAN 1,000 INHABITANTS COMPARED WITH TOTAL NUMBER REMOVING FROM AND DYING IN SUCH PLACES: 1906-16

1916-23

\begin{tabular}{|c|c|c|}
\hline \multirow[t]{2}{*}{ State } & \multicolumn{2}{|c|}{$\begin{array}{l}\text { PERCENTAGE WHICH NUMBER RE- } \\
\text { MOVING TO LARGER TOWNS FORMS } \\
\text { OF TOTAL NUMBER REMOVING } \\
\text { FROM AND DYING IN PLACES HAV- } \\
\text { ING (IN 1910 AND 1920 RESPEC- } \\
\text { TIVELY) LESS THAN 1,000 } \\
\text { INHABITANTS }\end{array}$} \\
\hline & $1906-16$ & $1916-23$ \\
\hline $\begin{array}{l}\text { Alabama } \\
\text { Kentucky } \\
\text { Massachusetts } \\
\text { New York } \\
\text { North Carolina }\end{array}$ & $\begin{array}{c}3 \\
22.1 \\
48.2 \\
39.4 \\
30.8\end{array}$ & $\begin{array}{l}48.9 \\
45.44 \\
62.0 \\
61.0 \\
41.84\end{array}$ \\
\hline
\end{tabular}

Selected portions only; for extent, see p. 186

2There was a small number of removals to these towns from larger places; these have been deducted, so that the figure used represents actually not the number removing to larger towns, but the net loss through removals to larger towns.

${ }^{3}$ Computed separately for $1906-12$ and $1912-16$ : 45.6 per cent. and 34.9 per cent. respectively.

41916-21 only.

TABLE 20

PROPORTION OF GRADUATES OF PRECEDING FIVEYEAR PERIOD TO ALL PHYSICIANS: 1906, 1916 AND 1923

\begin{tabular}{|c|c|c|c|}
\hline & \multicolumn{3}{|c|}{$\begin{array}{l}\text { PERCENTAGE OF ALL PHYSICIANS } \\
\text { FORMED BY THE GRADUATES OF }\end{array}$} \\
\hline & $\begin{array}{l}1901-05 \\
\text { in } 1906\end{array}$ & $\begin{array}{l}1911-15 \\
\text { in } 1916\end{array}$ & $\begin{array}{l}1916-20 \\
\text { in } 1923\end{array}$ \\
\hline $\begin{array}{l}\text { Alabama } \\
\text { California } \\
\text { Iowa } \\
\text { Kentucky } \\
\text { Maine } \\
\text { Massachusetts } \\
\text { Michigan } \\
\text { Missouri } \\
\text { New York } \\
\text { New } \\
\text { North Carolina } \\
\text { Pennsylvania } \\
\text { Washington }\end{array}$ & $\begin{array}{l}19.5 \\
13.8 \\
20.2 \\
20.4 \\
15.0 \\
14.3 \\
19.2 \\
17.6 \\
10.3 \\
22.6 \\
16.2 \\
23.6\end{array}$ & $\begin{aligned} 14.4 \\
11.5 \\
12.4 \\
6.8 \\
10.0 \\
11.9 \\
11.0 \\
9.9 \\
10.1 \\
16.0 \\
13.2 \\
6.7\end{aligned}$ & $\begin{array}{l}4.4 \\
9.8 \\
7.7 \\
4.2^{2} \\
5.6 \\
11.0 \\
12.0 \\
6.7 \\
8.8 \\
9.62 \\
9.5 \\
7.4\end{array}$ \\
\hline
\end{tabular}

'Selected portion only; for extent, see p. 186.

21921. 


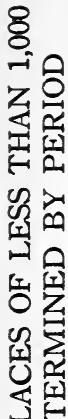

보워

ค음

台运是

Z 采

दू 0

ज्ञ

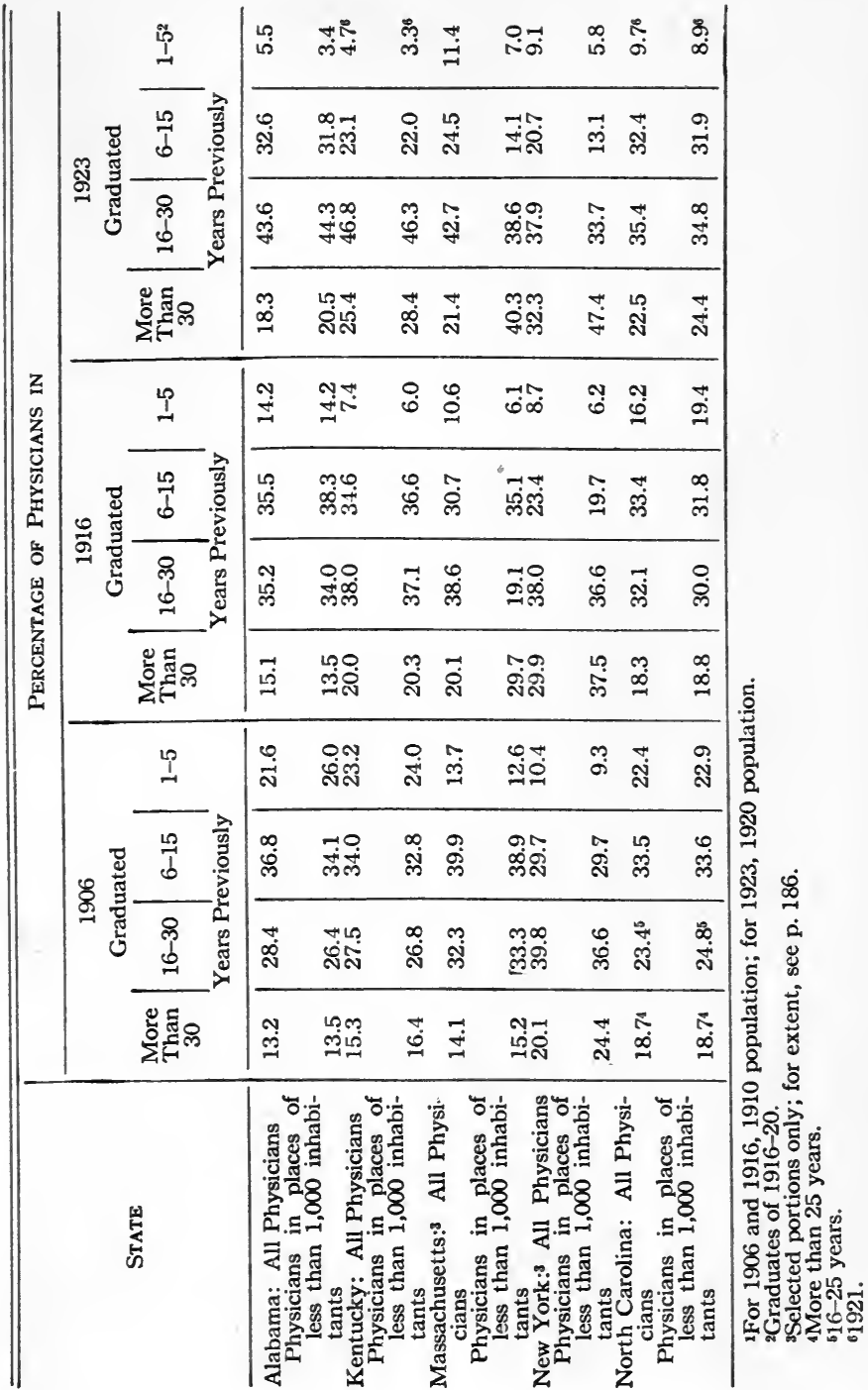

다 뇌 웍

皆岁䒘

至完

呅

只只

次

닌 은

品

농

U

齿

贸

z

占

安

趿

药

ค 


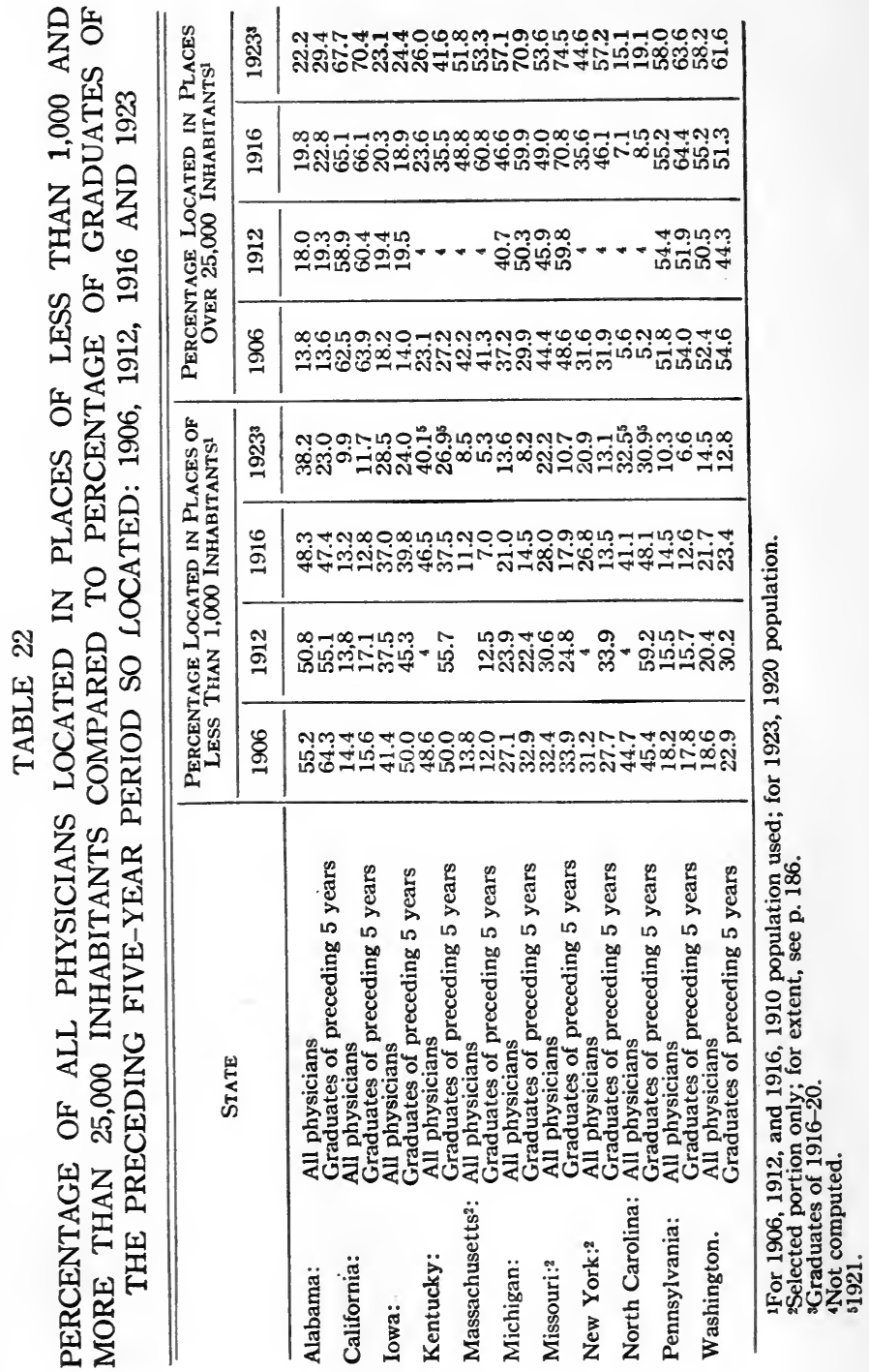


TABLE 23

ESTIMATED PERCENTAGE OF GRADUATES OF THE PRECEDING FIVE-YEAR PERIOD, AND OF THE NEXT TWO PRECEDING TEN-YEAR PERIODS, LOCATED IN PLACES OF LESS THAN 1,000, REMOVING TO LARGER PLACES: 1906-16 AND 1916-23

\begin{tabular}{|c|c|c|c|c|c|c|}
\hline \multirow{4}{*}{ State } & \multicolumn{6}{|c|}{ 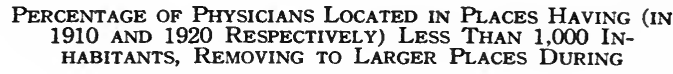 } \\
\hline & \multicolumn{3}{|c|}{$1906-1916$} & \multicolumn{3}{|c|}{$1916-1923$} \\
\hline & \multicolumn{3}{|c|}{ Graduates of } & \multicolumn{3}{|c|}{ Graduates of } \\
\hline & $1881-90$ & $1891-00$ & $1901-05$ & $1891-00$ & $1901-10$ & $1911-15$ \\
\hline $\begin{array}{l}\text { Alabama } \\
\text { Kentucky } \\
\text { New York }{ }^{1} \\
\text { North Carolina }\end{array}$ & $\begin{array}{l}6.4 \\
1.8 \\
2 \\
6.8\end{array}$ & $\begin{array}{l}12.6 \\
21.6 \\
21.2 \\
13.5\end{array}$ & $\begin{array}{r}18.7 \\
6.5 \\
18.3 \\
13.5\end{array}$ & $\begin{array}{l}5.4 \\
4.2 \\
8.6 \\
1.2\end{array}$ & $\begin{array}{l}23.8 \\
14.4 \\
31.0 \\
11.7\end{array}$ & $\begin{array}{l}23.4 \\
16.5 \\
43.2 \\
25.0\end{array}$ \\
\hline
\end{tabular}

1Central portion only; for extent, see p. 186.

${ }^{2}$ Not computed.

TABLE 24

PERCENTAGE OF GRADUATES OF EACH PERIOD PRACTISING AS SPECIALISTS': 1923

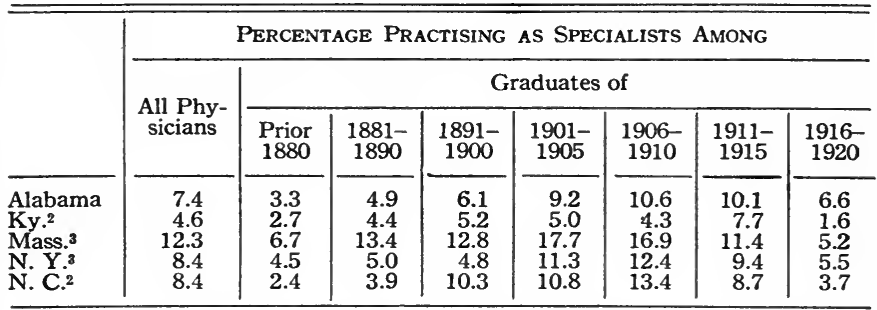

1The American Medical Directory (1923 edition) distinguishes in its lists between physicians who report themselves as engaged exclusively in a specialty and those who report themselves as merely chiefly interested in a specialty but as engaged also in general practice. Only names in the first class were counted in compiling the table.

21921 .

3Selected portions only; for extent, see p. 186. 
TABLE 25

PERCENTAGE OF DECREASE (OR INCREASE) IN NUMBER OF PLACES OF LESS THAN 500 INHABITANTS ${ }^{1}$ HAVING PHYSICIANS: 1906-16, 1916-21 AND 1921-23

\begin{tabular}{|c|c|c|c|}
\hline \multirow[t]{2}{*}{ State } & \multicolumn{3}{|c|}{$\begin{array}{c}\text { Percentage of Decrease IN Number of Places } \\
\text { OF LESS ThaN } 500 \text { InHABITANTS } 1 \\
\text { HAVING PHYSICIANS }\end{array}$} \\
\hline & $1906-16$ & $1916-21$ & $1921-23$ \\
\hline $\begin{array}{l}\text { Alabama } \\
\text { California } \\
\text { Iowa } \\
\text { Kentucky } \\
\text { Massachusetts² } \\
\text { Michigan } \\
\text { Missouri² } \\
\text { New York }{ }^{2} \\
\text { North Carolina } \\
\text { Pennsylvania } \\
\text { Washington }\end{array}$ & $\begin{array}{c}7.9 \\
16.9^{3} \\
9.5 \\
12.2 \\
0.0 \\
15.4 \\
18.2 \\
6.1 \\
8.3^{3} \\
11.0 \\
79.1^{3}\end{array}$ & $\begin{array}{l}22.3 \\
2.4 \\
17.9 \\
14.4 \\
27.14 \\
20.5 \\
17.7 \\
20.6 \\
11.6 \\
16.3 \\
19.5\end{array}$ & $\begin{array}{c}3.6 \\
4.2^{3} \\
5.9 \\
7.5 \\
14.8^{5} \\
9.0 \\
8.6 \\
4.5 \\
3.9 \\
18.0 \\
10.9\end{array}$ \\
\hline
\end{tabular}

1For 1906-16 the 1910 population was used; for 1916-21 and 1921-23, the 1920 population.

Selected portion only; for extent, see p. 186.

increase.

4The actual numbers involved are small-37 in 1916, 27 in 1921.

Increase; the actual amount of the increase is however only 4-from 27 to 31 . 


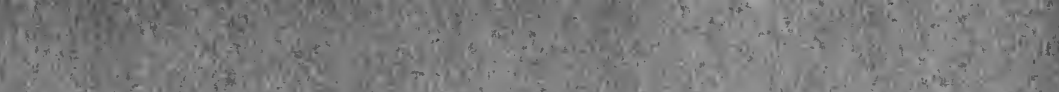

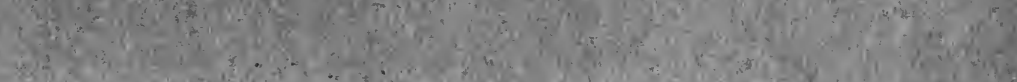

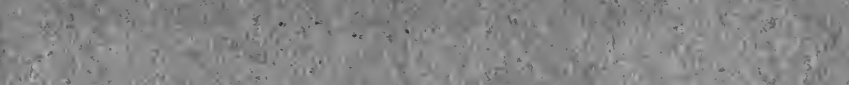

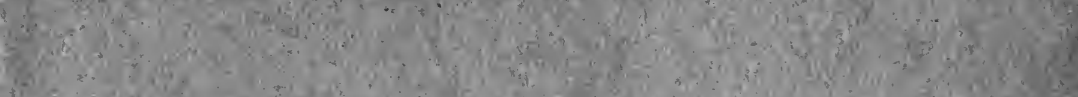

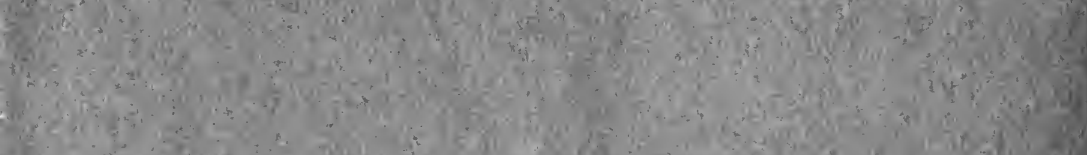




\section{Boston Public Library \\ Central Library, Copley Square

\author{
Division of \\ Reference and Research Services
}

The Date Due Card in the pocket indicates the date on or before which this book should be returned to the Library. Please do not remove cards from this pocket. 

